\title{
THE
}
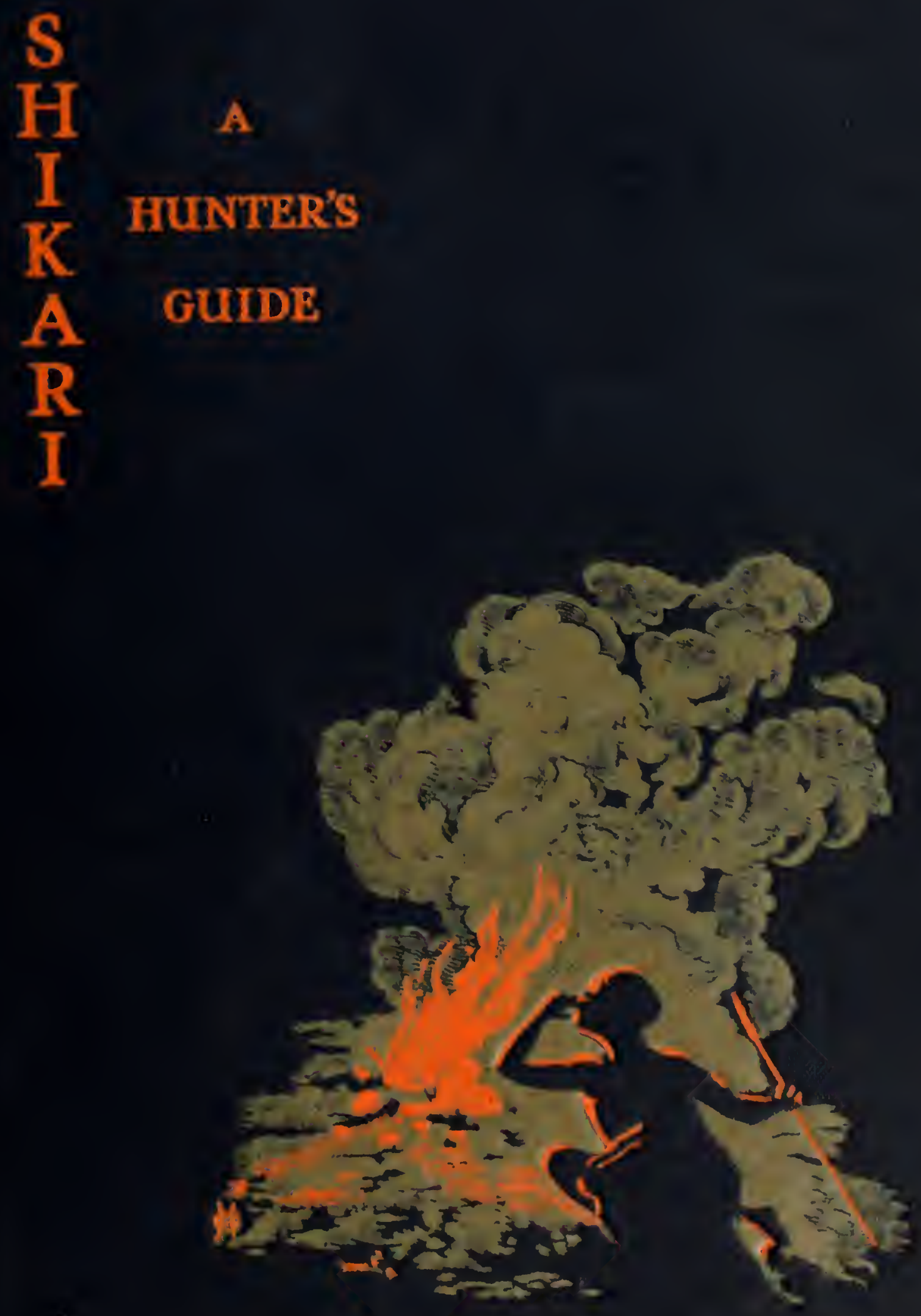


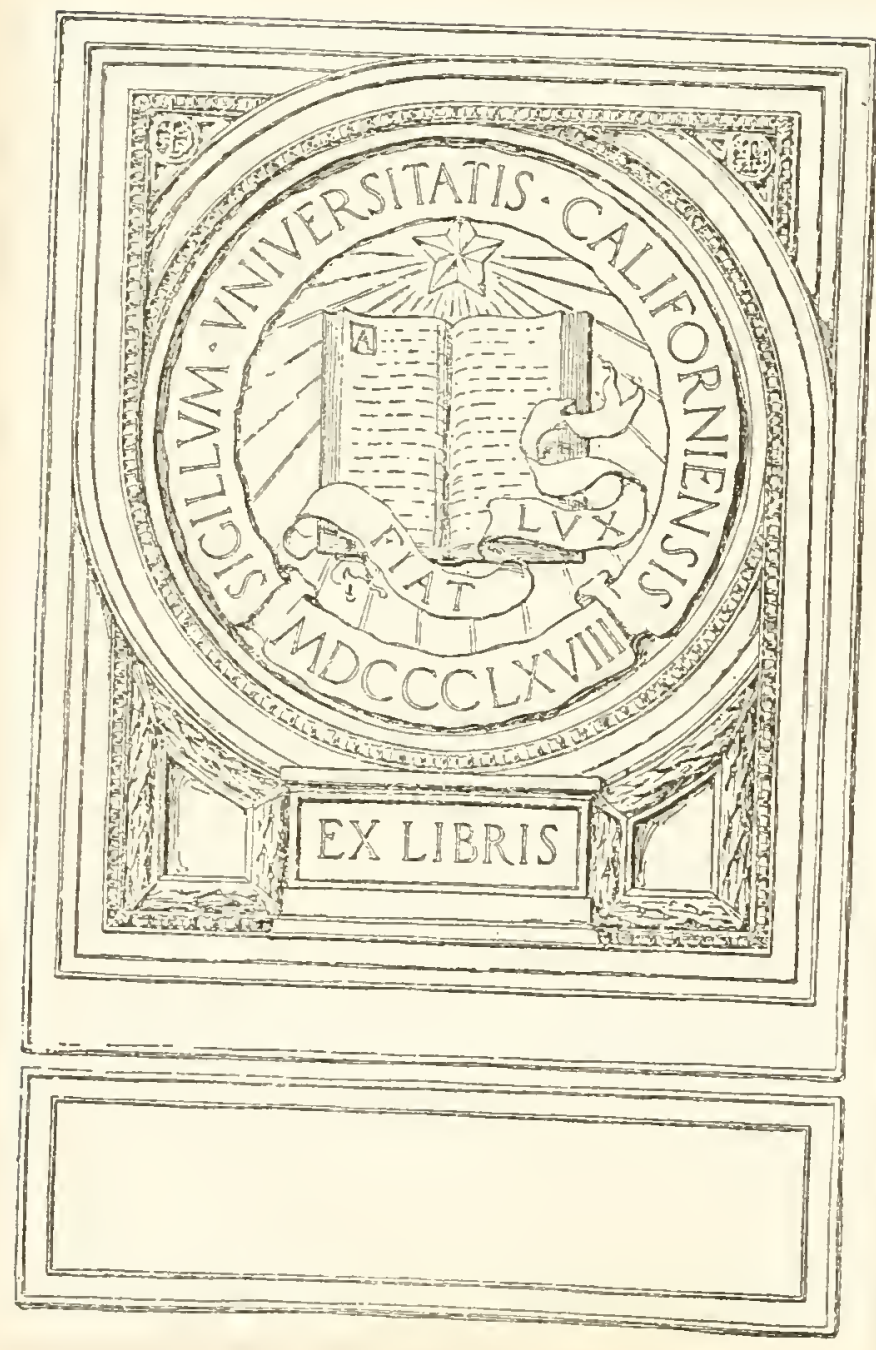





\section{THE SHIKARI}

A HUNTER'S GUIDE 




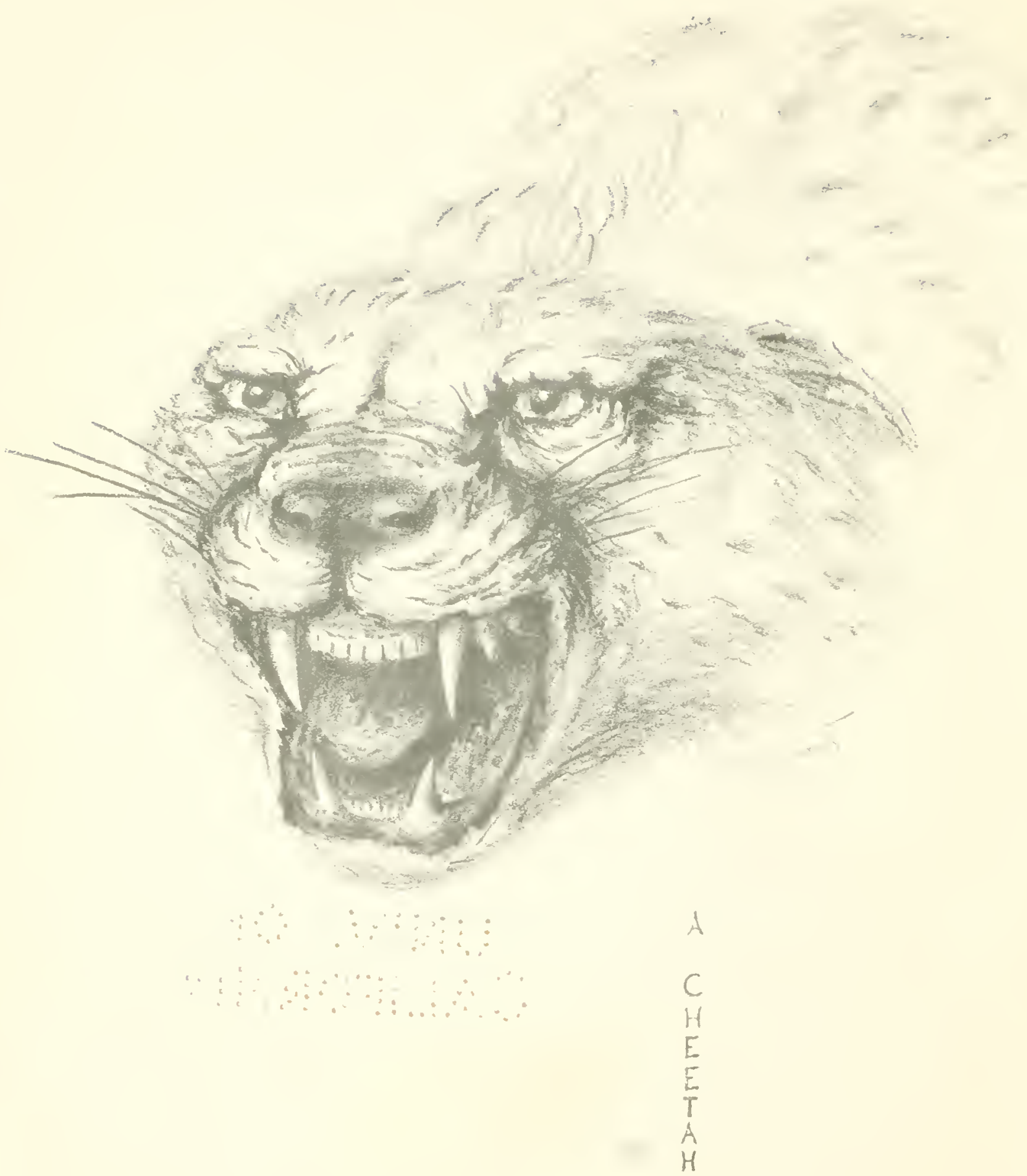




\section{THE SHIKARI}

A HUNTER'S GUIDE

BY

CLAUDE H. B. GRANT

F.Z.S., M.B.O.U., E.r.

ILLUSTRATED

THE RESEARGH PUBLISHING GO. LTD. CAXTON HOUSE. WESTMINSTER, S.W. 



\section{CONTENTS}

FOREWORU

CHAPTER I

FITNESS AND GENLRAL HEALTH.

CHAPTER II

OUTFIT AND CAMP EQUIPMENT . • . I

CHAPTER III

RITLES AND GUNS

CHAPTER IV

BIG GAME

52

CHAPTER I

SMALL GAME

CHAPTER VI

TAXIIDERMY

v

92

935889 
vi

\section{CONTENTS}

CHAPTER VII

PHOTOGRAPHY

CHAPTER VIII

TROPHIES AND COLLECTIONS

CHAPTER IX

GENERAL NOTES .
PAGE

- I 16 


\section{FOREWORD}

"In the same way that you introduced me to a love of sport, do, please, write a few words of introduction to my book. Describe a true sportsman."

CLAUDE GRANT.

A SPORTSMAN, to my mind, to qualify for this proud title, must have all the attributes of a gentleman. My old gunbearer, a Zulu, was a sportsman to his fingertips, while many men, who are good shots, fail to reach the necessary standard of temper and chivalry.

The charm of sport lies in the delicate craft with which its various manceuvres are carried out. The author of the interesting book, whose introductory chapter I have the honour to write, is the very person to explain both the ideals of the true sportsman and the modern technicalities of a big-game shooting expedition; and I believe that few will finish without regret the reading of "The Shikari, a Hunter's Guide."

Personally, I belong to the days of the heavy elephant gun, when the "kidney punch" and the polo player who gives $£ 500$ for his pony, were unknown.

I had long given up the shooting of big game when my young friend, our author, was kind enough to induce me to make one last trip (I had just lost my wife) and test for myself whether modern conditions had spoilt my old sport; and so it came about that 
I revisited Africa after an interval of twenty-three years. It gives me intense pleasure to recall the delicate tact with which he introduced me to the latest developments of scientific sport. And all done without a twinge to my vanity, or damage to some little reputation which an old native had untruthfully rubbed into our carriers before we started. Indeed, it was with a shock-so gradual was my lesson-that I made the discovery one night, when yarning round the campfire, that I had grown to allude to my old methods in much the same sorrowing fashion that one talks of the bow and arrow, armour, and other relics of the past.

I have made (and led) many expeditions in my day, and never have I enjoyed myself more than under the up-to-date leadership of our author. He may tempt me, once again, to shoot, but never to write. I shall therefore now stop, merely expressing the opinion that modern weapons, light equipment, and portable food in tins have done much to add to the enjoyment and lessen the hardships of big-game shooting, without diminishing its manliness; and to counsel all who have the opportunity (I) to make an expedition, and (2) to pay close attention to the excellent advice given in the following pages by one whom I am proud to call "my young friend." He knows his subject as few know it; and that he is himself a true sportsman, in the best sense of the word, is guaranteed by 


\section{CHAPTER I}

\section{FITNESS AND GENERAL HEALTH}

KEEPING fit and in health are the two principal matters that make or mar an expedition.

Keeping fit to stand the strain of long tramps over a rough country, the change of food, to have a continual reserve of endurance, and to be able always to keep in good spirits.

Good health, to enjoy thoroughly every minute of the trip, and to appreciate to the full the truly delightful days of the winter season in the tropics or the clear, cold, keen days of other climes.

Most of us flatter ourselves we are fit, and so we are for the life we lead at home; but long days in the office and travelling to and from the City by train or motor, big lunches, and bigger dinners are liable to make one soft, and on suddenly going off for a shooting trip, and plunging directly into camp life and hard walking, we soon realize that we are not so fit as we had thought. This does not, however, mean that the intending hunter need fast and take to long, hard walks, or in any way suddenly change his mode of 
life, for by so doing he will more likely make himself unfit and defeat the object he wishes to attain.

As a rule some weeks have to be spent on board ship to reach the port nearest to the hunting-ground one has fixed on, and it is during this time that the hunter can start to bring himself into that general fitness and health that will make his trip enjoyable.

Some men are always fit, others never will be, but the average man can bring himself to be fit enough to start off with, and the life he is going to lead will do the rest. The man who is really unfit should abandon all ideas of expedition work, and anyway every one before starting off should consult a doctor who has had tropical and overseas experience.

It is not proposed to preach or lay down any hardand-fast rules on this matter, but just to give a few hints and items of advice which can be taken or not according as the reader thinks in his own mind, or according as he knows himself and his own constitution.

The life on board ship for the passenger is one of practically enforced idleness. After the first day or so the sea air increases the appetite and the ennui, so that long before the voyage has ended every one is eating too much, taking long siestas in the afternoon, and staying up card-playing or drinking till the early hours draw near. All this is very well in its way and does not hurt the man who knows himself thoroughly, or who is merely visiting some town or taking a round trip. 
But for the average beginner, who is off on his first big-game shoot, it may or should be quite a different matter. He may arrive at the port of disembarkation feeling lazy, soft, and slack, and remain longer than necessary in the towns, leading the same life. When he does get to work the end may be that malaria will grip his unfit system and wreck the expedition he has so long looked forward to.

However, there is no need to go to the other extreme, but just to exercise that sense that should be designated as "uncommon sense"; as a rule people are seen doing their best to make it more rare than common.

Have good ordinary meals and take ample exercise both morning and afternoon, avoid the siesta, go to bed at a reasonable hour and do not over-drink or take very cold or very iced beverages, as not only is ice in the tropics bad, but it will not be obtained on the trek. Join the deck games, giving preference to those that give good healthy movement, such as deck tennis or cricket.

On leaving the boat the hunter will find he is quite fit and feeling infinitely better than when he left London behind him.

At all times, from the day England is left to the day the expedition ends, watch yourself carefully and see that the whole system is in thorough working order. If this is done and colds are not caught, the traveller need have little fear of not coming unscathed through even quite bad malarial districts. 
On the trip eat well, avoid unboiled water, and don't take alcohol till the sun has gone, and then sparingly. An excellent plan is to have the tot just on sundown, and never take it any other time of the day, except when coming in exhausted after an unusually long stalk or having been lost or got thoroughly soaked with rain, then just a "wee drappie" may save a nasty chill.

Being wet through will do no harm as long as walking is being done, but on reaching camp change instantly, without any delay, have a good rub down, the tot, and some hot coffee or cocoa. To sit about in wet things is simply fatal.

In Chapter IV the drink question when out stalking is touched upon, but though many men can adapt themselves easily to any conditions, others never can, and anyway a beginner should be very careful not to do the things that are second nature to the old hand immediately he starts off, otherwise he may find that he will simply knock himself up for the rest of the trip.

Take things easy at first, not too long days, and not too hard on one's muscles and stomach. Harbour the strength and endurance, test yourself carefully and never overdo it; far better abandon an animal in your first days than lay yourself up.

Wear clothes that protect from the sun or the cold, and at night sleep in pyjamas and blankets, and, however hot the night, never leave the legs, 
stomach, and small of the back exposed; remember the most tropical night will cool off and become tricky in the "wee short hours." A good plan is to double a blanket and secure it with safety-pins around the chest and stomach, so that however much turning and rolling is indulged in those important parts of the body cannot get exposed.

In the day-time the head should be properly protected, and the hunter must not forget that though the sun is not visible the danger from sunstroke is still there.

HUNGER. - When out, a belt is a good thing to have on, as should the hunter be lost or find himself further from camp than he intended, it can be tightened up hole by hole and the gnawings of hunger at an empty stomach be staved off for a time at least. When really hungry a pipe will satisfy the awful craving for a spell. Nothing, however, except food will put a final stop to hunger, and if once you get as far as an Irishman the author once had with him you must be bad indeed.

We had been out early, and came back tired and worn out, and on reaching camp I said, "Feel hungry, Micky?"

"Hungry, sorr?-me belly's sticking to me backbone!" came the reply, which caused a laugh and made us cheerful again.

An excellent plan is always to have a cake of chocolate in the pocket, and if small pieces are sucked 
at intervals a man can go a considerable time without real food. When water is come across, wash out the mouth only and avoid drinking any; merely washing out the mouth and wetting the lips greatly allays thirst.

If a man is really done up and has been without food for a considerable time, great care must be taken in administering only very small quantities to begin with.

Long periods can be gone through without anything to eat, but in a tropical country death soon ensues through lack of water, and this has been known to occur in twenty-four hours, though some men have gone for much longer periods and completely recovered in a day or so; but these are generally the men that are experienced and hardened, and have trained themselves to doing a whole day in the heat without a drop passing their lips.

PRINCIPAL ILLS.-Touches of fever, chills, and irregularities of the system are perhaps the principal indispositions that the hunter will have to contend with both for himself and men, besides cuts and sores caused by thorns, or other scratches, bad feet of the carriers, sore backs and swollen legs of the animals, and insect or snake bites.

Medical KNOWLEDGE.-Not every man can be a doctor, but the majority can pick up in a short time enough useful knowledge to be able to treat successfully the minor mishaps on an expedition. If more 
serious accidents occur, as broken legs or very severe cases of fever, etc., among the carriers, all that is possible should be done, and the man taken and left at the nearest village to be attended to by his own native doctor. This gives the man a better chance of recovering than muddling about with an insufficient knowledge. To any one who has seen how quickly most natives heal and what faith they place in their medicine men, no question as to the best course to pursue would arise.

The white man must, however, be his own doctor, and will have to cure all his own ills, unless unconsciousness or deliriousness intervenes, when the headman should have been previously instructed as to what to do on the spot, and have orders to carry him with all despatch to the nearest white man or town.

Medicine Ciests and Medicines, EtC.-A medicine-chest should be carried, containing every drug, wash, and bandage that will be required; do not cut these too fine, as it is surprising what a quantity of quinine, salts, and bandages can be consumed even on a short trip, for mild touches of fever, bush sores, etc.

Also allowance has to be made for medicines that may be administered to the natives, and if a cure of a dose of fever, indigestion, or dysentery has been effected, it is wonderful how soon the news spreads, and the whole country-side is besieging the white man for cures for every disease under the sun. Avoid, however, if possible, giving the medicines away to people 
not working on the staff, though it is difficult not to do so when obvious relief can be given.

A list of useful and simple articles for the medicinal outfit will be of value, and these can be supplemented or altered according to the knowledge and experience of the reader.

As far as possible all the medicines should be taken in a solid form, as bottles are liable to become broken. The whole should be taken in a compact form, in a small steel medicine-chest divided into compartments, so that any article required can be obtained without unpacking the whole case. As with the other articles comprising the hunter's outfit, the total weight of the case or cases must be borne in mind.

The really necessary drugs, etc., that should be carried are :

\section{Medicines.}

Quinine.

Phenacetin.

Cascara Sagrada.

Calomel.

Soda Mint.

Easton's Syrup.

Diarrhœa Pills.

Essence of Peppermint.

Dover's Powder.

Epsom Salts.

Chlorodyne.

Washes and Ointment.

Permanganate of Potash.

Tincture of Iodine.
Ichthyol and Hazeline Cream.

Vaseline.

Embrocation.

Boric Ointment.

Bandages and Instruments.

Bandages and Oiled Silk.

Adhesive Plaster.

Boric Lint and Gauze.

Scalpels.

Scissors.

Forceps.

Safety Pins.

Thermometer.

Hypodermic Syringe.

Snake-bite Lancet.

Curved Needles and Silk. 
These few things cover all that the hunter with no medical training will require; and they should all be in a non-liquid form, at least as far as possible, and most of the drugs in 5-gr. tablets. Plain are preferable to sugar-coated, as they are more easily assimilated; if certainty of absorption is doubtful, the tablets should be powdered and taken suspended in water or milk.

Malaria.-Quinine and phenacetin are good both for colds and fever. When the first feelings of fever come on, take the temperature, and, if above normal, instantly get between the blankets (unless, of course, the trek must be continued), take Io gr. of phenacetin and soon after a hot cup of tea; this will induce sweating. An hour or so after take 10 or $15 \mathrm{gr}$. of quinine, and endeavour to get to sleep; also give an aperient, and if at all constipated, administer $2 \mathrm{gr}$. of the calomel.

In the morning, if the dose is mild, the patient will be feeling quite fit, but do not imagine for a moment that the fever has quite gone; continue lying in bed if possible, and keep the quinine going for a day or so after, starting off with another Io gr. first thing and gradually tailing off, taking it in decreasing doses at intervals of two or three hours, and give $5 \mathrm{gr}$. daily for two or three weeks after, and Easton's Syrup as a tonic.

Dogs also are subject to a form of malaria, and then they should be treated much as human beings.

One of the author's best dogs was laid up for over a week and all but died. It was treated with $5 \mathrm{gr}$. 
of quinine morning and evening and $5 \mathrm{gr}$. of phenacetin middle day, besides repeated doses of brandy and condensed milk, mixed and fairly strong. On about the eighth or ninth day the fever had abated, but the animal was so weak that careful dieting and nursing had to be kept up for several days, after which recovery was very rapid.

On the whole, though, perhaps they suffer more from the bites of ticks than from malaria, and they should be continually overhauled and these pests removed. Tick fever in dogs can now be cured with injection of trypanblan.

The Daily Preventive.-Medical men seem very much at variance with many experienced travellers in regard to the daily taking of quinine as a preventive.

The argument is that, if 2,3 , or $5 \mathrm{gr}$. are taken daily, there is always the drug in the blood, and when the germs of malaria are introduced into the system the quinine is there to combat them. This may be so, but the other side say that if the system is saturated with a drug and the subject does get the fever, it takes a pretty considerable dose to break it down.

There is no doubt, without exceptional luck, that sooner or latter every one residing or travelling in a fever belt will catch it, whether they take a preventive or not.

The author's non-professional experience has been that the majority of malarial cases can be broken in 
a week at the outside, usually in a couple of days, if they are taken in time, and that two or three doses of phenacetin and quinine, not exceeding $\mathrm{I} 5 \mathrm{gr}$. at a time, have been all-sufficient. It may be added that he has never taken daily doses himself nor ever given them to his men, and has not had more cases of fever than other travellers.

However, perhaps it is all a matter of individuality, and where one man will go right through another will go down the first week; but it will more than likely be found that the first man had kept his system in good working order and the other had neglected himself and become unfit.

Most medical men and books advise the daily preventive, so that the beginner cannot do better than follow the advice of his professional man in this matter.

CoLDS.-Dover's Powder is also handy for colds and coughs, dose 5 to ro gr., and will induce perspiration.

Aperients.-Cascara, calomel, and Epsom salts are all aperients; the former will be sufficient for the average European, dose 2 to $5 \mathrm{gr}$, and the other two should be kept mostly for the natives, who will require stronger drugs.

INDIGESTION, ETC.-Soda mint is a wonderful remedy in indigestion, acidity of the stomach, etc.

Correctives. - The use of diarrhoea pills and chlorodyne, ordinary dose 10 to 20 drops in water, is 
well known, and essence of peppermint is invaluable for stomach pains-dose 20 drops in water.

Tonic.-Easton's Syrup is a splendid pick-me-up after a dose of fever or other run-down condition, and can be given with advantage when feeling offcolour, and can be kept going for two or three weeks without harm.

DisinfECTANT.-Permanganate of potash in water is an excellent disinfectant for the washing of all wounds and sores. If earth or foreign matter has entered, great care must be taken in seeing that all of it is removed and the parts well washed and cleansed with the disinfectant before binding and bandaging up.

OINTMENT.-Ichthyol and hazeline cream mixed make an excellent ointment for skin diseases and parasites; use vaseline for all general surface wounds, rubs, etc. The best treatment for bush sores is to keep them thoroughly clean, cover with lint or gauze, and continually keep wet with cold water. They should be very carefully watched, and not allowed to become too deep-seated or the parts get swollen. A disinfectant wash and boric ointment may also be used, and as they are to a great extent due to the state of the blood, some doses of salts or other cooling medicine will be advantageous.

Liniment.-Embrocation is invaluable for both men and animals. For ponies with stiff legs caused through fast or over-riding, rub thoroughly with the embro- 
cation to get up a good circulation in the part, and then suddenly dash over cold water. This will take out the stiffness and reduce any swelling.

An old Boer remedy for sore backs, which the author has used with success, is equal parts of salt and pepper mixed and pressed well in and on the sore place. Another remedy is to wash the sore with permanganate of potash and apply Stockholm tar, a small pot of which might be added to the stores.

INSTRUMENTS.-There is no need to comment on the bandages and instruments except to say more than one clinical thermometer should be taken. Never neglect the use of this instrument-it is a sure guide to fever coming on-and at all times consult it when feeling out of sorts, for a heightened temperature usually means deranged health. The hypodermic syringe need not be taken if the traveller does not understand its use.

The snake-bite lancet should be always in the pocket; and the curved needles and silk are useful for bad cuts and gaping wounds and easily manipulated. If snake bite occurs, thoroughly scarify the part, put in crystals of permanganate, and give doses of brandy or some other stimulant. If the use of the hypodermic syringe is understood an injection of strychnine may check collapse.

To remove adhesive plaster run in a little spirit or petrol, and it will peel off without giving the subject any pain by pulling at the hairs. 
The instruments must be kept only for medical purposes, and thoroughly disinfected both before and after use and wiped dry before being put away.

To the above may be added, or exchanged, mustard plasters, carbolic ointment, some small brushes for painting on iodine, etc., fruit salts in tablet or powdered form, oil of citronella, which if rubbed on the face, hands, and ankles will keep away biting flies for a time; a cholera belt, boric acid for an eyewash, aspirin for rheumatism and lumbago, and last but not least a small case of special invalid foods, such as meat extracts, cornflour, and brandy.

For the bites of scorpions, stinging flies, etc., strong ammonia rubbed and dabbed on the spot relieves the pain and irritation and often prevents swelling.

If the hunter wishes to preserve his health, a good mosquito-net (see Chapter II) is an indispensable article; this should be made so that it can be erected with poles affixed to the bed, and when the bottom of the net is tucked in under the blankets or mattress, the sleeper is practically immune from mosquitoes and other insects, and can with safety sleep in the open and in peace.

Dysentery.-Besides fever, perhaps dysentery or some mild form "of it will be the traveller's principal trouble, and a few remarks on this may not be out of place.

Most so-called cases of dysentery are merely severe irregularities of the bowels, and with a little care 
can be stopped. In all cases take a strong aperient; this often stops the illness. Then a treatment of bismuth and soda and non-emetic ipecacuanha will probably make a cure, giving as food infused tea only, and a little toast. If the case is severe, keep the patient on milk and extract for two or three weeks, when meat may be again given.

Chlorodyne and diarrhoea pills can also be used with success.

DENTISTRY.-For toothache, a small bottle of some cure should be added to the medicines, and if a slight knowledge of dentistry is part of the hunter's accomplishments, a pair or so of forceps for extracting teeth would come in handy.

Books.-One or two books on simple doctoring should be taken along and kept in the medicine-chest. A work that should not be forgotten is "First Aid to the Injured," published by the St. Jchn Ambulance Association.

It is perhaps more true with medical science than with anything else that "a little knowledge is a dangerous thing," but in the field, far away from any doctor, a little knowledge is better than no knowledge at all, and if but a few good principles and the intelligent use of a few simple drugs and instruments are acquired, and common sense, care, and great cleanliness exercised in treating sickness and wounds, much good can be done, and quite an amount of unnecessary suffering checked in the beginning. 
The hunter would, however, do well to consult a medical man versed in tropical ills before starting out, and glean from him just a few really necessary and practical hints, being careful to write them down and keep them in his medicine-chest.

If expense has not to be considered, a medical man might be attached to the hunter's retinue, and besides perhaps being a welcome companion, would save all trouble and anxiety.

On turning your back on the country of your exploits and embarking once more for home, due care must still be taken of the health, as the sudden change to sea air and a different diet may bring out malaria, etc., that have been lying dormant in the system. Malaria especially is peculiar in this way, and on the return from the New Guinea trip the author had no less than four attacks on the way home against only one mild touch whilst in the country.

A man on a pleasure trip and out for shooting and trophy collecting will be in the hunting veldt at the best time of the year, when the climate is cool, the country dry and fairly healthy, and by keeping ordinarily fit and in good general health he will probably go through his trip without a day's illness, and return home in the pink of condition and in the best of spirits. 


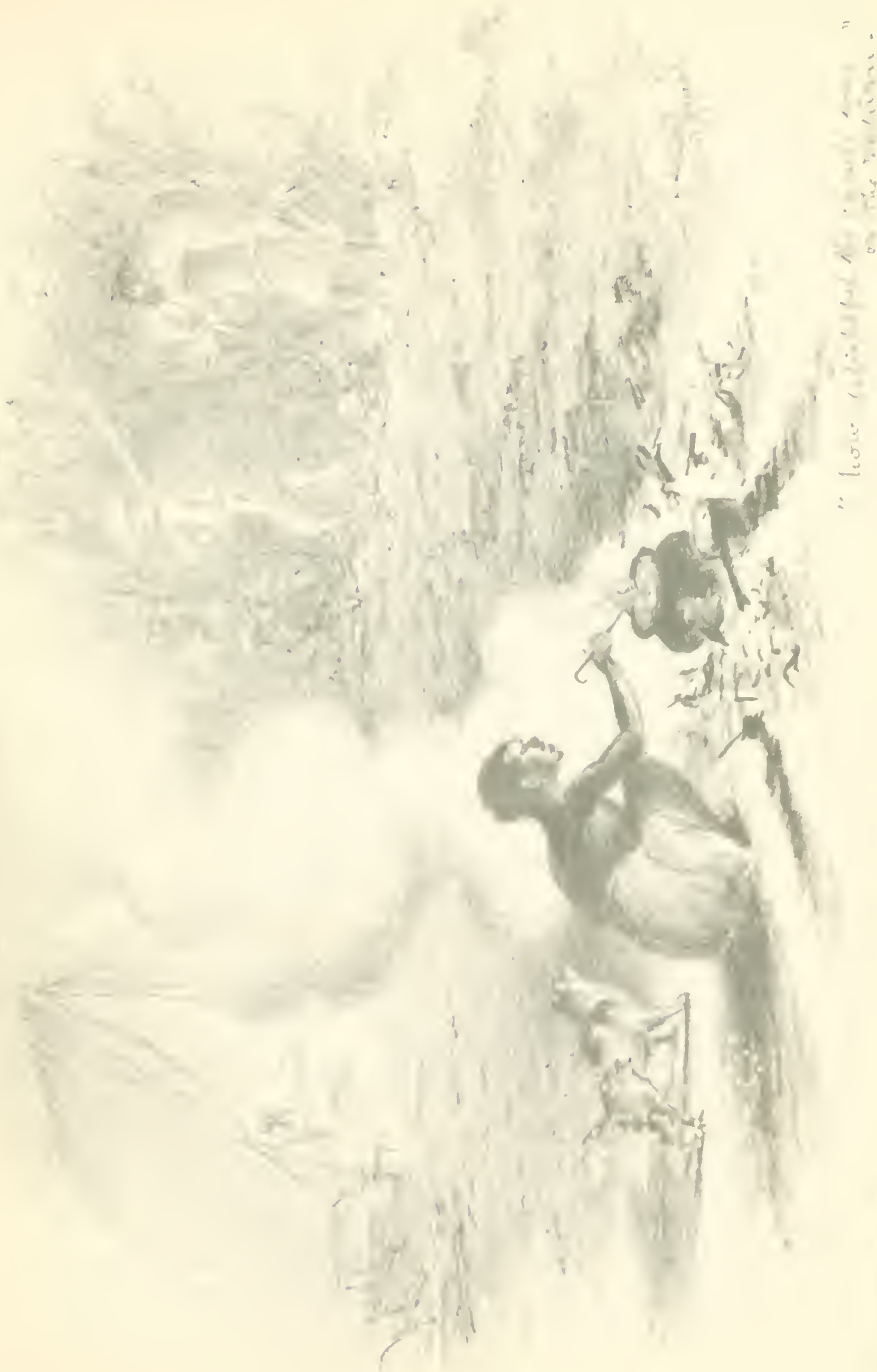




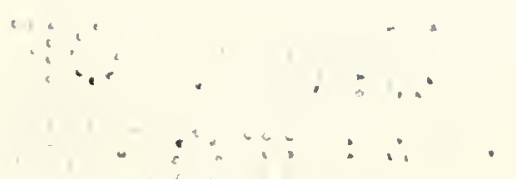




\section{CHAPTER II}

\section{OUTFIT AND CAMP EQUIPMENT}

Tre outfit and camp equipment are two very important and necessary parts of an expedition: to take and carry just what will be required, to take nothing superfluous and to leave nothing behind that will be of use, not to take heavy things where light ones will serve the purpose equally as well, or take flimsy articles where stoutness is really required; in fact, just to take the things, and nothing over, is what this chapter hopes to convey to the hunter who is fitting himself out for his trip after big and small game.

Very many points have to be considered: the climate, the kind of country, the means of transport, the distance away from centres, the length and duration of the trip, and what food supplies can be obtained on the spot.

All the equipment should be strong, durable, insect- and rot-proof, and as light as practicable; the food-stuffs should be on the whole plain, sustaining, and of first-class quality, carefully packed to keep 
them good and free from dust, etc., and in such convenient quantities that too much need not be opened at any one time.

The average person about to proceed on a hunting expedition has, probably, his fixed ideas of where to purchase. The danger of buying goods of inferior quality, that cannot be relied upon to last, must be impressed most seriously upon the reader. The author has always gone to the Export Department of Fortnum and Mason, I82, Piccadilly. Tents and camp equipment which he bought in I909, and subjected to the usual hard usage, have still plenty of service left in them, while the food-stuffs have always been good. The author and his party never had the sickness and alarms (and shortness of food occasioned by the tins being thrown away) which he has seen in the camps of his friends. The firm mentioned (Fortnum and Mason) have excellent catalogues, with lists of chop boxes containing splendid suggestions and reminders of what is wanted.

The CHOP Boxes. - The chop boxes can be divided into two classes: those with the bulk of the food-stuffs, and those so arranged that they contain a varied assortment covering several days' provisions. This method saves the continual overhauling of all the packages, and as the mixed boxes are emptied they can be replenished from the bulk.

MARKS AND LISTS.-The various packages must be plainly marked and numbered in consecutive order 


\section{OUTFIT AND CAMP EQUIPMENT}

arid a list of the contents of each made out in cluplicate; one to be kept in the box and the other in book form in the pocket.

Forethought of details like this saves much annoyance and hard words on the trip when the contents of the boxes have been forgotten, and some little article, as salt or pepper, cannot be found without opening half or all the cases.

LOADS.-Travelling by native carrier or pack animals, the loads must be kept within the weights that such means of transport allow.

The author has always found it better to have the loads somewhat lighter than the regulation weight allowed in any country, as not only does this allow for the weaker men or animals, but quicker and more satisfactory treks can be made and there are fewer laggards to wait for.

This will probably involve more carriers or animals, but the lighter load system well repays the man who is anxious to get along and do good treks daily.

Even with wagon transport the packages should not be too large, so that they can be conveniently lifted off and on. The advantage of this will be soon apparent to the man who has had his wagon stuck several times and been forced to unload it to pull it out.

Practically the same quantity of equipment will be required for a short as for a long trip; but the food supplies can be regulated to a day, though they 
should never be cut quite so fine, as delays of some sort are almost bound to occur.

Most readers of this small volume will be seekers of big and small game, and not explorers in the true sense of the word. That is to say, they will always find themselves in a country more or less stocked with game, and during part of the trip at least will be in some sort of touch with the natives of the country and be able to obtain some supplies, such as mealies, rice, sweet potatoes, tomatoes, etc. It will not, therefore, be necessary for them to plan out to a nicety each man's food per day, but to consider more those things that cannot be obtained in the country and to take at least a few luxuries.

Exploring and hunting trips of to-day do not necessarily involve rough food and rough times, as in the days gone by. The camp can be made almost as comfortable as one's own house, and the wonderful variety of excellent foods that are now put up in tins almost ensures the catering of a first-class hotel.

EQUIPMENT.-As stated above, the equipment must be strong, durable, insect- and rot-proof, and as light as strength will allow.

The following list gives all the essential articles of the outfit. There are other minor things that, though not imperative, will greatly tend to increase the comfort of a trip, and are more or less subservient to individual taste. 
There is no necessity to mention these in detail as they can be left to the outfitter to bring them before the notice of his customer, and the liunter should therefore go to a firm of good standing and expericnce when purchasing the outfit.

The total equipment for one man should consist of :
2 Uniform cases
I Tent
I Bed
I Mosquito-net
2 Blankets
I Pillow
I Trek table
2 Haversacks
2 Water-bottles
I Covered basin
I Field-glass
I Watch
I Meat-safe
2 Chairs

2 Tables

I Bath and washstand

I Lamp and candle-lantern

I Electric torch

Cookery utensils and food

2 Buckets

Toilet requisites and rough towels

Personal clothes

Saddle, bridle, etc. (if required)

Strong pocket-knife

2 Hatchets

Tools

Medical stores, guns, rifles and cartridges, and photographic outfit are dealt with in Chapters I, III, and VII.

Whatever the nature of the trip may be, whether travelling by carrier, pack animal, wagon, or boat, the particular weight of individual packages and the total weight of the whole outfit and food-stuffs have to be carefully worked out in detail, so that the men or animals can be got ready beforehand, or the number of wagons and boats that will be required can be adjusted with the necessary men to work them.

Therefore it will be of value to give the weights of 
the various articles that comprise an outfit, so as to enable the sportsman to get a good approximate idea of the size of his proposed expedition and thus avoid what so often happens to beginners, that they have purchased articles too heavy or have a total weight far beyond what they had in their minds. A point that is sometimes overlooked, and that has caused more than once the reorganization of the transport, is the carrier's own clothing and food.

To return to the items of the outfit.

UNIFORM CASES.-For the personal clothes, there is no better trunk than the uniform case (with or without a false wood bottom). This is made of steel, has good clips and locks, and has a rubber or leather band on the inside which effectually prevents wet, damp, or dust entering.

A case weighing about I $8 \mathrm{lb}$. and measuring 25 by 15 by 10 is a useful size and allows contents of 32 or 42 lb., which brings the total up to a load of 50 or $60 \mathrm{lb}$. Two of these should carry all the personal outfit that will be required for several months.

Avoid leather or all-wood trunks, as they, especially leather, are affected both by climate and by insects.

Tenrs.-The tent is a most important item, and it is not easy to combine size, strength, and weight for a one-man load.

And even when this has been accomplished, it will be found to be beyond the one-man load after a night of heavy rain or dew; so that although a single-load 
tent should be aimed at, allowance should be made in the transport for the extra weight when wet. With carriers or pack animals this will adjust itself as the food supplies are diminished, so that only perhaps at the very beginning will consideration have to be given to this point.

The best type is the ridge pattern with a fly. There are very many variations of this type, some having cross poles at the ends (Fig. I), and others having centre poles at either end and a ridge pole (Fig. 2).

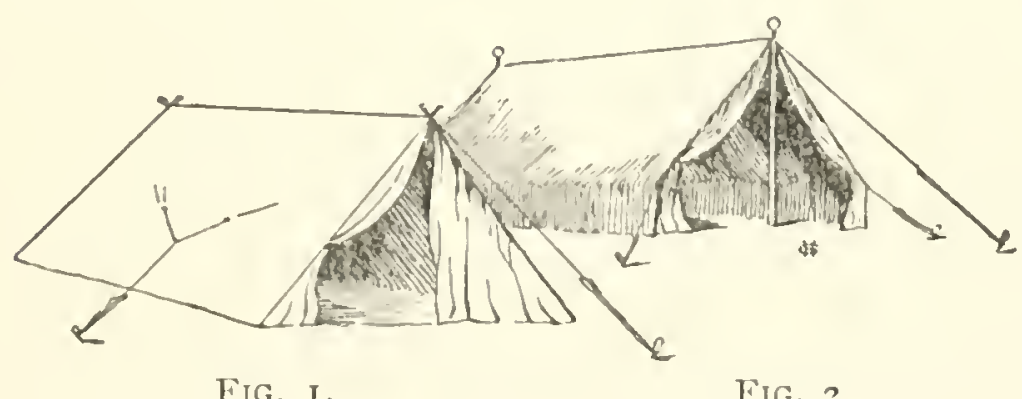

The system with the cross poles at either end with a single rope strainer across the tops and along the whole length of the ridge, is perhaps lighter than the other system; but the drawback is that when wet the canvas becomes taut and the poles are not easily withdrawn.

With this tent in a wooded country no ridge pole need be carried, as one can always be cut and must be of sufficient length to project beyond the cross tops over which the fly can be thrown.

If the centre-pole tent is decided on-and it has 
many points in its favour-the poles should be of a light strong wood, and jointed so as to pack into a convenient length for transport; the ferrules being of brass or some non-rusting and non-corroding metal.

The canvas must be rot-and insect-proof and preferably of a green colour, stout, but not too thick, and strong enough to stand heavy weather, wind, and rough usage.

The fly can be of a much lighter and smoother material, especially as this will catch the bulk of the rain, and if thick will absorb too much and double or treble its original weight. For large tents a much stronger canvas is required. In this connection it must be borne in mind that trekking frequently has to be done in the early hours and there is neither time nor sun to dry out the night's dew or rain. It is well to have the fly of such width that it will almost reach the ground and allow of many articles being stowed away beneath it on the outside of the tent, safe from wet.

A ground-sheet is a cleanly and useful thing to have, and this can either be separate or sewn on to the tent, and should be of the same material as the tent itself. The author has usually had his made all in one piece with the tent, and found it extremely useful in keeping out dirt, insects, and floodings from heavy tropical rains.

Large and small pockets can be sewn on the inside of the tent and are useful for stowing away note-books, 
brushes, towels, and other articles in daily use. Hooks can also be sewn on in convenient places for hanging up coats, etc.; and if desired, the whole tent can be made mosquito proof by having nets sewn down the edges inside the doors, so that they fall across each other, and though still allowing a free current of air, effectually stop insects from entering.

This plan is also very useful in the day-time when writing or other work has to be done, giving complete immunity from the hordes of flies that infest most tropical countries.

Such a tent of, say, an $S$ by 6 feet size ought to be turned out complete under a total weight of $65 \mathrm{lb}$.

Besides the permanent tent, a smaller patrol tent might be taken along if short trips of a few days away from the main camp are necessary to get hold of certain trophies, for which the whole caravan need not be moved.

For wagon and boat work it must not be forgotten that covering sheets will be required to tie over the whole baggage. If this form of transport is being hired, it must be learnt whether or not tarpaulins are being supplied.

BED AND BEDDING.-A good useful fold-up bed can be had at the weight of $16 \mathrm{lb}$., and a make at this weight should be preferred to any other that exceeds it.

Sheets should not be taken, only good warm blankets of about $\sigma \mathrm{lb}$. weight each and a green canvas pillow of $2 \mathrm{lb}$. weight. 
Pillow-slips may be taken, and are cleanly and useful.

A mosquito-net to fit the bed can be obtained at $3 \frac{1}{2}$ lb. in weight and the rods for it at about the same.

The bed, net, pillow, and blankets need not exceed a total weight of about $40 \mathrm{lb}$. A cork mattress can be added if desired, and weighs about $7 \mathrm{lb}$.

TABLES AND ChaIRs.-Folding tables and chairs are the most useful, and the lighter these are and the closer they pack the better.

The $x$ form is one of the best, and the largesize table is preferable to the smaller and weighs only 7 lb. This table is quickly erected, and is quite stable enough for all the camp work, such as writing, skinning small beasts, and for dining purposes.

Chairs must be more or less a matter of taste, but the author has always carried an $X$ chair, weighing 6 lb., and a light green canvas deck-chair, with arms for resting, reading, etc., and the weight does not greatly exceed the ordinary $X$ chair. The weight of the two need not be more than I $5 \mathrm{lb}$.

BATH AND WASHSTAND.-A canvas bath and washstand on the $X$ principle are very necessary articles, are cheap, and weigh only $\& \mathrm{lb}$.

If preferred, an enamelled basin with a canvas cover can be taken and is certainly useful, as all the smaller toilet requisites can be stowed inside and are 
always at hand for immediate use. This basin and cover weigh $5 \mathrm{lb}$.

By taking this and the canvas bath the weight would be $12 \mathrm{lb}$. as against the $S \mathrm{lb}$. with the canvas washstand; the advantages, however, perhaps are worth the extra $4 \mathrm{lb}$.

LAMP AND LANTERNS.-A table-lamp for tent use and a lantern for outside work at night should be constructed for use with candles, and need not exceed $4 \mathrm{lb}$. for the two.

Another very useful thing to carry and to have handy at night is an electric lamp or torch. The torch is perhaps the more convenient and weighs, ready charged, only I lb. 4 oz. Refills for this are packed in tins and weigh I lb. each, including the tin.

BUCKETS, WATER-BOTTlES, AND HAVERSACKS.Buckets are required for the carrying of water for cookery and washing purposes, even when camped right on the edge of water, and can either be of metal or canvas. The latter are perhaps the most serviceable for the traveller for all purposes, are strong, last well, and weigh $\mathrm{I} \frac{1}{4} \mathrm{lb}$.

Water-bottles can be either I pint or $2 \frac{1}{2}$ pints. The former weighs about I2 Oz. if of the Army pattern, made of aluminium or some light metal and covered with felt.

In the larger size the "Fortmason" water-bottle can be highly recommended, especially for its hygienic 
qualities. If it has a disadvantage at all it is in being round and having no flat surface to fit against the body; but this is negligible, and would make difficult the system of unscrewing and cleaning which is its recommendation. This make weighs $\mathrm{I}_{\frac{1}{2}} \mathrm{lb}$. empty.

If it is intended to use the water-bottle on the saddle, a swivel or swivels must be arranged to clip on to the D's (Fig. 3), and the carrying strap taken off when in use this way.

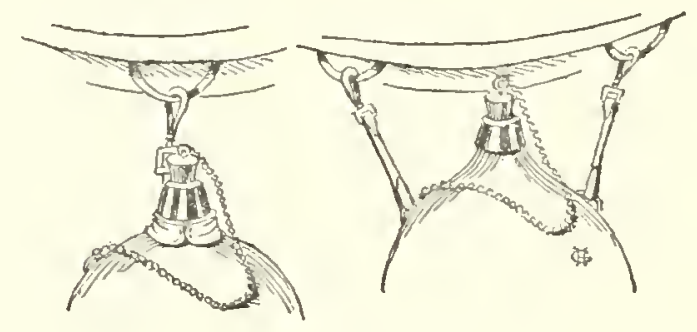

FIG. 3.

Haversacks should be of green rot-proof canvas, very strongly sewn, and with broad webbing for the carrying strap. They should be about I 3 in. by I I in., weigh just under $I \mathrm{lb}$. and have three compartments-two on the front and one on the back. The flaps should be broad and cover the opening well.

SADDLERY.-Where riding has to be done, take out the saddlery from home; the bridle, etc., may, if desired, be obtained on the spot. Some writers recommend the use of the saddle of the country in which they happen to be shooting, but the author has 
done this himself and by no means recommends it. They are generally the opposite to comfortable, and many a day's stiffness and soreness will be saved by never being without an English-made saddle-the saddle which one is used to and can ride with ease.

The "Colonial Military" or "Semi-Military" pattern is the best for hunting game; it is broad, suits every rider, and fits every horse. Let the stirrups be wide, wider than the sole of the shooting-boot, so that mounting and dismounting are not attended with jammed feet and consequent dangerous falls.

It must be remembered that the riding will be done in a country that is somewhat different from Rotten Row, and has many pitfalls even for the most experienced.

A pair of spurs are useful, but avoid wearing them if possible, as they are awkward for walking in thick stuff and are in the way when kneeling.

FIELD-GLASS.-This should be of good make, the "prism" pattern, of about an $S$ diam., and not exceeding in weight I lb. $14 \mathrm{Oz}$, including the case and sling.

WATCH.-A good reliable watch, preferably one worn on the wrist, should be taken, not too small, and having the hours and hands illuminated is invaluable for night purposes. Sucl a watch can be purchased for 30s., and the one in the author's possession has kept excellent time for over two years in widely diverse temperatures.

KNIVES.-A good strong pocket-knife, having a ring 
to attach to the belt, is an indispensable part of the equipment. Also a strong-bladed hunting-knife can be carried; but as the natives accompanying the hunter usually carry one, it is not essential for the hunter to do so.

Hatchets.-Hand hatchets for chopping wood, poles for scherms, cutting up game, etc., should be taken. These should be of the American pattern and about $2 \frac{1}{2} \mathrm{lb}$. in weight, including the handle.

Tool RoLL.-A tool roll containing a few useful articles, as hammer, screw-driver, soldering tools, solder and acid, etc., and a few nails and screws come in handy, and can be got in a canvas case at a total weight not exceeding $\mathrm{I} 2 \mathrm{lb}$.

Cooking Utensils.-A complete outfit of cooking utensils, including all pots, frying-pans, mincing machine, kettles, etc., should be in a box by themselves, so as to be ready and handy for the cook to at once get to work when the camp is pitched. Everything necessary can be obtained for a total weight of $50 \mathrm{lb}$., including the box.

The three-legged iron pot-which curiously enough the Boers call a "Kaffir pot" and the Kaffirs a "Boer pot"-makes excellent bread by putting the fire both below and on the lid, and can be left to simmer for the making of soups or stews. In fact, it is generally a very useful article, and there are many who never travel without it.

A folding portable meat-safe ought to be added 
to the list, and though this sounds somewhat of a luxury, it is surprising how useful it can be, especially in a standing camp. It need not exceed $7 \mathrm{lb}$. in weight.

TABLE REQUisItes.-All the crockery should be of earthenware, except such large things as dishes.

One or two enamelled iron cups and saucers and plates should be added, as breakages may occur, though many native servants are extraordinarily careful. The author in Africa used the same crockery for a year or two continuously.

More crockery than is sufficient for the party alone should be taken, as one may have strangers calling; and anyway an allowance for losses should be madc.

There are various ways of packing, but they should all be together in one box.

Messrs. Fortnum \& Mason, of Piccadilly, make what they call a "Trek Table"; this contains articles for more than one person, and the case converts into a table. This is an extremely handy article; the table and table articles are always together, and the whole packs into a neat package weighing only $48 \mathrm{lb}$. If the "Trek Table" is decided on, only one of the canvastopped tables need be taken.

Tablecloths, serviettes, and dish-cloths should not be left out, as they help the servants to keep the table clean and neat.

Personal Clothes, etc. - The personal clothes, etc., must be so arranged that when packed the cases do not exceed the regulation load; that is, with the two 
I S-lb. uniform cases, 32 or $42 \mathrm{lb}$. of clothing, toilet requisites, etc., would be the allowance, and this should cover all that would be required for an ordinary shooting trip.

The personal equipment must include :

6 vests and 6 pants; the pants should be short and not come below the knee.

I 2 pairs of socks.

4 or 6 bush shirts of khaki colour, and having double cloth down the spine.

2 pairs of strong boots at least; more if the country visited is very mountainous and stony.

I pair of spiral puttees and I pair of stout leggings: the puttees should be on the spiral, as the straight-cut ones soon work loose and slip down the leg.

2 suits of a material suited to the country, with kneebreeches, and at least one pair of slacks for a change in camp.

A felt hat or a topi; never wear a cap in the tropical sun.

A leather belt, either quite plain or not over-encumbered with pouches and swivels.

I pair of light mosquito boots for camp use.

2 pairs of flannel pyjamas.

Soap, both for personal use and washing clothes, tooth and nail brushes and tooth powder; the teeth need special care in the tropics.

Hair brushes and comb, a strong folding mirror, a sponge-a rubber one is the most hygienic. 


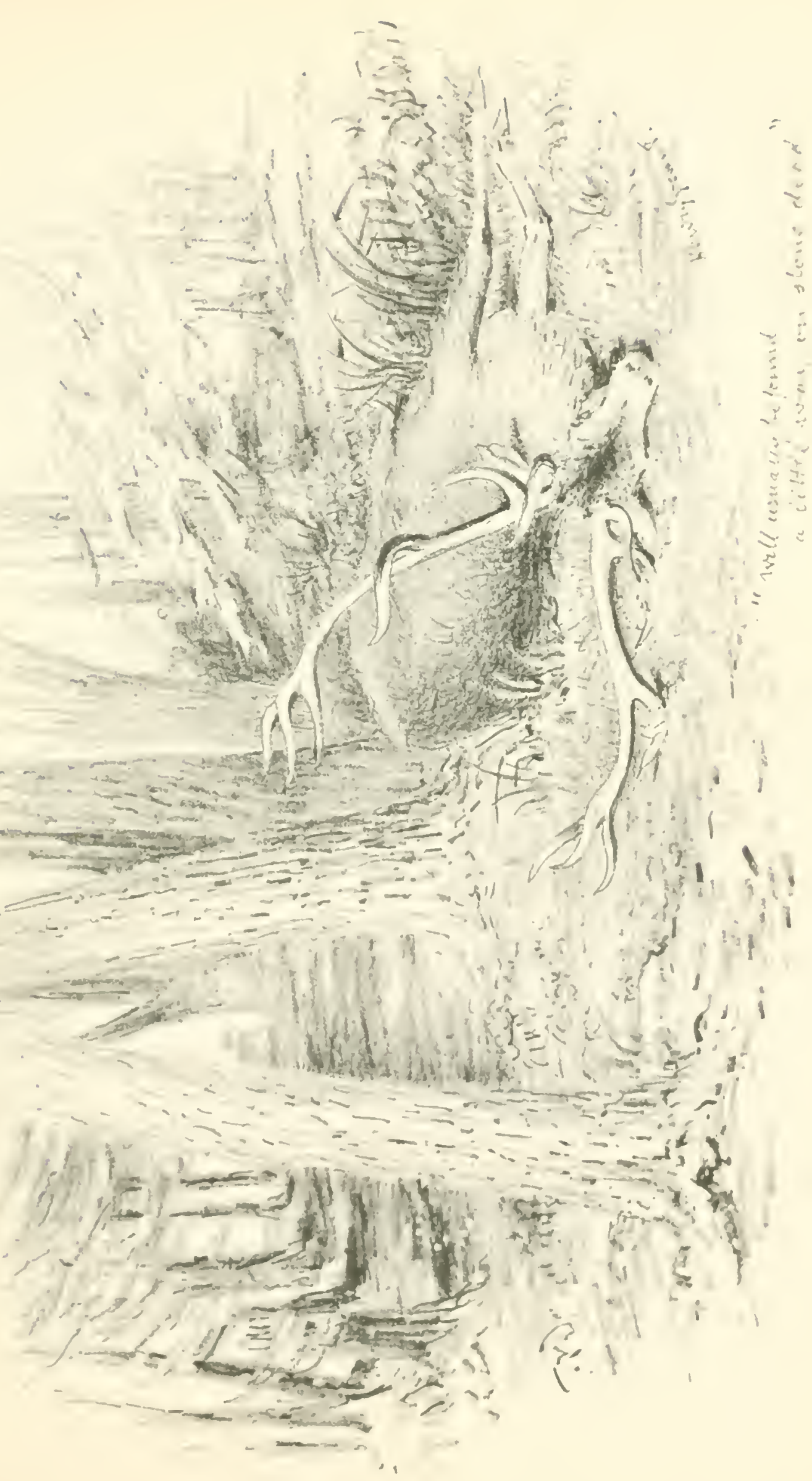




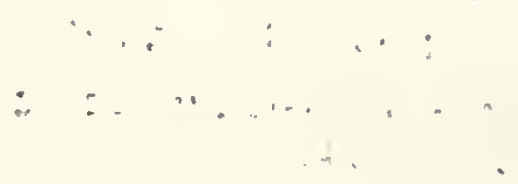


Razors, shaving soap and brush, if it is proposed to shave, and a clothes-brush, which is useful for the "boy" to brush muddy clothes and puttees.

Dubbin or other grease for the boots, otherwise they won't last long in the heat and sun, or keep out the wet and cold.

Good rough Turkish towels are better than smooth ones, and three or four should be quite sufficient. Add to these a pair of hair-clippers and a dozen or so of handkerchiefs and a housewife, and one should have an all-sufficient quantity of personal articles.

The weight of the above is approximately $40 \mathrm{lb}$, so that there is ample allowance in the two uniform cases for cither more clothes or any other small articles that will conveniently pack away.

We have now a total weight of equipment of about $300 \mathrm{lb}$., or say loads of $50 \mathrm{lb}$. each for six carriers.

Approximate Total IVeigut and Number of CARriers, ETC..-Taking $50 \mathrm{lb}$. for the medical stores, $200 \mathrm{lb}$. for guns and cartridges, and $50 \mathrm{lb}$. for the photographic outfit, we have approximately a total weight of $600 \mathrm{lb}$, or loads for about twelve carriers. This comprises all the necessary outfit and camp equipment for several months; less the food for self and men.

Wagons will take any load, according to their sizes, so that a big margin can be allowed if the hunter is kecping to this form of transport.

Boats and canoes will also carry pretty considerable 
loads, but the packages should not exceed $50 \mathrm{lb}$. a-piece, as stretches may occur where porterage will be necessary, or falls and rapids may demand continual unloading and reloading.

In the case of pack ponies I 50 to $200 \mathrm{lb}$. per animal is about correct, though the load should be kept on the lower margin to allow for the weak and laggard.

Foods.-The food must be given the most careful consideration and thought, for on it depends greatly the health of the members of the trip, and should be so selected that a variety will obviate the monotonous repetition of the same daily dishes, which becomes so appalling on a long trip and destroys both the appetite and the pleasure.

The first thought will be as to what can be got in the country-probably all the necessary meat, some vegetables and fruit. Many things can be more conveniently purchased at the port of disembarkation, as for instance rice or the meal for the carriers or fodder for the animals (if the country being passed through is deficient in pasturage), matches (which are difficult to ship from home), and perhaps cheap blankets, etc., for the men. Again, it may not be necessary to obtain all the food for the men at the outset, as, if there are villages along the route, the stores can be replenished at possibly cheaper prices than what would be paid in the towns, and would mean a less number of carriers to feed. All this must be learnt beforehand. UP-COUNTRY PRICES.-On the author's trips in 
Portuguese East Africa, chickens varied in price from 2s. each to eight for a shilling, and eggs from 2s. $6 \mathrm{~d}$. a dozen to four a penny, according to the distance from the towns; pigs in remote villages could be had for $4 \mathrm{~s}$. 6d., and the mealie meal for the men worked out exceedingly cheap, and being able to pick it up at intervals entailed fewer carriers than would have been required had the whole food for each trip been purchased outright.

Although in nine out of ten shooting trips much of the food can be obtained on the spot, the tenth may demand the taking of practically everything, so that a table giving a good approximate idea of what a white man requires per week will be a guide on which the calculations could be based:

Per avek, per man.-8 lb. of flour, I lb. of sugar (some of this at least may be in the form of saccharine); 8 oz. of tea and coffee, $7 \mathrm{oz}$. of salt, $4 \mathrm{lb}$. of fruit and vegetables, $2 \frac{1}{2} \mathrm{lb}$. of potatoes, $2 \frac{1}{2} \mathrm{lb}$. of bacon, I lb. 6 oz. of Quaker oats, and about 3푤. of meat. Per month, per man.-About $\mathrm{I}_{2} \frac{\mathrm{T}}{\mathrm{O}} \mathrm{Oz}$. of pepper, $\mathrm{S}$ oz. of soap for personal use and say $16 \mathrm{oz}$. for washing clothes; with this, allowance must be made for the men wasting it, and using it for cleaning the cooking pots and their own clothes.

For a hard smoker allow one box of matches a day at least. One candle per day should be ample, and care should be taken that these fit the lamp that has been selected. 
VARIETIES. - Sardines, potted and tinned meats, jams, milk, dried fruit or in syrup, macaroni, cheese, mustard, dried beans and dried vegetables, chutney, pickles, sauce, biscuits, soup squares, curry, butter, sausages, fish, baking powder, tongues, puddings and cakes, lard, vinegar, spices, may all be added in varying quantities and add to the variety of the menu.

Of the above, jams, milk, fruit, cheese, vegetables, butter, baking powder and lard are absolutely essential and must be included in the stores.

Native cooks are usually wasteful in the use of cooking fats, so a certain allowance should be made for this, and for some pilfering in such things as sugar and jam, if these are not kept strictly locked up.

PACKING.-All these stores should be packed in cases not exceeding a load, the case being of threeply wood and weighing, for a $60 \mathrm{lb}$. case, $8 \mathrm{lb}$. empty, this allowing 40 or $50 \mathrm{lb}$. of food-stuffs for each case.

Especial care must be taken to see that the salt, pepper, flour, mustard, and baking powder are properly tinned or bottled, as in most expeditions these are the things that are found to have deteriorated. The smokes and drinks must not be forgotten, and in this connection a small pump filter ( $9 \mathrm{lb}$.), a sparklet siphon ( 3 lb. IO oz.), and sparklets and the thermos (I lb. I4 oz. in case) may be added to the equipment. The thermos is, however, very liable to break and should be treated carefully.

One must superintend everything, leaving nothing to 
chance or others, and see that the equipment and food are all sufficient, and that the quantities in relation to the duration of the trip are neither underestimated nor greatly orerestimated.

Bear well in mind that health, comfort, and success, and perhaps one's very life, depend entirely on this part of your transport.

If the search for game takes one into the snowy wastes, remember oil will be wanted for cooking; and if crossing dry and waterless deserts, water must be carried and arranged for beforehand.

When on river trips stretches of country between may have to be crossed, and this is where folding boats, that can be transported, will be just the thing. Extra tents for the men may be wanted where wood and palms cannot be found for crecting scherms (lean-tos).

In fact, take time and give thought to all these matters and endeavour to forget nothing, and at the conclusion of a successful trip there will be not only the remembrance of a jolly good time, but the additional intense satisfaction of having organized the expedition scientifically and to a detail.

How many big exploring expeditions have broken down owing to the equipment having been wrongly constructed and badly packed, or the food being seriously underestimated!

Let not the reader's expedition number itself among these. 


\section{CHAPTER III}

\section{RIFLES AND GUNS}

RifLES and guns completely absorb the attention of the sportsman when he is buying his outfit, and are, perhaps, one of the most difficult questions for him to settle to his own satisfaction, inasmuch as he hears and reads so many opposite opinions. Every maker has some speciality that will kill or stop every sort of game, sometimes small bores, often medium, and seldom large; and the matter becomes so bewildering that the intending purchaser never really knows whether he has got a real stopper or not.

RIFLES LARGE AND SMALL.-In choosing a rifle two questions have to be considered: first, the kind and size of game one expects to get; and secondly, whether one is a good sportsman and does not wish to inflict unnecessary suffering by wounding large beasts which get away and die a lingering death.

If the hunter is such a good shot that a bullet can be placed every time in the right spot, then bore does not count, for a pea rifle will kill just as well as a -600 bore; but he never is. Pulling at the wrong 
moment, the moving of the beast, bad calculation of distance, and many other unforeseen circumstances, cause him often to place the bullet too far back or too low down, thus merely inflicting a wound which, if caused by a small ball on a large beast, may mean it getting right away and later, possibly, being a prey to flies, gangrene, or carnivorous animals.

Too often the question is settled by taking into consideration only whether the game to be pursued is dangerous or not; but this is a very selfish consideration, based entircly on one's own safety (which of course has always to be thought of, and rightly so), and does not bear in mind any humane feelings for the game. This should never be lost sight of.

Again, have not men said that they cannot be bothered to carry a great heavy rifle, and buy the small ones just because they are light and because they have been told that with a certain type of bullet they are equal to the larger bores?

But when all is said and all arguments exhausted, the truth remains that a small bore with any type of bullet will not stop big game unless it is actually hit in the right place.

The writer well remembers many years ago being firmly convinced that a 303 with soft-nosed or split bullet would stop anything, and how an old hand said to him: "My boy, you don't know, because you have never done it; your rifle is all right for the kind of game you have been shooting-duiker, 
steinbuck, reedbuck, and such small things-but wait till you see half your animals just go off as though not touched."

Of course, he was not believed. But disillusion quickly came, and a larger bore rifle (a 577) was soon invested in.

As an illustration of the disappointment that often ensues through the use of weapons too light for heavy game, the author when shooting in East Africa lost several good heads through using a 303 , instead of taking out the heavier rifle.

On one occasion hours of careful tracking from a waterhole in well-wooded country brought him up to a large herd of sable, and a very fine bull was picked out with the aid of the glasses. The shot was taken and the animal brought down, but in the dim light and stampeding of the others it was lost sight of for a moment, and when looked for had got up and gone. This occurred about middle day ; the beast was followed till sundown, and though obviously weak, having lost much blood for the first mile or so, was not come up to, and was only sighted once on the far side of a stretch of open country, wandering hopelessly on and on.

Night put a stop to the day's proceedings, and the next day at dawn a return was made to the spot left overnight, and the spoor was picked up and followed.

As the morning wore on, it became obvious from the spoor that the poor beast was getting weaker, but 
had not once lain down, only stopped two or three times to lean against a tree. Hope ran high of a sure find, but hard ground was reached, the spoor got mixed with other beasts' and the tracks were difficult to define.

This wasted much valuable time, and what was still more vexing was that the sky had become overcast; and though as much speed as possible was exercised, rain fell heavily and completely obliterated all the tracks. Thus the animal was lost though very hard hit; but if the heavy gun had been taken out one of the finest sable bulls, if not quite the finest, the author has ever seen would now be hanging on his wall instead of lying derelict in an African forest.

On another occasion, before the 577 was acquired, a small herd of wildebeest were approached very closely, thanks to the aid of some clumps of palms. An old bull facing was brought down with a shot at the base of the neck, and as the others started off a second bull was toppled over, but got up and went on, looking very uncomfortable, and though a parting shot was given tail on, no sign of a hit was shown.

On rising and walking round the clump of palms to go across to examine the first bull, nothing was to be seen of it except a pool of blood and disordered grass. It had gone, and yet came down at the shot as though stone-dead, and attention being concentrated on securing a sccond beast, it was not seen or heard. 
The spoor showed that both had followed the rest of the herd; and, to cut a long story short, though they were followed till sundown they were never even sighted again, and whether or not they both died or both recovered will never be known. Anyway, natives sent to search for their dead bodies the next day came back empty handed.

Of course, the game is not always lost, and under very similar circumstances two beasts out of three in one herd were eventually bagged, but took both time and patience to again get within shot.

But the point of these incidents is to show that even if the game is eventually brought to bag: fewer losses occur, much valuable time, patience, and unnecessary suffering to the beasts themselves is saved by using a gun that, after all, weighs only a few pounds more, can be carried by the tracker or bearer the greater part of the day, and makes all the difference between almost absolute success and almost certain uncertainty.

Two rifles should be taken, one for small and medium game and the other for the larger beasts.

The $303^{\mathrm{I}}$ is an excellent weapon for all ordinary small-game purposes, and with soft-nose or split bullet will effectually stop any animal up to about the size of a reedbuck. This can be either double

$x$ It must not be forgotten that in some countries certain rifles and bores are not admitted, and any legislation on this matter must be known before the battery is finally fixed on. 
or single, and almost any price can be paid; but as the rifling in the best of makes will eventually be cut out, there is no practical reason for paying too high a price. The author has always found a sporting type with magazine, and having the wood almost up to the muzzle, a strong, reliable weapon and capable of much ill-usage. This weighs, with sling, 8 lb. 6 oz.

But for larger game something heavier is required, and the writer has used with success a single 577 cordite ritle, weighing with sling and rubber heel-pad I4 $\mathrm{lb}$.

No doubt there is a great satisfaction in handling a weapon that, if only held straight, will knock out everything that it is pointed at. Hence every hunter should be recommended to take a rifle of as large a bore as he can shoot with comfortably, and not fall into the error of believing because a bullet from a small bore will turn completely inside out in a lump of dead beef that therefore it will kill an eland.

Consideration might also be given to the many excellent rifles turned out in America; though beyond target practice, where they have given good results, the author has had no experience with them.

Fit and Sighting.- - Having selected the bore and the type of rifle suited to the game it is proposed to pursue, due consideration must be given to how the rifle comes up and specially to its sighting.

A rifle, like a shot-gun, is the better for coming up 
to the eyes and shoulder without effort; that is to say, when thrown up as if taking a snap-shot the fore and back sights should fall into correct alignment with the eye, so that the trigger can be pulled at the same moment and so ensure successful snap or running shots.

Have the back sight placed far enough away from the eye to prevent blurring, and if possible have the top rib or top of the barrel engine turned to counteract glint.

The sighting should be simple and open and so arranged that the fore sight can be placed in the back
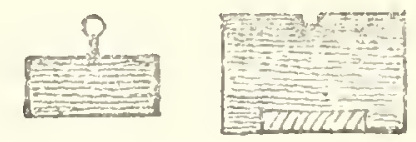

FIG. 4.
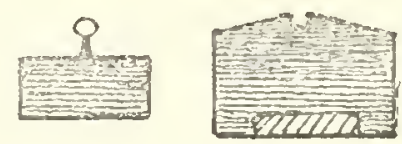

FiG. 5 .

without loss of time when taking a shot. The wide $V$ cannot be recommended for accurate shooting, as not only is it somewhat difficult to get the fore sight correctly in the centre, but there is little or no guide to the rifle being held level. After using many various forms of sights the author has come down to a simple bead sight and very small notch in the back large enough to take it.

Two forms of this back sight can be used, having either a straight top (Fig. 4) or cut away at the side (Fig. 5).

The latter is the sighting invariably used by the 
author with great success, and by having the notch on top in this way there is nothing to catch the eyes when quick and running shots are being taken. Also if the bead is in the notch and both in a direct line between the eye and the object aimed at, all question of centring as with a wide $\mathrm{V}$ is eliminated.

The fore sight should have a platinum tip and the back sight wholly blackened and without a silver line down the centre. The fore sight should be protected, and the protector should be of some pattern that is fixed on the rifle and will turn down, and if accident-
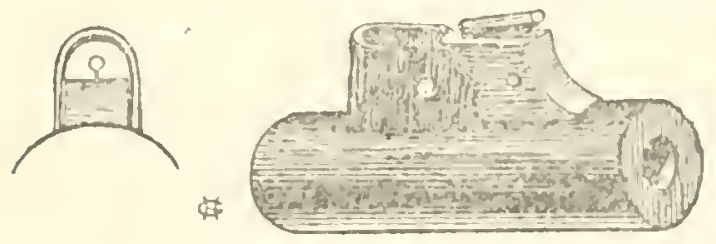

FIG. 6.

ally left up when a shot is taken, the sight can be taken through it (Fig. 6).

Every hunter could record instances where shots have been spoilt or not taken owing to the sight protector being solid in front.

The writer lost a cheetah this way once in the low country of the Transvaal. This occurred on a long ride from the Portuguese border. When riding out of a drift, the cheetahs were seen just crossing the road. Giving one look, they bounded into the "bush."

Quickly slipping off the horse, a run was made for where they had disappeared, and, dashing into the 
bush, they were run right on to at only a few yards' distance. With a growl, one sprang out into an open stretch of country beyond. It presented a fine shot at only twenty or thirty yards' distance, but, as the rifle was brought to the shoulder, it was found the sight protector had been forgotten in the excitement of the moment, and though the trigger was pulled and the fore sight guessed at, a hopeless miss resulted.

A run was then needed to get outside the patch of bush to obtain another view of them. By this time they were a good way off and going like mad, one already disappearing into some trees and undergrowth.

Meanwhile, the fore sight protector had been pulled off, and by taking a quick shot from a standing position, allowing just a little in front, the pleasure was experienced of seeing the other turn a somersault like a shot rabbit. Had the fore sight been visible, doubtless both would have been added to the bag.

Whether or not it is decided to have a rifle made or to buy one outright, the buyer should make a point of insisting, before the sights are finished, on the maker sending him and a man down to the range and let him shoot and sight the rifle for himself, at exact measured distances.

There are no two men who see quite the same, and though a rifle may shoot accurately with one man it will be a little out with another; so bear this in mind, and if the expert on the ground takes a file, the back 
sight can be cut down to suit the purchaser's requirements. For this the maker should keep the back sight full enough to start with.

The sighting should start at 50 yards, then go to I00, 200 , and so on. Some writers recommend the first sight at So yards, the next at I50, and so on. Both systems are equally good, and the only thing that counts is that some sight under Ioo yards is most useful for game shooting: therefore perhaps the 50 yards is more practical than the So.

Take more than one fore sight, and a sling is also most handy when the rifle has to be carried any distance.

For the ammunition have both solid and soft-nosed bullets. The latter can either be the true soft-nosed, hollow-nosed, or split; the last is perhaps the most deadly.

About 1906 some special bullets for the 303 with copper tips, called "Axite," were used by the writer. These certainly did mushroom; but except with small animals, where they were no better than ordinary soft nose, they had a bad habit of breaking up on the skin and losing their penetration.

Unless forced to, never file down the solids to turn them into "dum-dum," as, with most, the lead is exposed at the base of the bullet, and, should it stick, the lead will fly through, leaving the nickel in the barrel, even if no worse result happens.

This once happened to the author, and had the nickel 
not stuck so near the breech that a second cartridge could not be inserted, there is no doubt a bad burst and possible injury would have occurred, as, except for a rather harder kick and no accounting for not hitting, no thought was given to anything really wrong until the cartridge refused to go "right home."

SHOT-GUNS.-For overseas work, where a certain amount of rough usage is entailed, a shot-gun should be made on the strong side-strong in the barrels and breeching and solid enough in the wood, especially at the grip, to stand falls and knocks.

Select a hammer before a hammerless, as not only may the latter more easily get out of order, particularly in sandy countries, but with the hammer the hammers can be seen and less risk of accidents can be assured.

The weapon chosen need not be a highly finished and highly priced article, as it won't shoot any the better, but the use and service to which it will be put should be kept in mind when purchasing.

Though bores are much a matter of individual taste, and there are many who prefer a 16 or 20 to any others, and stick up for their hard hitting and straight shooting of these guns, there is no gainsaying that for all-round general use (for perhaps the game that springs up under the foot may be a quail or a small antelope) the double I2-bore cannot easily be superseded.

Extra length of barrel is of use, and one or both barrels may be choked. A good strong hammer gun 

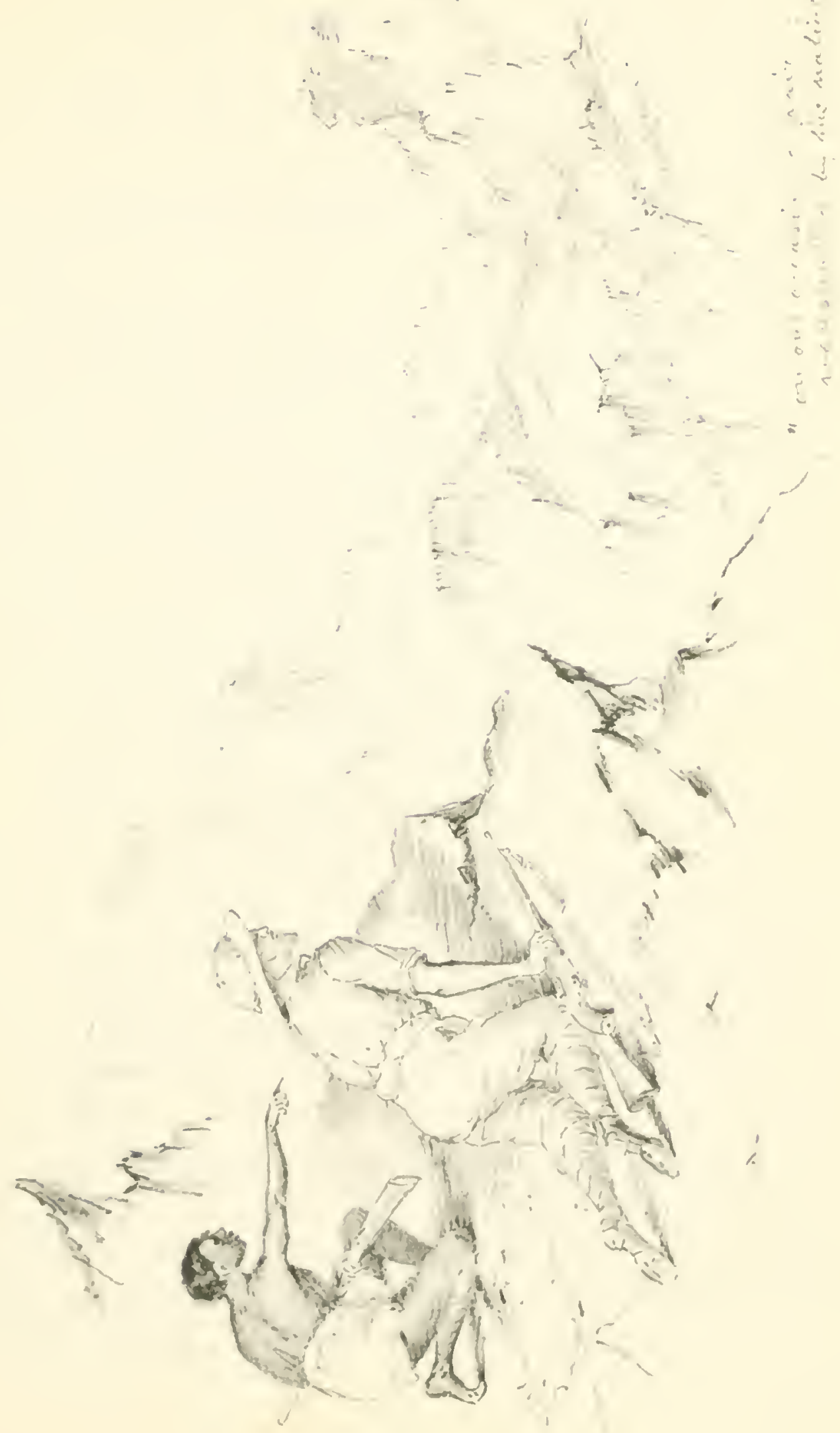
$\therefore \quad \therefore$

$\because \div \quad:$ 
suited to rough work need not exceed $7 \mathrm{lb}$. in weight.

The cartridges should be varied and a fair number should be loaded with large shot, including No. I, B.B. and "loupers."

If it is proposed to shoot small birds or do any collecting, a double 4 io hammer gun should be added to the battery. These little guns weigh only $5 \mathrm{lb}$., are very handy, and with No. 4 shot will kill partridges, hares, etc., neatly and cleanly, and are the very thing for securing the Livingstone antelope, guinea-fowl, etc., when they are shot at close quarters, as happens if the hunter joins organized native hunts. Indeed, on more than one occasion even duiker have been shot stone-dead.

For years the author has confined himself to using only two sizes of shot in the 4IO-No. 4 dust or No. 12, which give excellent patterns and serve all the purposes for which this little gun can be used.

There is no doubt that if the collector wishes to obtain the best shooting with this small gun he must load the cartridges himself and use the best black powder, ramming them well down.

Those loaded by hand will hit far harder and give a better pattern.

It is not inadvisable to carry reloading apparatus both for this gun and the I2-bore, as bulk is saved by carrying a little extra powder and shot, and the reloading is a simple and quick opcration.

Paradox guns have been improved of late years, and 
will now place a ball in a 4-inch circle at 100 yards. Though, perhaps, useful in certain circumstances, the author has never had occasion to have one, and therefore cannot personally speak of their practicability or otherwise.

Other Notes. - As the reader will learn how to handle his weapons when testing and shooting themand only long and continual practice will teach him how to aim and use his various weapons and of what they are really capable-it is unnecessary to enlarge

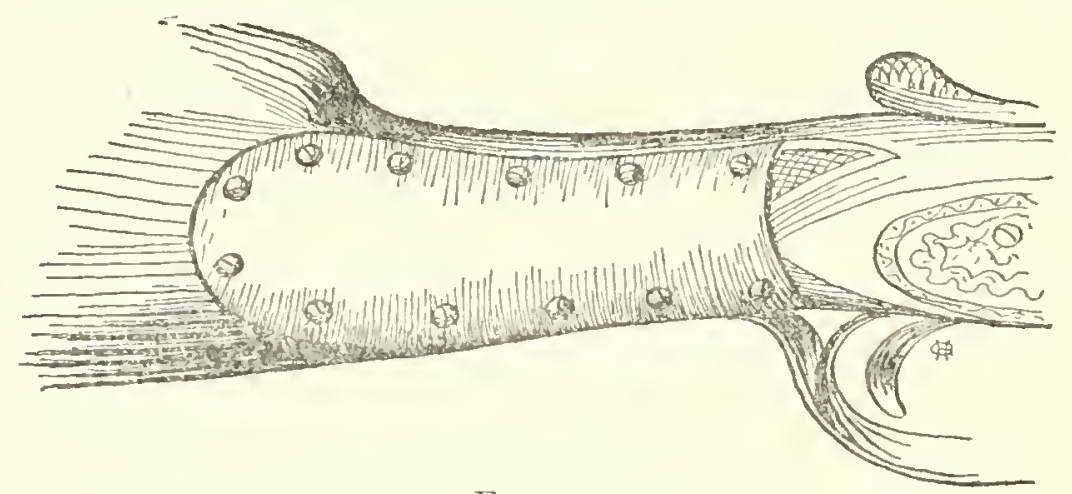

FIG. 7 .

upon these questions here, especially as where to shoot big game will be discussed in the next chapter.

Always have good waterproof canvas covers for carrying the weapons when in trek, and take an ample supply of oil, vaseline, and cleaning tools, as the care and cleanliness of the guns and rifles cannot be too strongly emphasized. To the total outfit mentioned in Chapter II should be added a small sheet of brass and some short, round-headed brass screws.

With this can be mended a broken stock (Fig. 7) or any fracture of the wood of the guns. 
As a guide to the weights for transport, it may be mentioned that 100 'I2-bore cartridges weigh about Io lb. ; IOO 4 4 IO about 3 lb. 3 oz. ; IOO ' 303 about 7 lb. ; and 100.577 about $\mathrm{I} 7 \frac{\mathrm{d}}{\mathrm{I}} \mathrm{lb}$. This is without packing of any sort, which must be allowed for. The shot cartridges anyway should be packed in tins, and the cases so arranged that each package contains an assortment of all the ammunition.

With the guns and rifles, ammunition, and accessories, as with the other part of the outfit, take time by the forelock, and do not leave the purchasing till the last moment. For only by having weapons and ammunition that suit both the hunter and the hunted can the trophies of the chase be brought homc. 


\section{CHAPTER IV}

\section{BIG GAME}

"BIG game!" How these words bring back to the memory past episodes and adventures, or conjure up to the imagination great deeds to be done, where every stalk is successful and every head a record!

Around your own fireside or at the club, when the talk is on Overseas sport, how quickly the conversation turns to the larger beasts, to successful and unsuccessful stalks, the arguments on the different bore rifles, on camp and camp-equipment, native servants, and last but not least, the different sporting qualities of various countries and various beasts!

To the "old hand" memories crowd thick and fast, and he sees himself again in many a wild spot and remembers only too well how the best heads always managed to get away--they always are the best that are missed, or only just sighted after a long and arduous stalk; how many a long day was spent without drink in a dry and arid country or in the cold or wet, among the snows or in the vast swamps; how delightful the camp was on the return; how fit 
one always was, and how the appetite never seemed to be satisfied; and however tired, one got up again and again to re-examine the trophy of the day and measure it over again, to be quite sure it had not been measured too short.

To the "old hand" in the making, the beginner, after all, lies the cream of life, for his first experiences and excitements are to come and have not been dulled by use. He has no disappointments to remember; to him all days are successful days and his every head is a beauty, if not a record, and he sees himself returning from his first trip with many a head that will make the "old hand" long to be at it again.

Let him dream, for without dreams there is no romance and often no reality; and don't we all know how many a dream has come true, and many an imagined red-letter day has been even more than fully realized?

So, beginner, dream on, for in dreams there is hope, and in hope there is life and sport.

The quest of big game carries one into almost every country of the globe. There is the red deer here at home; the Continent has its deer, elk, chamois, and pis; farther afield are the well-stoclied countries of India and Africa, the former having elephant, bison, tiger, deer and antelope, and the latter the true home of numerous antelope, the buffalo, the elephant, and the lion. From India through the Malay Peninsula and the 
Dutch Islands to China good sport can be had; or if we turn our backs on these and go "out West," we have the vast continents of North and South America, the former renowned for its sport, but the latter seldom visited for this purpose, though several species of interesting deer, besides the llama and guanaco, are to be found there, and afford some hard tramping and good shooting.

Even New Zealand now has its red deer, and many a fine head has been secured in that remote land. Australia perhaps stands alone in yielding no real trophies, though kangaroos may be designated as big game, and afford good sport both with rifle and dog, but are hardly worthy of a place on the ancestral walls.

But among them all India and Africa have the most attraction for the home sportsman, and again Africa more than India, for that country holds the most beautiful of living game, the graceful and numerous antelope, ranging from the great kudu through a wonderful variety of species to the small duikers and dikdik, which, though not truly big game, may well be included among them, as they are equally as interesting and it is often hard to secure good heads.

Rifle AND SHOT-GUN.--Wherever possible, antelope, deer, etc., should be shot with the rifle; this is the true sporting way, both for the sportsman and for the game. Of course, there are quite a number of 
the smaller forest beasts, and even some medium ones, as for instance bushbuck, that would be extremely difficult to secure in this way, and many and many a day might be spent in hunting these antelope and deer, and, although plenty may be seen, never a decent shot could be taken with the rifle, so that where these circumstances exist it is quite legitimate to use the shot-gun for securing the trophies or meat.

It so often happens, too, that this shooting involves driving with natives or dogs, and as the gunner is usually squatting on the ground, concealed behind some tree, bush, or rock, shots with the rifle are by no means safe for the beaters, and even a shot-gun with large shot has to be used with care.

In open or sparsely timbered country a rifle only should be used, except under exceptional circumstances and for very small beasts, and the practice which the author has so often seen of men hunting such beasts as reedbuck with the shot-gun cannot be too strongly condemned, not only because it is unsportsmanlike, but because very many beasts are badly peppered and not brought to bag.

Naturally, if one was out with the shot-gun and a good head was walked on within easy range, the hunter could not be expected to hold his hand, though the head would never be valued as much as one taken with a ball. It would, however, be quite a legitimate thing to do, and it is only the promiscuous pulling at everything that is both cruel and not "cricket." 
Hunting ON FoOT, ETC.-Big game can be hunted either on foot or on horseback, or, as in India, on elephants; but we do not propose to discuss the latter here, as it is a specialized form of shooting and the gun is very much in the hands of his elephant.

Taking the world all over, most hunting is done on foot, because only in very few districts does the country admit of other means of progression or the game allow itself to be approached without careful stalking.

The sportsman can either go out by himself or take with him one or more natives who know the country well, do the necessary tracking, know where water is to be found, if any is required, can find the shortest way back to camp, and last but not least, guide the camp men to the game that has been brought down, for them to cut it up and bring in the skin and meat.

A man should not be advised to go out by himself, especially in a new country, as it is remarkably easy to get lost when the attention is concentrated on some stalk or following on a wounded animal; and even should he find his way back it is quite probable he would never be able to locate again the spot where he had left his quarry. There is, however, little risk in just pottering round near the camp for small beasts or birds, and when any smaller antelope is secured it can be brought in on your own shoulders; but the man who is on a shooting trip and has natives with him should always take at least one out, not only 
as a greater security against being lost, but also for carrying in the bag.

There are yet vast tracts of country where game is plentiful and tame, and where as many as half a dozen species can be seen at one time; in these places little or no stalking is required, and the trophies and meat are easily secured; but there are other places where the game is less plentiful and wild, and long days and careful stalks are necessary to bring a head to bag.

These are the days that are most enjoyable, for they involve hours of following on a spoor, which has often been picked up at a water-hole in the early morning, patience and endurance, going without food and often without drink from sun up to sun down, and frequently a final hard tramp of many miles back to camp without having fired a shot or sometimes even sighted the game.

But when they are secured, these are the heads that are prized most.

Starting OUt.-On starting out for a day's stalk one should travel light, taking the glasses, rifle, and cartridges only; and if the sportsman can fall into the practice of going without food and drink till the return, so much the better; especially without drink, as unless plenty of water is likely to be passed, one cannot carry enough on oneself, and there is nothing so fatal as to start drinking on a hot day and not have enough to see one through. If the first temptation and desire 
can be overcome it is surprising how long one can go without.

FOOD AND DRINK.- - It is well to have a good breakfast before starting, however early it may be-something substantial; and for drink, coffee, which is more sustaining than tea. Never under any consideration have a nip of any sort of spirit, and do not take any out with you, unless it be in a very cold or very wet country; but even then I do not agree with it. Have your tot always after the return, when you really need it; then it will do you the most good.

If you do take out drink and food, carry it, if possible, yourself, especially the drink; just a waterbottle of diluted tea or coffee will carry you a long way if taken sparingly.

Also, always have a cartridge or two on yourself, but let your tracker carry the rest; and in most countries this man, or a special gunbearer, carries your gun right up to the time of taking the shot.

If one is leaving the tracking or spooring entirely to one's tracker, and is merely following close on his heels, which has usually to be done in thick country where game has to be approached very close or it is not seen at all, it is often found that the man carrying the gun is carrying it the right way up on his shoulder (really the wrong way for safe carrying in such a position), and that the muzzle is pointing straight into your eye.

In these cases it is not always policy to keep on 
at the boy, but just to leave him to carry the rifle any way he likes, the sportsman himself taking the precaution of either shutting all the cartridges into the magazine, if it happens to be a magazine rifle, or if a single, to carry the cartridge in his hand ready to slip it into the breech when the boy hands him the weapon.

Just a simple precaution like this may save many a serious accident; and as shots at big game are not often talien hurriedly, especially in dense country, no real time is lost in the loading of the rifle, and if done carefully and expeditiously, the quarry seldom hears the click of the lock.

SeEing Game.-For the beginner, perhaps one of the difficult things in big-game shooting is seeing the game in any sort of cover; this is not easy, and even after considerable practice the largest beasts can still be orerlooked.

To the "old hand," seeing game comes easier, and the writer can well remember in his carly days in Africa how time after time klipspringer and rhebuch were pointed out to him and he failed to see them until they moved.

In the dry, arid country near the mouth of the Orange River, klipspringer were plentiful; some delightful days were spent in hunting them in their mountain homes.

On one occasion a pair were spotted by the native guide, one standing up and the other lying 
down, just below us, and not more than 50 yards away; and yet it took the writer quite an appreciable time to make them out at all, they so resembled the surrounding rocks and were as still as statues.

On a shooting trip taken with a friend in South America-a friend who was new at the game-the writer pointed out two large deer standing at the edge of a forest and quite in the open, and his friend failed to see them.

We got down and stalked up to within about 80 yards, and even then he could not make them out, and it was not till he was shown the exact trees they were standing in front of that he saw them, and then he was surprised to realize that, though he had been looking straight at them all the time, he had really been looking through them.

We were lucky, with my friend's head waggling about trying to see something, in securing them both.

Zebra are perhaps the most conspicuous of beasts when seen in a Zoo, but put them in a palmettocovered country and they lend themselves so beautifully to it that the oldest hand will sometimes overlook them.

In following on spoor a very sharp lookout has to be kept, so that the quarry does not see you before you see it, and though perhaps it may not travel far, it may mean a long tramp before it can be again sighted: and in some districts where game has been hunted by natives with dogs, or much harried 
by sportsmen, it will, after being disturbed, turn down wind, when for obvious reasons it would be foolish to follow; even then it can be sometimes circumvented by taking a wide detour to get below the wind: and here a native is absolutely necessary, as he alone will know the probable direction which they have gone in and where they are likely to stop.

Practice and knowing what to look for are the only things that teach the beginner to see game, it may be lying down or standing up, head or tail on, feeding or resting, probably half concealed by some tree or shrub or rock or long grass; its head end may be visible or only its tail end. In forest the light may be so bad that there is twilight everywhere, or in more open country the alternate shadows and bright sunlight break up their forms and make them invisible: their horns look like branches; their ears like the thousand leaves around, and their bodies the colour of the ground or trees or rocks. At every step you imagine you see the beast you are after, and when at last there is a sudden movement and the quarry has gone, you find you had made sure that it was nothing alive till it had moved, and then it was too late.

This is where the glass comes in, and with its aid these illusions can be dispelled, and often the game made out where the eye had failed to find it, and an exciting stalk brought to a successful conclusion.

CRAWLING.-Frequently the last stage of the stalk is 
a crawl or a wriggle flat on the ground; then if the country is in any way open it must be done with great caution and slowly, and it is then often better for the stalker to carry his rifle himself, so that he can take the shot at the exact moment that the beast offers itself in the right position.

When crawling, great care must be taken that the muzzle of the gun is not dipped in the ground, and also that the safety catch is on, so that any twig or obstruction catching at the trigger will not explode it, and either put the game away or as likely injure the stalker himself.

Always approach as near game as the nature of the ground, wind, etc., will allow before firing, not only because it means a surer kill, but the best beast can be picked out. This, again, is very much a question of practice, and a beginner would do well to be guided by his tracker - in his first stalks at least.

In country devoid of trees longer shots can be taken, as not only is it difficult to approach very near, but the light is good and the animal very distinct, so that sure shots can be talien far farther than could be done in bushed land. Of course, in any dense cover like primeval forest a head must be approached close to see it at all.

In the open shots up to 400 yards can be taken by the man with the steady hand and straight eye, but in forest you can seldom see farther than Ioo yards, and usually much less. 
By taking time, studying the wind, and taking advantage of every scrap of cover and carefully watching the game itself, if the country allows one to do so, a man can get remarkably close up. All this requires practice, and a keen man will soon find himself falling into the habits and actions of his experienced tracker.

In open country keep the eyes and senses to windward; in hilly country stalk the game from above. Most animals, unless they have scented danger, watch the hills and plains below them. In country with alternate forest and open patches endeavour to keep in the forest, preferring to slirt right round rather than cross the open, and even in forest lieep close to the larger trees, so that should game be sighted one is near to good cover.

If it is proposed to work a stretch of thinly wooded or grassy and broken country, as for instance grassy sand-dunes along the coast, a detour should be taken right round, so as to take it up wind; this often has to be done to get hold of the smaller deer and antelope when they have lain up for the day.

WOUNDED GAME.-Of course, in following any wounded game these rules cannot be always applied, and one has to work according to the circumstances, but it must always be remembered that wounded game will often, after crossing an open piece of ground, stand just inside the cover on the farther side, waiting to see if the sportsman is following, so that before 
debouching into the open the farther cover should be very carefully examined through the glass, and should the wounded animal be seen there, one of the men should be left to watch it and the hunter himself endeavour to get up to it by a flank movement.

It frequently happens that an animal, though badly wounded, will keep going, and becoming very cunning, continuaily stand where it can see the hunter approach without his being able to detect it, however careful a lookout is kept; or, after being again caught up and having slipped away, it will travel a tremendous distance, though only perhaps going in a great circle or taking great zigzags, and it is obvious that many hours will be spent in coming to close quarters, and perhaps not before the day is spent.

A good plan under these circumstances is to abandon the chase, marking the spot where the spoor is left, and leave the beast to lie up during the night, and on again picking up the tracks in the early morning, it will often be found that it has become stiff and can be at once approached, or will only travel a short distance before again stopping.

Many good trackers, when an animal has been shot and has got away, will advise a wait of an hour to give it time to lie down and get the idea it is not being followed.

Always remember that a wounded animal is often more difficult to stalk than an unwounded one, for fear makes its senses sharper, so never make the 


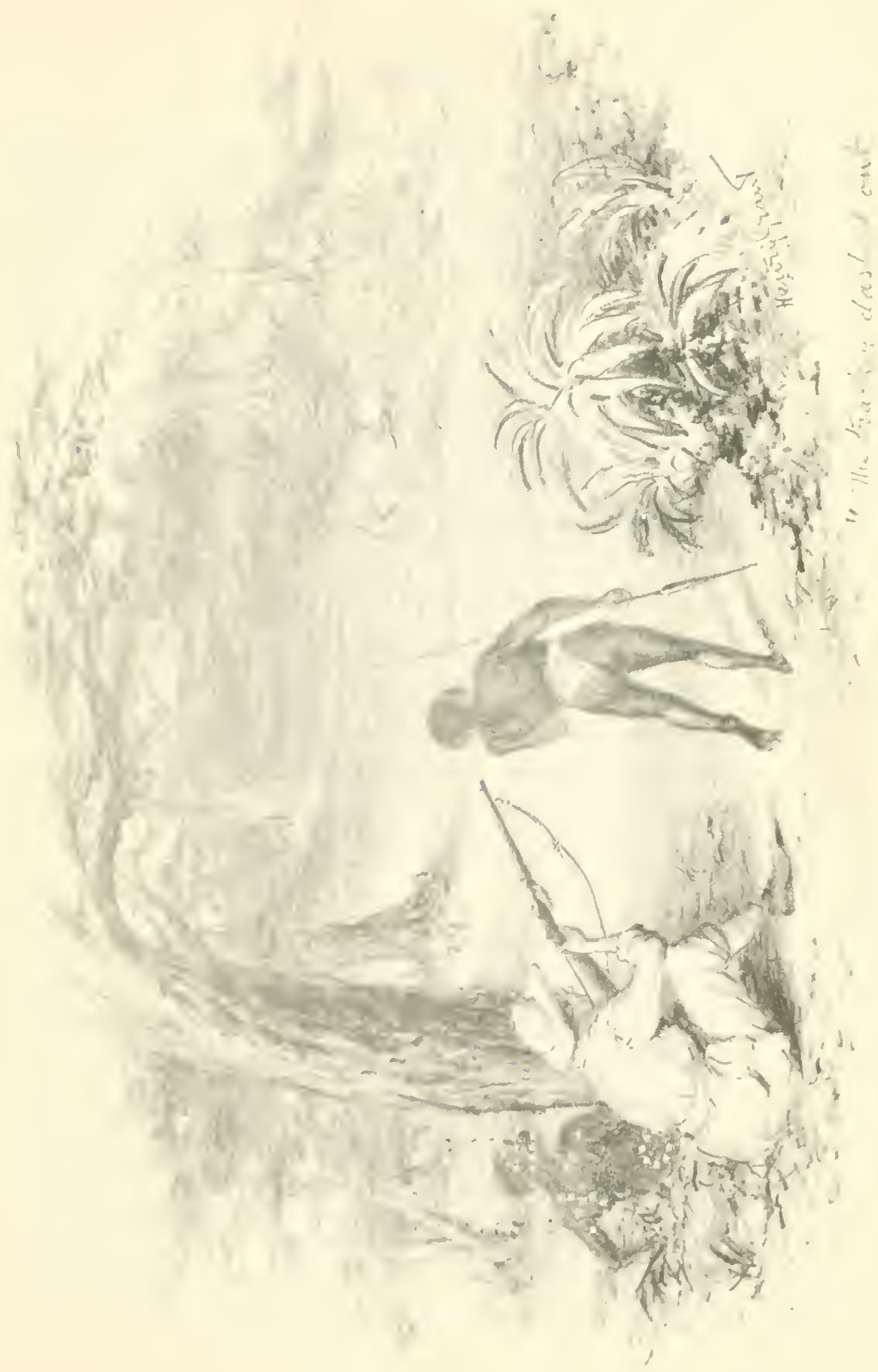




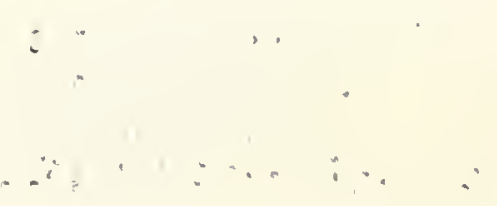


mistake of thinking that the beast is dead-beat and done for. The energy and vitality of big game is wonderful, and many a fine trophy has been lost through the hunter being rash enough to approach openly.

Indeed, at times game takes a lot of killing, and one wildebeest in the Portuguese country took no less than a dozen 303 bullets to stop it; most of the hits were in the right place, and the last two or three were given as the author sprinted alongside the wounded animal.

Many cases of antelope going for 200 or 300 yards could be recorded, in all instances being found dead in their tracks, the shot having raked some vital part. Perhaps, however, the most interesting example, and one that will be hardly believed and yet is true, is that of a solitary wilclebeest that was hit chest on by a friend, and, though followed for many hours and much blood found, got away.

Some fortnight after the natives reported the return of the old fellow to his haunt, and the author himself went over to verify the report, which was quite true, and though the poor beast looked thin and weak, he was perfectly well and took good care that no one got within shot of him a second time.

However, no hard-and-fast rules can be laid down on this matter, as it all depends where the animal is hit and how badly, whether it is losing a lot of blood or none at all, whether the country is open or forested. 
In fact, only experience can teach one when to keep on or when to give up, and an experienced and trustworthy tracker is invaluable in the early days of the big-game hunter.

An animal that is knocked right over and gets up and goes is generally the one that is going farthest, and the one that dashes away at top speed on receiving the shot will usually be found a little way on stone-dead. A leg shot is noticeable, and the beast will often travel a great distance; a stomach shot often makes the animal cramp itself up, and if hit with a large ball it may not go far, but if with a small one it may get away altogether.

Spine, neck, and head shots are instantly fatal, but heart shots do not always drop the quarry, though, of course, the beast never gets far.

It sometimes happens that the hunter is deceived and thinks that he has hit when it has been a case of a clean miss.

The author well remembers an instance of this, when he had taken a long running shot at a particularly fine reedbuck, which instantly showed lameness in the foreleg. So it was followed up hour upon hour across open country and finally bagged in a reedbed where it had gone to lay up, but on examination no sign of any previous hit could be found, and so the only conclusion was that at the exact moment the trigger was pulled it had stepped in a mole-run and sprained the fetlock. 
It is just such trivial things that so often bring the hunter his best heads.

A stricken animal will endeavour to keep up with the rest of the herd, but on finding its strength giving will break out and go off on its own. This is where more than one of you come in handy, for the spoor of the herd can be followed by spreading out across it, and the tracks of the wounded beast can be spotted by the flanking men at the point where it has left the others.

Ordinarily always proceed in single file and thus present as small a front as possible to the game ahead.

Blood-marks should also be looked out for, though these may peter out if the shot-hole is not large.

WHERE TO SHOOT.-To return to the stalk: having successfully negotiated all the difficulties of wind and cover, or lack of it, and the other members of the herd, and come within striking distance of the beast one has been stalking, the spot at which to aim has to be decided.

This depends entirely upon the position in which the animal is standing or lying down. If broadside on, you have the choice of two or three spots, all of which are fatal: there is the spine, which can be taken anywhere; the heart and main arteries, which are the best points to take; and the neck, which is never taken unless no other part is visible, but which is equally as deadly if the bullet catches the vertebra fair and square. 
If facing, the point is in the angle of the neck and collar-bone, aiming, if anything, high, so as not to catch the latter, as the neck is then caught and broken, or if the bullet is placed properly it rakes the lungs and arteries.

If quite tail on, do not shoot, but endeavour to work round so as just to see the flank, when a bullet fairly high up behind the ribs or shoulder will be the shot.

If, as sometimes happens, just as one has got up to and is taking aim at the beast, it or another sees you and they are all off, there remains nothing for you to do but shoot at the hindquarters, and though not a sporting shot, there is no other choice or the chance is lost for that day. Then aim high up on one of the thighs, and if your rifle is fairly heavy a smashed femur will result, and it is quite possible your trophy will be secured fairly easily.

If a good chance should present itself, do not hesitate to take a beast lying down. It is not unsportsmanlike, for after all you have had to stalk it whether it is standing or not, and it is risky waiting for it to rise or trying to put it up gently, for a sudden dash off, giving you nothing but its hindquarters, will surely result, and it is really surprising how quick big beasts get on their legs and away when frightened.

Where game is plentiful, at times one species can be used as "stalking-horses" for securing another 
species, and just such an incident occurred to the writer when five wildebeest were judiciously kept on the move, and by their aid a pair of warthog were approached within shot and secured.

RUNNING Shots.-Running shots have to be taken at all kinds of game on occasion, and though shots at big beasts are more often taken standing, a sportsman need not hesitate when they are on the move. When they are taken at close quarters, aim straight at the point to be hit; if a little off, allow a little in front, and so on according to the distance away and the speed of the animal.

Running shooting at smaller deer and antelope has very often to be done and makes very pretty practice, especially when they are put up at close quarters and get away quick; then is the shooting tricky, and more misses than hits are the usual results.

Allow enough in front and aim high, as a clean miss over the top is better than a leg broken low down.

For these shots your rifle should so fit that the sights come at once in line with the eye, and always pull at the moment these coincide, for your first sight is your trucst if but your hands and eye are working in unison. A man who dwells over running shots will never make a bag. The author himself seldom dwells even on a standing one, but shoots by first intention.

Two of the best bags for total hits that have come under personal obscrvation took place in Africa and were made by two personal friends. 
The first was over a particular troop of ten ostriches which none of us had ever been able to approach within shot, until one day they were ridden on round a spur of the hills and twenty shots brought down the whole ten birds; this is truly remarkable when it is considered how hard a running ostrich is to hit, how quickly he can get out of range, and that only the first shot was a standing one. It is worthy of record that the shooter had only twenty cartridges on him.

The second occurred when three of us were out for a day or so after rooi rhebuck, and one of the party spotted and stalked a herd of five which he approached within I 50 yards, and taking steady aim, bowled number one. At the shot the others started off, and three more shots brought down three more antelope, the fifth disappearing out of sight round a spur. On going to pick them up, one got up and made off, requiring another shot to bring him to book.

Thus five shots were fired and five hits recorded, and four meant four head of rhebuck.

Both these are known to be true tales, and surely cannot easily be beaten for quick and accurate shooting.

RELOADING AND RUNNing In.-Opinion is much divided amongst big-game shots as to the best course to pursue when the quarry is brought down, whether to run in or walk slowly up, or remain where they fired from. It is a question, and a question on which no fixed rule can be laid down.

It is entirely a matter of doing the right thing at the 
right moment, and therein lies the trouble; it is so fatally easy to do the wrong thing and to know afterwards what the right thing was to do; but we all do this more times than not.

A good maxim is never to stop where you are if you can get closer, and should a beast be dropped and struggling on the ground, walk rapidly up to it with rifle at the ready, so that should it rise a fatal shot can be put in.

In every case reload at once, and walking rapidly or slowly, always have the rifle at the ready, as the "deadest" beasts have been known to spring up and clear off as though not touched. If the beast is only brought to its knees, keep where you are and give it another shot at once, and above all do not let your tracker, in the excitement of the moment, run across your front and either get the shot or prevent you getting in another, as has more than once happened to the author.

The author remembers the case of a sable bull, which had been "spoored" for hours, and when come up to broke away, offering a good flank shot as he cantered across an open glacle and was brought to his knees. As the rifle was raised to give him another shot, the tracker dashed out and across the line of sight, and though yelled at he was too excited to hear, with the result the beast got on its legs and away into the thick cover before a shot could be got in, and though followed was never seen again. 
Also never approach head on, as should the beast spring up it will bowl you straight over, and to say the least you will not be very steady for a departing shot when you get on your legs again.

The author was nearly caught this way once with a wounded waterbuck which was hit high up on the shoulder, and only just jumped aside in time to let the great heavy beast blunder past him, when a quick shot broadside on fetched him down for good.

In the Transvaal the writer was on one occasion called to the aid of a small Kaffir child that had been struck with the horn of a reedbuck. It appeared that the boy had been walking through the grass not far from the kraal, and had evidently unwittingly walked head on to the sleeping animal, which in its fright sprang up straight into him, caught him with the point of the horn, knocked him over, and had gone clean away. The lad said that the buck attacked him, but the above seems the more reasonable explanation.

Hunting ON HORSEBACK.-A good shooting pony is a very useful adjunct in many parts of the world, especially in open country where the smaller antelope, such as the springbuck of Africa, or deer, as the pampa and savannah deer of South America, are to be found, not only for galloping down the game and so getting within shot, but also a pony can be left in a prominent position for the game to see, and this gives the rider a chance to make a detour and stalk within range. 
When shooting the pampa deer and rhea along the sandy and rough country of the Atlantic seaboard of the Argentine this was the method usually employed by the author.

A stag would be spotted feeding in the early hours around sunrise, and by dropping the horse on the top of a rise for the quarry to notice and stalking round through the hollows it could generally be approached well within shot and bagged, unless the wind was wrong or the head too much exposed.

This makes pretty and exciting shooting, the halflight of the dawn, the dew-covered grass, and the light sea mists being slowly rolled back and dispersed by the great red and orange orb of the rising sun coming up out of the Atlantic, which floods the scene with a rosy tint and makes life seem well worth the living.

A pony also can be used for getting out and back from camp when any distance has to be covered to a shooting ground, but it is liable to be in the way when stalking big game, and as we cannot tell in what direction the day's sport is going to end, it is not easily picked up again at any given point.

In choosing a shooting pony have it on the small size, so that mounting and dismounting can be accomplished quickly and easily. This is essential for hunting herds of the smaller antelope. See that it does not stumble, will guide easily from the neck on a loose rein, gallop fast, but won't pull, is easily 
stopped, and, above all, will stand when dropped without being held or tied up. ${ }^{\mathrm{I}}$

Such a pony can be secured in most shooting countries where game is hunted on horseback, and should be compact in build, sturdy, and of good wind.

An amusing incident of mounting and dismounting quickly and easily occurred whilst the author and a friend were shooting ostriches in a remote district.

A couple had been ridden within shot and wounded, and were again getting rapidly out of range, so one of us said, "Drop shooting and let us ride them down," whereat we ran for our horses, which were standing only a few yards off.

S. was the quicker of the two, and putting his foot in the stirrup, sprang into the saddle, missed his grip, overbalanced, and landed right into a thorny bush, so that what with one swearing and the other laughing, neither could mount for some time, and when we did get again on the move both the birds had disappeared.

Never cut the mane and tail, as they are the only means of keeping off the innumerable flies.

If good in the mouth, which it should be, bit it with

I If the mount cannot be trusted to stand, hold the lead in the hand with the reins, as is always done in South America, instead of tying it round the neck, so that in dismounting it can be kept in the hand or tied to some convenient place in a minimum of time. It should be of sufficient length to allow the sportsman to get a short way ahead of the pony, as shots fired immediately under its nose tend to make it more nervous. 
a light snaffle, so that when left it can crop the herbage round about.

Should it wander off a little, walk up to it quietly and pat its neck as though it had done quite the correct thing; hitting it and showing annoyance in any way will only make it worse.

An animal treated kindly will soon learn to know its master, will frequently follow without being led, and take a pure delight in the sport.

Croppers in galloping game over any sort of country are frequent, and when the rider feels that his mount is going and cannot be recovered, it is far better to let everything go and endeavour to fall as lightly as you can, as sticking to the saddle at any pace may cause the animal to roll on you, with very unpleasant results.

Let it have its head, as an animal that is used to rough ground will gallop with its head more or less down, and will see and avoid most of the holes and bad places.

POPUlated Districts.-In shooting in populated districts or where stock is being run, great care should be taken in, if possible, avoiding shots on the sky-line, as, should a miss occur, bullets travel far, and if often practised the sportsman will soon make himself unpopular.

AgreEd Signs. - The sportsman and his trackers should have agreed signs, such as a low whistle or some noise that will not travel far, or a movement of the 
hand or head, so that if one of you sights game he can attract the attention of the others without speaking; the human voice carries far, and will alarm most animals.

Even with agreed signs fatal mistakes can be made and the wrong thing done at the wrong moment; and this brings vividly before the writer's memory a thick and tangled patch of bush and a man and himself spooring a kudu bull, which was at last come up to and galloped off without even being sighted.

So we gave it up and walked out on to a small open patch (mistake No. I) to have a look round and light a pipe, and the man was handed the rifle to hold.

But a few seconds had passed when the man gave a low but distinct whistle, and there, not ten yards away and just inside the bush, stalked past the magnificent bull.

The whistle did it though, and we had but a fleeting glimpse of his fine proportions and graceful horns before he vanished with a crash into the tangled woods.

Whistling was the second and fatal mistake. The bull was too close and could hear it distinctly; and had the man silently and quickly thrust the rifle into my hand without a word or other sign, a snapshot might have been successful, or maybe he hadn't seen us, and a more certain one could have been taken.

DANGEROUS GAME.-In the tracking and shooting of dangerous game, as buffalo, elephant, lion and tiger, 
extra special care and precautions must be taken, especially if they have to be followed into thich stuff, which is distinctly risky and requires great coolness and steadiness. Take natives of proved courage; panicky ones but make the risk the greater and upset the hunter's own nerves.

Dogs are sometimes of use in thick stuff, especially if the animal be wounded, and one or more should be taken along, but kept on the leash till required.

The life of the big-game hunter, whether for a long or a short period, is a life of great things, wandering with Nature in her great solitudes and untouched grandeur, pitting skill and cunning against the far superior senses of great and oftentimes dangerous beasts, coming into touch with native tribes having a great and ancient history.

It may be at times a life of hardship and short commons, of great tests of endurance, coolness, and courage, or the combating of deadly diseases, but it is a life that holds and draws beyond all else in the world.

The long after-years that soften things down only leave to the memory the best side of those glorious days that can never be wholly forgotten. 


\section{CHAPTER V}

\section{SMALL GAME}

SMALL game is usually despised and overlooked in a locality where big game is found, but a great mistake is made in doing so, for small game can afford many a good day's sport and many a good hour's yarn after.

A shooting trip can be made doubly interesting in variety of sport and bag, and many a pretty skin brought home for mounting, by taking into consideration the smaller sporting creatures, such as game birds, hares, and rabbits, etc., which can always be found in any game country, and duck and geese on the lagoons and waterholes where the big game go to drink, thus passing away many an off-day when one is too tired for a long tramp after larger stuff and making a pleasant change from the rifle to the shot-gun.

On the safe return home, how a snap-shot of some bit of scenery or a camp, or a yarn of some incident connected with a trophy now hanging on the walls, will recall those days with a shot-gun and of how 
on such and such a day "I felt too slack to go after sable, so had a potter round for duck, and bagged thirty couple in an hour, and real good fast shooting too, when they got well up and on the move from pool to pool; quite a change from the rifle, I assure you, and very nearly as exciting at times."

Or, "You ought to have been with me when the sand-grouse came down to drink in the evening, simply thousands of them, and top-hole shooting, taking them on the wing; twenty or thirty brace was nothing as a bag, and they were not bad eating either-a change indeed from the eternal buch-meat."

The variety of small game is infinite-partridges and pheasants altering in name and structure in different countries; duck and geese in wonderful variety and numbers; sand-grouse swarming like flies; snipe, hares, rabbits, pig, bustards, and guinea-fowl.

Many of the smaller antelope and deer are designated as small game, but I prefer to place them under the heading of their larger brethren, though it is true they can more often be secured with a shotgun, especially those little chaps that inhabit long grass, forested, or jungle country.

Then they are best got at by driving with a dog or natives, or by quictly walking along tracks and keeping a sharp lookout for them feeding or standing like statues in the shadow of some tree or bush, or may be with a sharp alarm-note going like 
streaks for cover, when one gets a snap-shot in as at a rabbit-more often than not planking the whole charge in some tree, the little beggars being very quick to take advantage of any cover.

Another excellent way of obtaining the small bushhaunting antelope is to find out from the natives when they are organizing a drive and join it, getting one of the head-boys to put you in a good position.

These drives are extremely interesting apart from the sport that may be obtained. The modus operandi is usually for a stretch of country to be surrounded on three sides; most of the natives squat in convenient spots with their bows and arrows ready, and a few drive through the bush with the dogs on the fourth side, these men also being armed to take any game that may break back. At times this sport is quite exciting, for one never knows what may break cover, as it may be bird, antelope, pig, or even leopard; and a regular mixed bag often results.

The natives of course have the advantage, shooting with the silent bow, and it is fascinating to watch the man nearest you, who is squatting on the ground, a few arrows laid by his side and the bow with an arrow strung, watching intently the bush in front of him. Slowly he raises and bends his weapon, and as silently the arrow speeds on its mission of death; perhaps he has missed, when he rapidly strings another and takes aim again, or more likely he has 


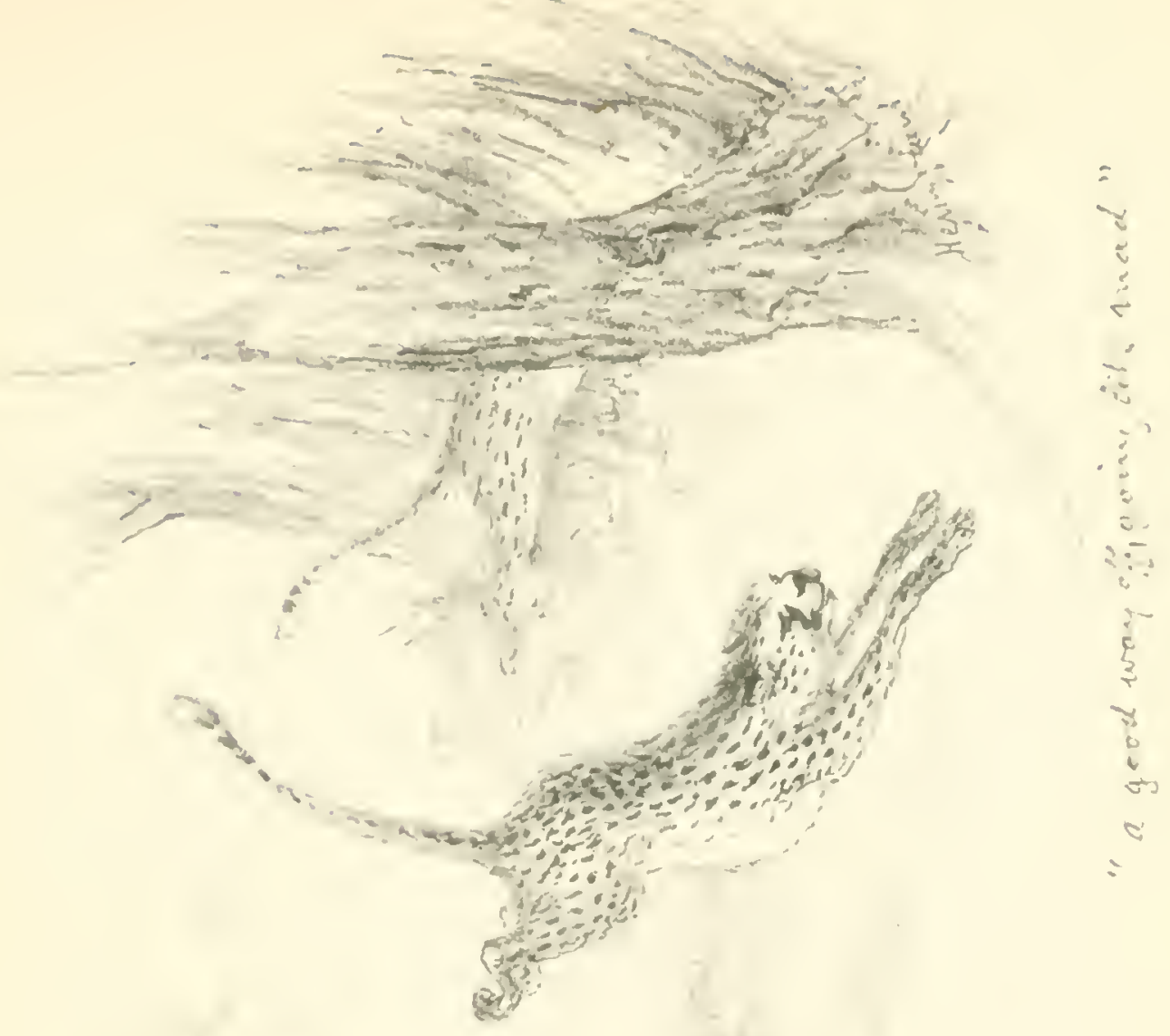



hit and a loud "Baa" or a flutter of wings proclaims that his quarry has "got it."

On these occasions the game will creep silently up and stand within a few feet, listening intently behind, and taking no heed of the squatting enemy in front till the arrow strikes it or some unfortunate sudden movement attracts its attention. A man with a gun is not usually liked, for a shot will scare everything within hearing, where the arrow has hardly raised fear in the beast that may have just been missed.

The author has frequently joined these drives in Portuguese Africa, where forty or sixty natives have taken part in them and every man has bagged at least one head of game. Bushbuck and larger antelope are shot at and secured by the natives with bows and arrows, though doubtless many escape, and an interesting case of how an animal can recover and live, though wounded, came before the notice of the author.

He was hunting, accompanied by two natives, in the foot-hills of a well-known range of mountains, and on hearing wild dogs chasing some animal, made away across in that direction and came up to them just as they had killed, but owing to the long grass they were not seen. On reaching the spot where the kill had taken place the remains of a bushbuck ram were found, and the boys naturally hunted round to see if any meat had been left which might be worth their while to 
carry home, and on picking up the backbone a bright object caught our attention, and there, embedded between the processes and only just clear of the spinal column, was a clean and polished iron arrowhead, and so firmly was it fixed that the vertebræ had to be separated before it could be released.

It was carefully looked at, and one of the boys instantly recognized it as one he had shot at a young bushbuck still with its dam some year or so before. There it had lain ever since, and though doubtless giving the little beast untold agony, he had recovered and grown to maturity.

Always remember that most Kaffir dogs are brown, and even the natives will frequently crawl through the bush on their hands and knees, and both at times can be easily mistaken for game. Just such a mistake did happen in Zululand some few years back, resulting in a native killing his own son.

It happened this wise. Baboons had been pestering and robbing the lands, and at last the old native took down his gun and sallied forth into the forest after them, taking with him his younger son. The baboons were artful and could not be approached, so the son was sent round to try and put them back to the old man, who was hiding. After some little time the son lost the direction of his father, so climbed a tree to see where he was, but, unluckily for him, close to where his dad lay in hiding, and as he showed up the trunk above the surrounding undergrowth, his father 
mistook him for a baboon and shot him dead. If a native can make such a mistake, how much more careful ought a European to be!

Baboons are artful and destructive animals. In the native lands where the crops are ripening they do an extraordinary amount of damage and lieep the whole village fully employed chasing them away. If the villagers are only armed with spears, sticks, and stones, they are very chceky, just galloping round out of range and dodging into another part of the crop. But if the hunter appears with a gun they seem to know instinctively that it is quite a different matter, and at a warning bark from the sentinel the whole packi disappear.

If thoroughly alarmed, the pack go off barking and screeching as hard as they can for cover, the younger members always being the last; and scared at being left behind and with unknown danger following, they lose both wind and almost power to run at all, and frequently fall victims to the dogs that are let loose on them.

As a rule they are artful enough not to allow their natural cnemy completely out of their sight, and though he may be stalking them, he thinking they have not seen or heard him, all the time one or two old chaps are kecping him in sight and giving occasional barks to warn the others that there is danger.

This habit of stalking the stalker, so to speak, has 
perhaps given rise to most of the stories of baboons following human beings. On one occasion, in the dense forests of Zululand, the author tried walking and then running rapidly away, with the result that the baboons could be heard also coming along behind, and when he stopped they stopped, and if he walked rapidly back they simply melted away.

To the beginner or the man with a nervous temperament such experiences would lead him to believe that the whole troop was after him, and cause him but to run the faster and not inquire the why or wherefore; which is of course but a very human desire not to be caught napping.

When bayed with dogs, the old fellows fight like fury, and many a brave dog has been badly mauled through being too venturesome; in fact, seldom do the dogs close in if they are old hands.

Boar and pig cannot easily be secured without the aid of good dogs or systematic driving. On occasions the bush-pig is accidentally come across without dogs, but as a rule days and days can be spent in the forest without getting so much as a sight of one, though plenty of signs and even their still warm beds are constantly struck.

They can be killed with a shot-gun and very large shot, though a rifle is a much more certain weapon, and a bush-pig which had no less than six barrels in it got away and was not picked up till later with the rifle. It was one of a pair found by the dog in very thick stuff 
and which instantly charged, the dog rushing back and getting between the legs of her master.

Three times the pig charged the dog and three times it got both barrels of No. 4, finally clearing off altogether. Being close to camp, the rifle was taken down and the spoor followed, and when again come up to, the pig charged for the fourth time, and received a bullet in the brain. When skinned very few of the pellets had penetrated far into the flesh, but it was so badly contused that blood-poisoning must have set in.

Dogs are useful not only for the hunting of antelope and pig, but they are almost essential to the small-game hunter, to ferret out and put up the numerous furred and feathered beasts and birds, to find them when shot or run them down when wounded, to go out on boggy places or swim into lagoons to bring out the dead fowl.

In many parts of the world, rivers, pools, and lagoons are swarming with crocodile or alligator, and if a dog is sent in, it stands a poor chance of ever getting out again; indeed, fowl have been pulled under and devoured by these monsters, and on one memorable day, out of thirteen duck brought down, only three were recovered, and these three were winged and got ashore.

This was in Africa; in South America we have frequently seen birds, both dead and wounded, deliberately taken almost under the nose of the shooter. 
That these creatures have a wonderful sense of smell is shown not only by the above, but by an incident that happened to the writer on a tributary of the Zambesi.

A reach with shallow water and a sand-bank or two was a very favourite spot for crocodiles, and when an hour or two could be spared, good practice could be obtained by lying hidden behind the bushes on the bank, the trick being to only shoot the beast through the eyes.

One that was shot like this and was rolling over and over, first belly up and then back up, was waded out after to give it a finishing shot; when some 50 or 60 yards off, it seemed to steady itself, waggled its nose about as though getting a line, and without warning came like a torpedo straight at him, and had not another shot through the head at only a few yards' distance stopped the brute dead, a nasty collision would have occurred, especially as the writer was too deep in the water, nearly up to the waist, to be able to run out.

A lesson like this was worth remembering, and was always borne in mind afterwards.

Duck, geese, and swans are almost universal, especially the former, in country where there are rivers, swamps, or lagoons, and afford both excellent shooting and good eating. Very big bags can sometimes be made where they are plentiful, and as a rule where lagoons and large waterholes supply water for the big game there 
will be found waterbirds in remarkable numbers and a wonderful variety of species.

In the early morning geese and duck will be seen feeding out on the open veldt, but soon after sunrise they retire to the water for the day's rest.

In parts of South America, at the season when the thistles are in seed, perfect flight shooting can be had, and by holding straight good bags will result. The best shot that ever came under our notice was that of a friend of the author who, on seeing seven duck coming towards him, waited till they were almost over, and as he lifted the gun they swung off all in a line, with the result that six fell to the first barrel and the remaining one to the second barrel. This is almost a Munchausen feat.

Where swamps are extensive or a chain of lagoons found, as the overflows of large rivers, the shooter should place himself in between two and get his men to disturb the duck on the end pools, and by the noise of his firing and the men exposing themselves they can be kept judiciously on the move and many a plump bird added to the pot.

It is when trekking through country where big game is scarce that the best sport is obtained with small game, as then the shot-gun is carried without fear of losing some large trophy, and by just walking level with the wagon or carriers, or making short detours, quantities of the smaller antelope, knorhaan, partridges, hares, etc., are put up and give excellent practice. 
This helps to pass away the tedium of long days of travel and makes welcome additions to the daily menu.

Cultivated lands yield many species, and in these is the best place to find some of the varieties of francolin and tinamou, the innumerable doves and pigeons, and last but not least, the toothsome guinea-fowl. This last has a bad habit of recovering after being shot, and one native made a practice of always chopping off their heads however dead they appeared; and the many occasions on which birds have suddenly flown clean away seemed certainly to demand some drastic remedy.

Sand-grouse can be found in the day many miles from water, but are usually much scattered. The time to get them is when they come to drink in the afternoon and evening; then they come in their thousands, and can either be taken on the wing or, if cartridges are scarce, they can be taken on the ground and as many as a dozen or more killed at one shot.

Two of us at a small waterhole in the Karoo shot sixty-four brace in less than an hour, and this was taking them on the wing, though more than one was sometimes killed at a barrel.

To make a bag of partridges, francolins, or tinamou successfully a good dog is necessary, and any old mongrel with a good nose and that can be kept in check will do.

The author's best dog was a very cross-bred collie, 


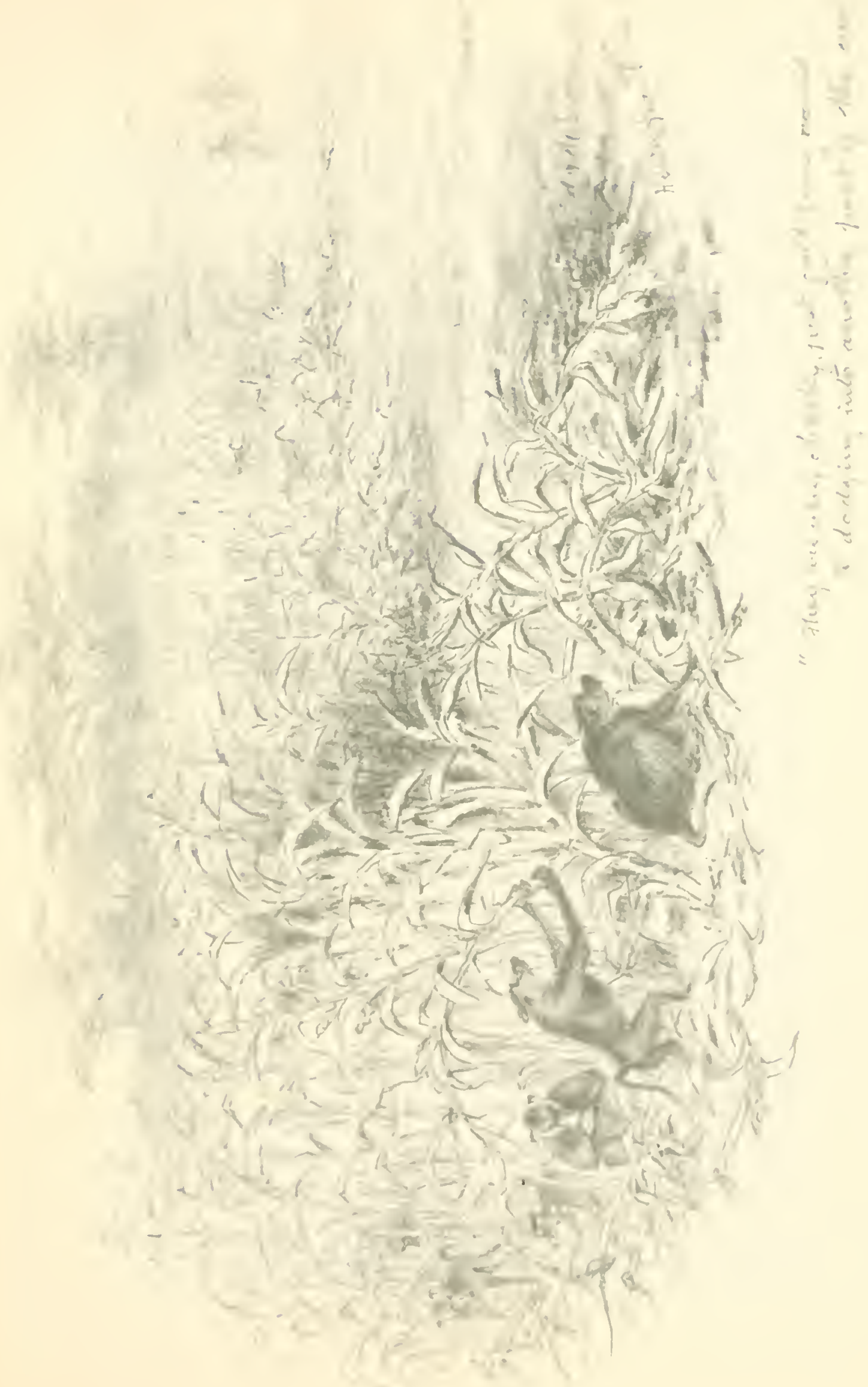




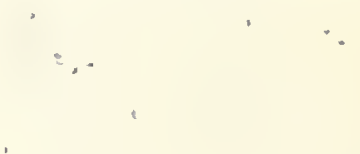


small and short on the legs, but what this dog did not know about sport was not worth knowing. She could point, nose out any sort of game, chase and pull down wounded antelope, swim out for duck, find monkeys or squirrels in the trees, and at odd times amuse herself by finding and digging out rats. She obeyed every sign and word of voice, never lost her head, and was an excellent camp dog, fighting every strange dog that came prowling round and growling at every native that did not belong to the party.

But perhaps her most wonderful and useful trait was that, when chasing wounded game or rounding up small antelope for her master lying in hiding, she always barked in cover as a guide to where she was, but never in open country where she knew she could be seen. However, like all good creatures she became more venturesome and impetuous, and finally ended her days in trying to fight a leopard.

Without a dog the majority of the birds will be walked over or passed by, and but for the cross-bred collie many and many a brace of birds and many a hare and rabbit would never have been added to the bag.

At times hares and rabbits sit very close and can be actually stepped on before they will jump; indeed, quick-eyed natives have been known to jump on and capture them whilst in the form. Dogs are here required either to point or ferret them out.

Hares also provide excellent coursing, and in the 
Karoo we had a couple or so of cross-bred greyhounds and some good fast ponies, and enjoyed many a morning's coursing.

Some of the most exciting runs were, however, on the small antelope and the springbuck, and although quite a number of the former were captured, often after runs of two or three miles, only on very rare occasions did we succeed in pulling down a springbuck.

If the hunter has a pony which will stand shots being fired from its back, bustard, knorhaan, etc., will the more readily be secured: for when sighting intruders these birds have a habit of lying flat on the ground, and if circled in slowly decreasing circles they can be approached well within shot; where often, if on foot, and however manœuvred, the game will rise long before the shooter is anywhere near.

Partridges, francolin, tinamou, etc., can also be shot this way over dogs, especially where the grass is long and, if on foot, shooting would be anything but easy, or the birds not seen at all.

There are also the plovers, the waders, quail, and many other furred and feathered beasts that can all be numbered as small game, and each in their season or country provide the hunter with both a varied shooting trip and a varied game list.

In fact, the small game ranks in its way as high as the big game, and the beginner who is primarily out for trophies of the larger game animals should 
not disdain to consider the lesser denizens of the hunting veldt. His bags and shots made with the scatter gun will be remembered with as much pride as those made with the rifle, besides adding to his collection small trophies well worth the trouble of careful preservation and mounting. 


\section{CHAPTER VI}

\section{TAXIDERMY}

THE quarry brought to bag, and its shape, colour, and the pretty graceful sweep of its horns having been duly admired, the excitement of the stalk and shot, and the elation at so successfully securing a trophy worthy of a place in the home collection having somewhat subsided, the question arises as to how to prepare it, so that it can later be made an attractive and interesting specimen for the house.

This is but a simple and easily grasped matter, and with big-game trophies all the hunter has to do is to know how to do it himself and he can then direct any native.

Mostly the head and head skin are all that the sportsman requires, though at times he may like to have the whole animal mounted, or the body skin for rugs or mats.

There are many big and small game trophies, as lion, tiger, bear, etc., that have no horns, and the whole skin with the head mounted flat is the correct method, so that in this chapter it is proposed 
to give those notes which will cover all the taxidermy the sportsman and collector will require in the field.

Where the head and head skin only are required the method of procedure is as follows:-

As the animal lies on its side, put the point of a sharp knife through the skin at the extreme base of the neck at the point where it joins the withers and

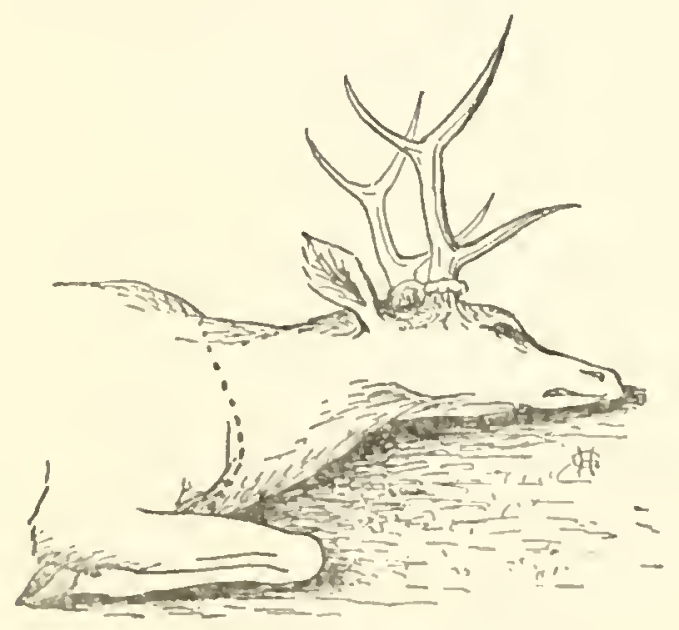

FIG. 8 .

cut downwards past the point of the shoulder to the apex formed by the collar-bone (Fig. S).

Repeat this on the other side and the head skin is severed from the body skin. Never cut off the head and skin at the base of the skull, and avoid cutting the animal's throat; it is not necessary to bleed it-the bullet does that. But if, as happens in parts of India, the natives will not eat the meat unless it is bled, plunge the knife in at the apex of the collar-bone; this will not damage the head skin. 
Now take hold of the horns and force the head over till the top of the neck can be got at and make an incision in the centre of the poll some inch or so below the horns, and cutting in a direct line down

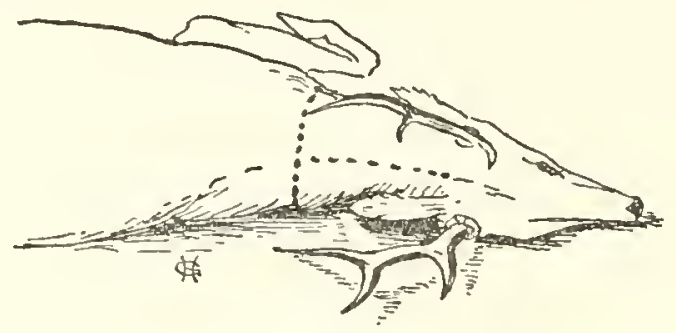

FIG. 9 .

the neck, sever the skin to the cut already made across the withers (Fig. 9).

Next, from the point of the cut on the poll make two cuts, one across to each horn (Fig. IO).

The preliminary cuts are now made and the head skin ready for removal.

Picking up the neck skin at the angle where the

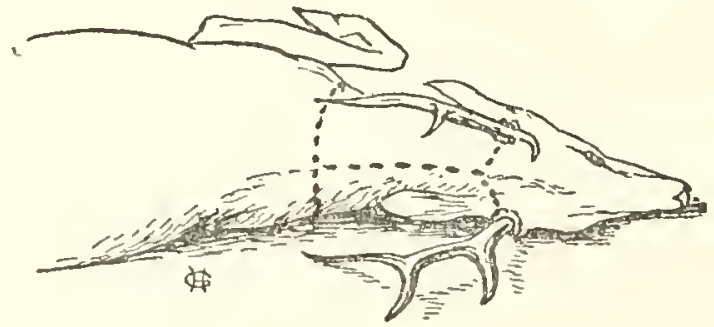

FIG. IO.

top cut joins the wither cut, proceed with the aid of the knife to peel both sides back from the meat, working also underneath until the whole skin is removed to the base of the skull. 
Now cut the skin carefully away round the base of the horns, sever the cartilage of the ears close against the skull, and start skimning off the head (Fig. I I).

Proceed carefully as the eyes are reached, and 'be

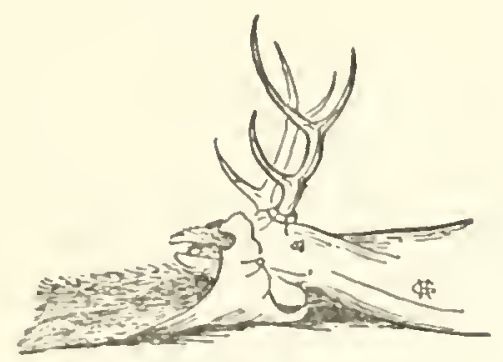

FIG. II.

especially careful not to cut the eyelid; cut close to the bone, and by keeping a finger in the eyehole from the outside the skinner can feel his way.

The eyes passed over, the lips and nose come next. Cut the lips well out, keeping close to the bone; here again fingers on the outside are useful

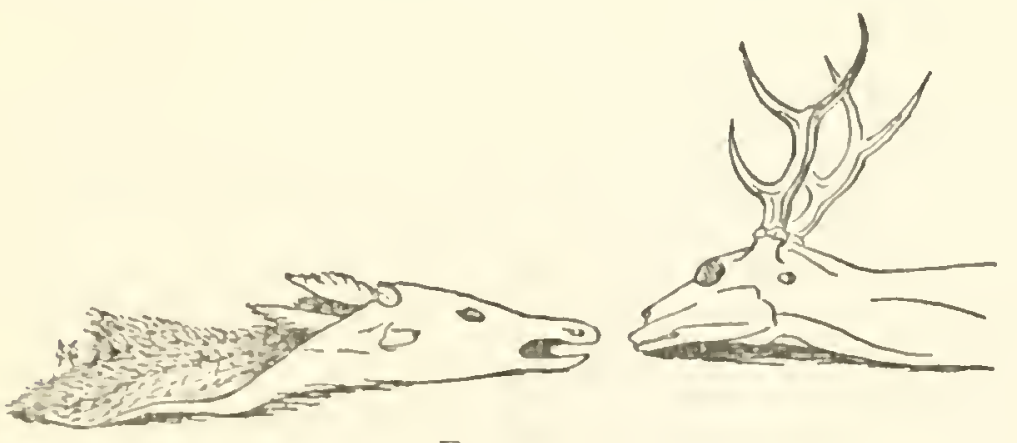

FIG. I2.

as feelers. Cut off the nose also well near the bone so as to run no risk of cutting the skin. The lips and nose skinned off, the head skin should now be free from the head and inside out (Fig. 12). 
The ears, lips, and nose still require a little more attention. Catch hold of the exposed cartilage of the ear and with both the thumb and knife work the skin back till the skin is free from the flesh, cut off all the flesh, leaving the cartilage. Split the lips and remove the superfluous flesh, but not the lip itself and be careful not to cut the outside skin. Free the cartilage of the nose from the skin; cut away the greater part of it.

The eyelid in large animals will also need splitting

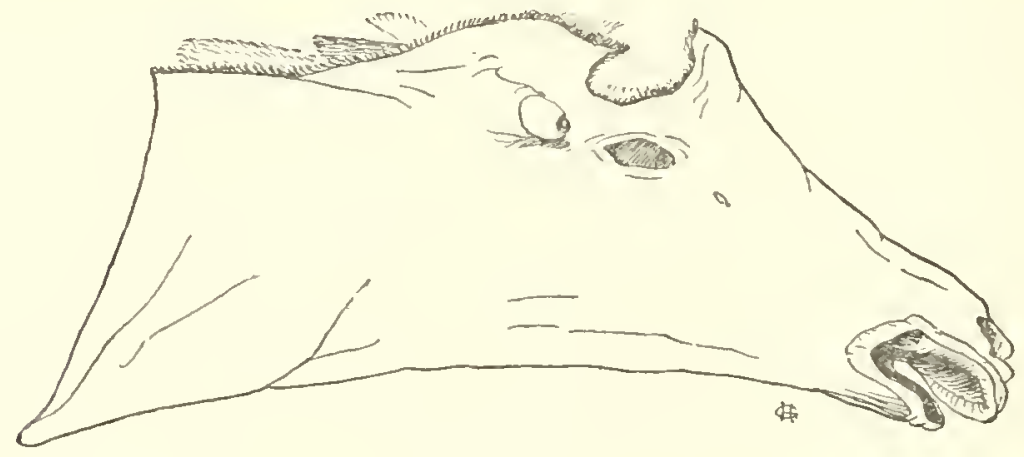

FIG. 13.

and the thick flesh removed. Finally, scrape or cut away all flesh and fat adhering to the rest of the skin. Now rub in thoroughly the preservative, especially in the eyes, ears, lips, and nose.

Lay the skin out flat but do not peg it; pull the ears back into their natural place, take a wisp of rough grass or other material and push it loosely up into the head so that the air can circulate freely, and lay it out to dry (Fig. I3).

Examine it every now and then and see that any 


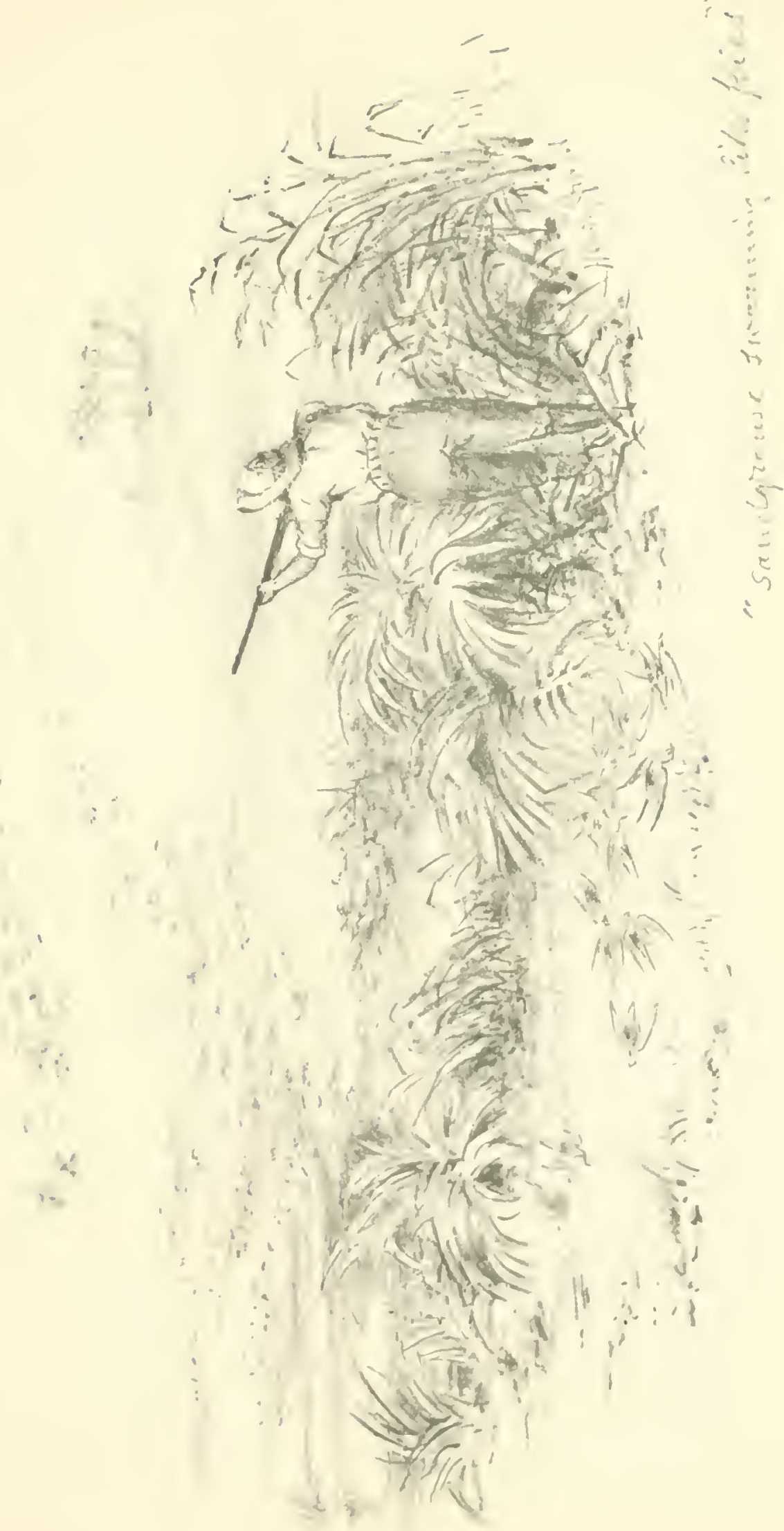



part of the skin does not curl or crease sufficiently for two surfaces to come in actual contact, otherwise it will not dry quickly and decomposition may set in.

So much for the head skin; to return to the skull, cut this off at the base and rough off all the flesh, scrape or wash out the brain, and put it in the sun to dry up quickly.

Do not damage the base of the skull, as, should the head skin be accidentally destroyed, the horns and sliull can still be utilized.

The author saw a pathetic instance of waste caused by neglect of these principles when he visited Mr. Harwood's Natural History Studios at Hammersmith. Skulls hopelessly broken, horns damaged almost beyond repair, were lying around awaiting the skill of Mr. Harwood to make the best of a bad job.

METAL LABELS.-With quantities of trophies the heads and head skins are liable to become mixed, so a good plan is to have a series of metal tabs in pairs, numbered in running order, and attach one to the head and the other to the skin to facilitate sorting afterwards.

The Whole Anmal.-In preserving the whole skin of an animal proceed as follows, for all ordinary animals without horns :-

Lay the animal on its back and make a cut down the centre from the chin to the tip of the tail, and 
four others from this down each leg on the underside (Fig. I4).

Remove the whole skin, clean the head as above,

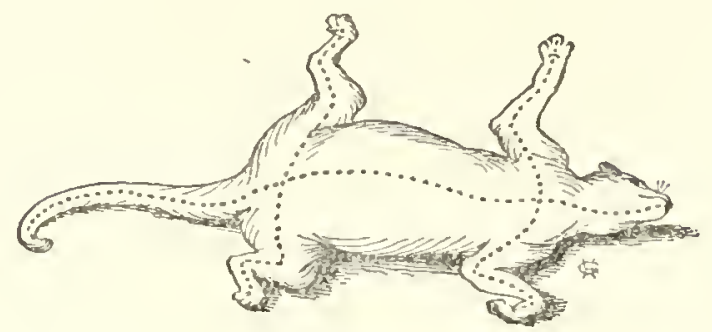

FIG. I4.

skin out the pads or hoofs, and stretch out to dry, rubbing in preservative on the head and feet; but little will be required on the body, as when once stretched out it dries rapidly, unless the weather be wet.

For horned animals cut as above, but start the body

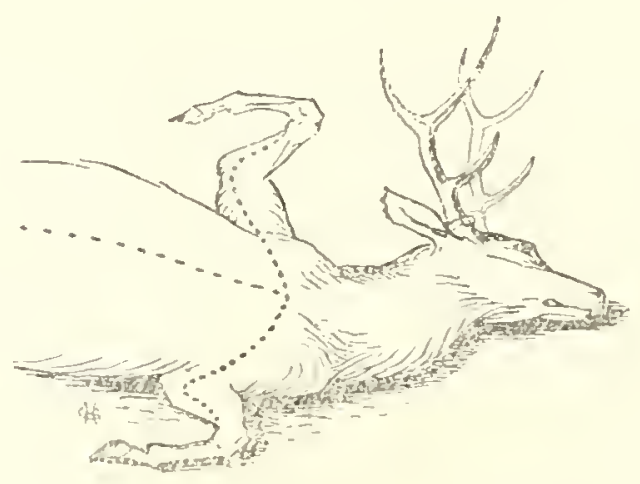

FII. I 5 .

cut at the collar-bone (Fig. I5), removing the head by the top cut and horn cuts, as shown in Figs. 9 and $\mathrm{I}$. 
HORNS AND SKULL ONLY.-When the horns and skull only are wanted, rough off the meat and detach and throw away the lower jaw.

SNAKES, ETC.-Snakes, crocodiles, and the large lizards must be skinned out flat, and can be pegged out or not as desired. With the crocodile and lizards the head cannot be skinned over, as the skin is practically part of the bone, so merely endeavour as much as possible to remove all the flesh that can be seen and felt, and the eyes, brain, etc, and rub in plenty of preservative.

PACKING.-On the arrival at the coast or the point at which the expedition ends and all the trophies have to be packed for shipment, carefully overhaul the slins to see that no beetles are destroying them, and if any are found use turpentine liberally.

Keep the skins separate from the skull and horns, packing them if possible in tin-lined cases, and throw in plenty of naplithaline.

The skulls and horns can be packed in an ordinary box or crate, and should insects attack them on the way home little or no damage can result; but never mix up the heads and skins, as the meat on the former is sure to attract bectles, and on the arrival home it may be found that the whole of the head skins have been damaged beyond repair.

This covers all that the hunter need know in the way of taxidermy for the preservation of his trophies in the ficld. 
If every possible care is taken from the time of shooting to the day they are delivered to the professional man for the final mounting, the hunter will ever after have the untold pleasure and delight of seeing the beasts that have cost him many a hard day's work, and no little endurance and straight shooting, looking at him from his walls, as in the days, never to return, they gazed at him from their native bush.

The Scientific Side.-There are two sides to everything, and having disposed of the hunter's side of taxidermy, we come to that other side which has its fascinations, and which the hunter might find time and pleasure in taking up.

That is the making of collections for scientific purposes, to bring back the material, with full details and data, that, submitted to the scientist, help to solve the many problems of nature that are at present shrouded in obscurity.

The field is illimitable; there are the plants, the insect life, the reptiles and fishes, and the beasts and birds.

The two last are, perhaps, the groups that will attract the hunter and explorer most, and so it is to these we propose to confine ourselves, especially as they come strictly within the title of this chapter.

If it is desired to take up the other groups, the reader inust be referred to the many works that treat of this kind of collecting, or to the authorities interested in those branches of natural science. 
It will be enough to mention that plants require to be either pressed or kept in a dry or living state; insects either have to be pinned or papered, or put away in carbolic or other preservative, according to the family, and the reptiles and fishes in spirit.

The animals and birds have to be skinned, and the sportsman who wishes to devote part at least of his trip to this work, or who only proposes to bring home a few pretty and striking specimens for casing, must first learn how to skin and make up into neat objects the various birds and beasts he hopes to secure. This requires a small outlay of patience until he becomes somewhat practised, and he must not be disheartened if his first attempts are not successful.

At the same time he must learn to identify the sex, which is a very important matter and requires very great accuracy to be of any use, but it is not really a difficult matter, and also how to label the specimens properly, and in the case of mammals to take a few necessary simple measurements.

His labels should bear on one side the date when killed, sex, locality, his name or initials, and on the reverse side the soft parts, i.e., eyes, bill, and legs and toes in the case of birds; and the measurement in millimetres of the head and body, tail, hind foot, and ear of mammals; however large the beast, these should always be recorded in millimetres when possible. 
The labels will then look as follows :-
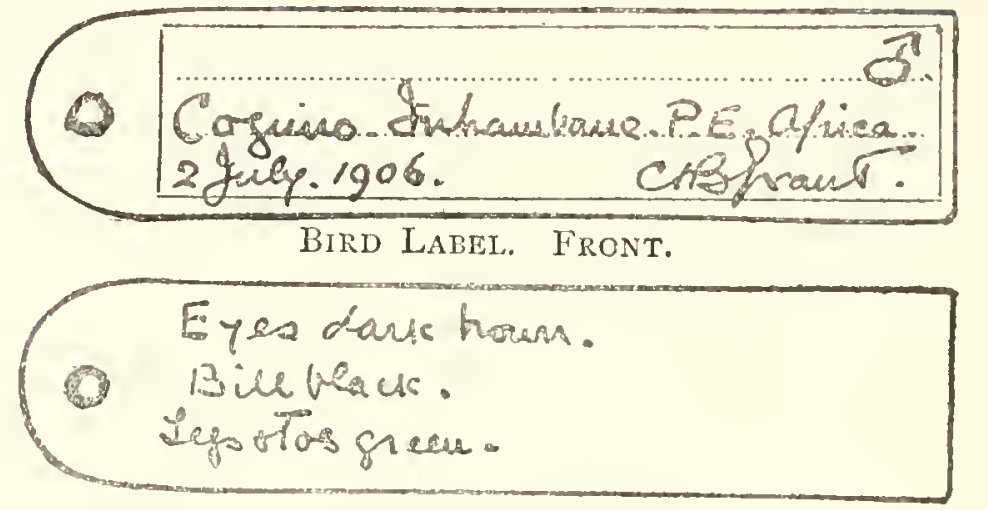

Bird Label. Back.

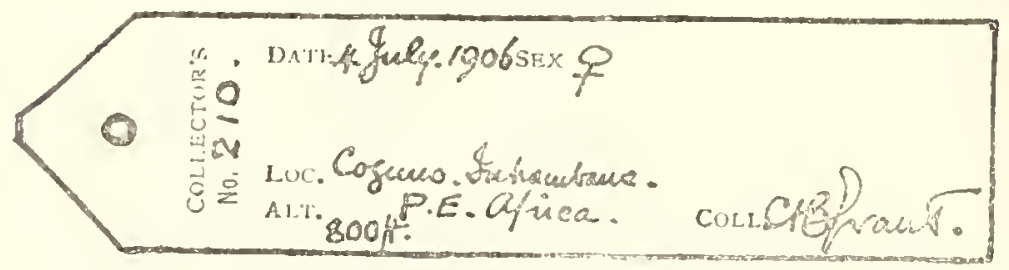

Mammal Label. Front.

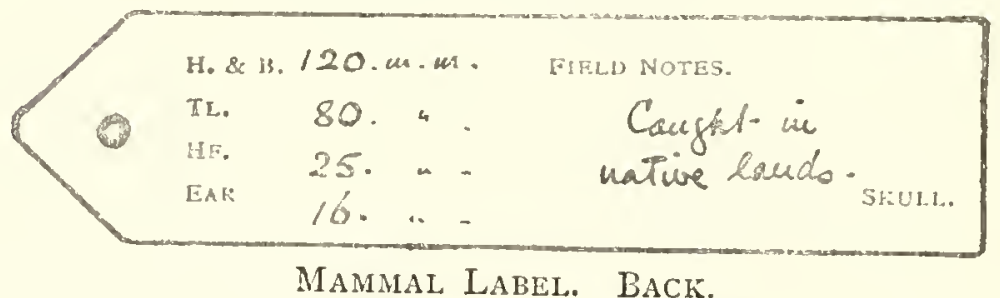

Mamalal Label. BaCK.

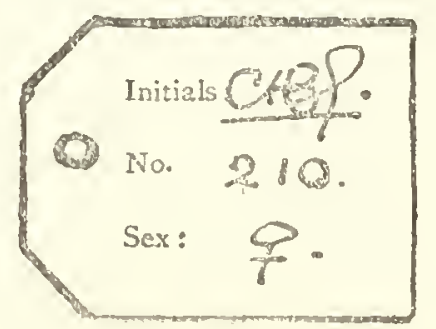

SkUll LaBel.

In the case of mammals the skull must be kept and dried, and can either be attached to the specimen, or better still, labelled separately with a number corresponding with the slin to which it belongs. 
The skull label must therefore give details of initials of collector, number, and sex.

The usual signs for the two sexes are: Male, $\delta$; female, or.

All this is but a simple system, and when once acquired is as casy to do rightly as wrongly and much more satisfactory in every way.

Tools.-Only a few simple tools are required to do all the collecting, and it is by no means necessary to go to great expense and purchase the complete outfits that are often advertised. All that is required is a knife, pair of scissors, forceps, some sticks, cotton-wool, labels, and paper for the birds; a pair of dividers, millimetre rule, steel tape, some wire for the tails, and a needle and cotton and pins extra to the above for mammals.

Preservative.-A good all-round, useful preservative is a mixture of burnt alum and arsenic powder in a proportion of about $\frac{1}{4} \mathrm{lb}$. of arsenic to $\mathrm{I} \mathrm{lb}$. of alum. These few things take up very little extra room, and of course the quantity of preservative and cotton-wool will be arranged according to the length of the trip and how many specimens are expected to be preserved.

PACKING AND TRANSPORTING.-It must also be borne in mind that provision must be made for the packing and transporting of the specimens, and it will be found that the chop-boxes when empty will come in very handy for this purpose. 
To make these boxes really serviceable they should be lined with thin tin or zinc (which will not greatly add to the weight), having a turned-over flange at the top. A sufficient number of ready-cut flat tops must be taken along, and when these are soldered down on the flange a perfectly water-tight and insect-proof case will be the result, at but a trifling extra cost and with a minimum of trouble.

SKINNING A BIRD.-When out shooting birds for specimens, some paper and a little cotton-wool should be carried. When shot the mouth should be plugged with the cotton-wool to prevent any leakage and the specimen then wrapped tightly in paper and placed in the breast-pocket, or better still in a haversack that should be carried for the purpose.

Birds shot in a moderately cold climate can be left till next day, but anywhere in the tropics must be skinned the same day as killed, as often specimens shot in the early morning will be found quite decomposed by the evening.

The man who has become practised will find many opportunities for preserving his catch; an hour snatched during the midday rest, the halt for breakfast if the trek has started early, will give the quick skinner a chance.

Now to the skinning. Lay out a piece of paper with your bird on it and your tools and preservative handy. Remove the plug of wool from the mouth and replace it by another fresh one; also, if necessary, stop up the nostrils. Part the feathers down the belly and with the 
knife make an incision from the lower end of the breastbone to the root of the tail (Fig. 16), being careful not to penetrate the abdomen.

Pick up the edge of the skin, either with the fingers

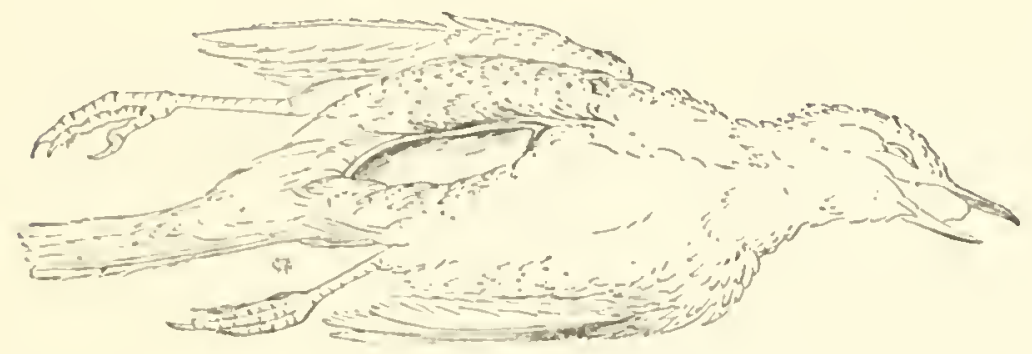

FIG. I6.

or with the forceps, and separate it from the body down towards the back until the leg is exposed; snip this off at the knee-joint (between femur and tibia) (Fig. 17), and completely separate it from the body.

Repeat this on the other side. Now cut carefully round the root of the tail and cut this off from the body

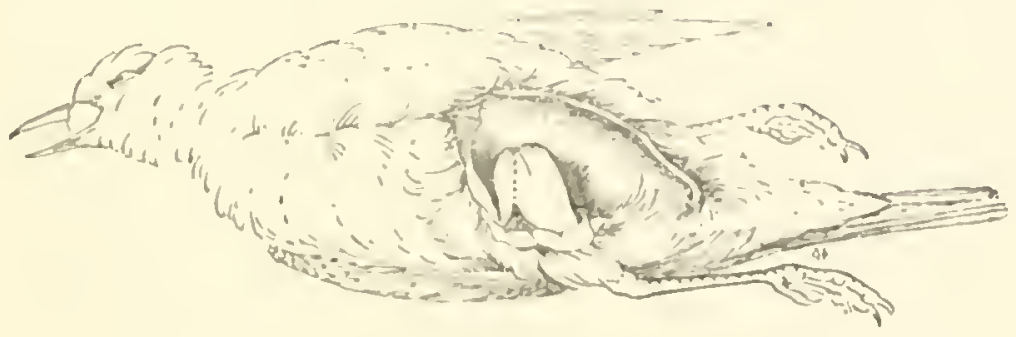

Fig. I7.

being careful not to cut through the roots of the tail feathers, which, in consequence, will drop out; but cut only through the bone (caudal vertebra) which lies between (Fig. IS). 
Stand the bird on its head and remove the skin all round off the body till the wings are reached.

Cut these out at the body (end of humerus) (Fig. 19). Now down the neck and carefully force the skin over

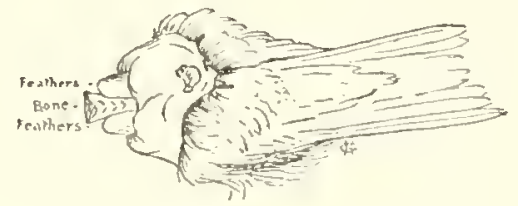

FIG. IS.

the base of the skull. The ears will now be seen-cut these out close into the skull. A little farther on come the eyes; these must be passed over circumspectly, great care being exercised not to cut the eyelid. Once over the eyes the base of the bill is reached and the slinning stops.

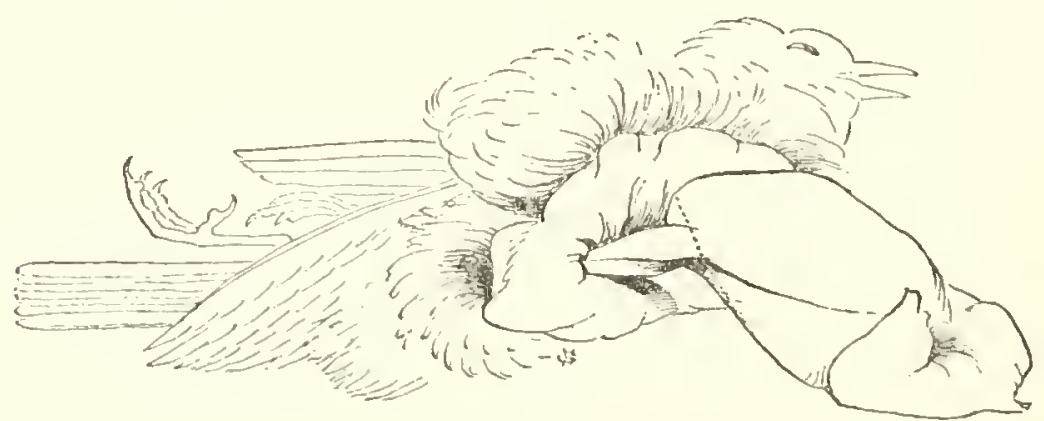

FIG. I9.

The body will now be entirely nude on your right hand and the skin completely inside out on your left, both being merely attached to each other at the base of the bill (Fig. 20). 
With the knife cut off the neck and a slice of the skull at its base (Fig. 20); remove the brain, eyes, tongue, (with the tongue out will come the plug of wool you had previously placed in the mouth), cut away the superfluous meat on the palate and around the base of the jaws and skull.

Rub plenty of preservative on the skull and head and neck skin, place with the forceps a wad of wool in each eye-but not either in the mouth or brain cavity-and by keeping the head towards you and

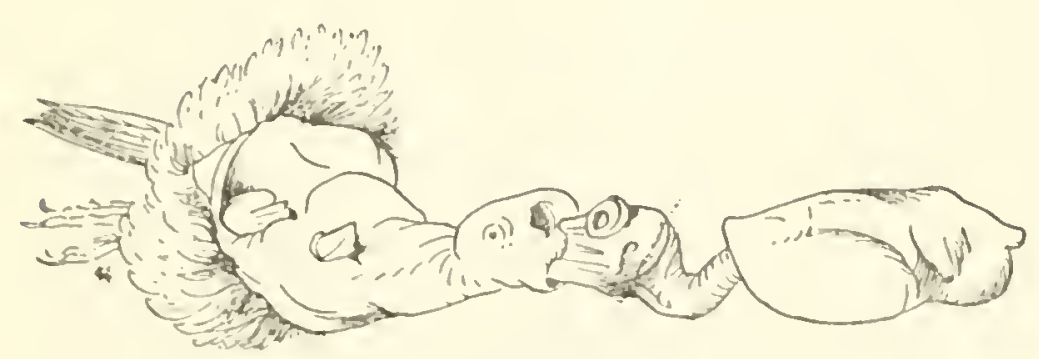

F1G. 20 .

placing the thumbs on the base of the skull, and the fingers on the head skin, procced to turn the skin the right side out again. This is not a difficult matter, but requires working all round at the same time.

Skin out each wing from the inside till all the flesh is exposed, which remove; but do not cut away the flight feathers from the bonc.

If, as in the case of large birds, the whole of the flesh cannot be exposed from the inside without separating the flight feathers from the bone, remove as much as possible and cut the wing on the outside to remove 
the rest, making an incision on the underside along the ulna and radius, where the feathers are thin (Fig. 2I).

Skin out each leg and remove the flesh and any that adheres round the root of the tail.

Scrape off any flesh or fat that is on the body skin.

Thoroughly rub in the preservative; wind some cotton-wool on the leg bones to replace the flesh, but not on the wing bone, except in the case of large

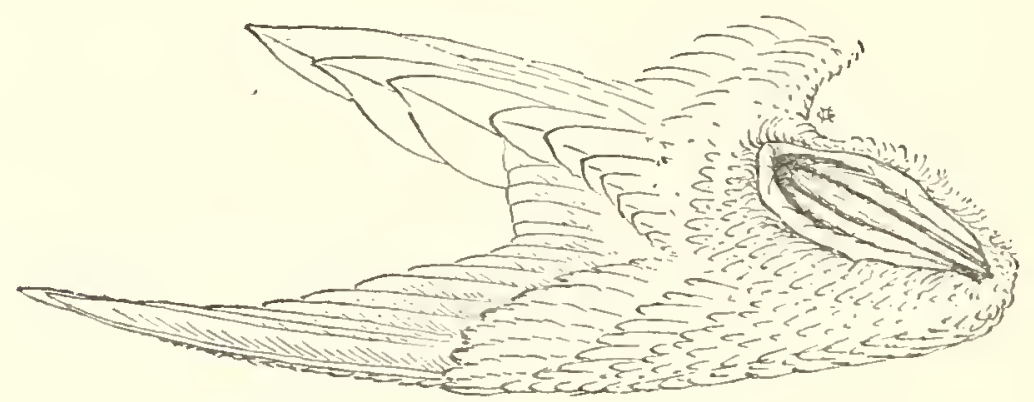

FIG. 2 I.

birds, and pull back both the legs and wings into their proper places and smooth down the feathers.

Pick up the bird by the bill and give it a shake, and with the aid of the forceps smooth and place the feathers on the head, open the eyelids to a nice round shape and pull the cotton-wool into them; lay the skin on its back with the head towards your left. It ought now to be ready to be made up.

MAKING UP THE SKIN.-Take a straight piece of stick of about the length of head, neck, and body, 
wind on some cotton-wool at one end to make the neck, and passing this up the neck force it tightly into the brain cavity.

Now shorten up the neck, still keeping the skin on the table on its back, and talie a long wad of wool between the forceps; this place carefully and neatly in the throat and along the neck on the top of the stick, seeing that the neck is still kept short.

Take a piece of wadding equal in size to about half the body, and with the forceps place it in the
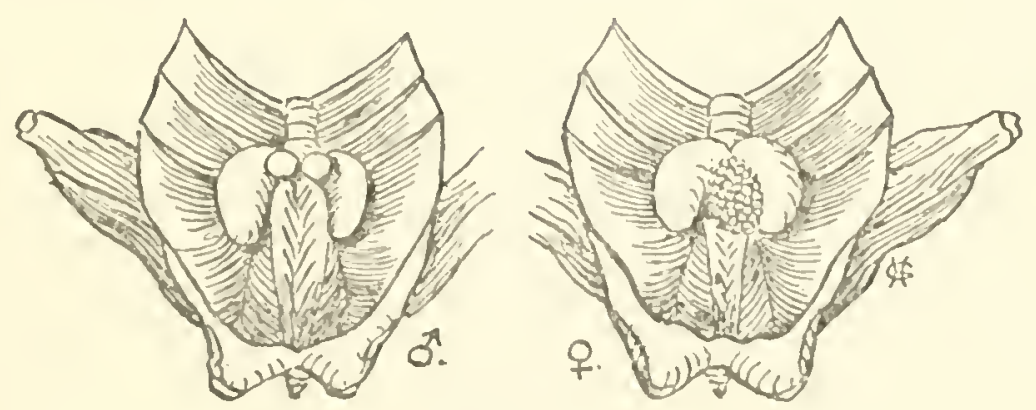

FIG. 22.

body skin on one side of the stick and up to where the shoulders end.

Repeat this on the other side and the skin is now stuffed.

SExiNG.-Cut open the body (which be careful not to throw away) along the left ribs with the scissors and lift up the viscera till the back is exposed, when the kidneys will be plainly seen lying each in its hollow on each side of the backbone, and at the top end of these will be found the sexual organs (Fig. 22) -in the male two long or oblong bodies which are 
the testes, and in the female a bunch of small or large granular objects, which are the ovaries.

Having determined the sex, write out the label as

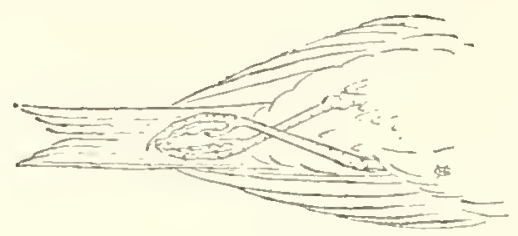

FIG. 23 .

shown above, cross the bird's legs one over the other (Fig. 23), and tie them together with the label.

Press and pull the belly feathers together till the opening is closed, and turn the skin over on its breast.

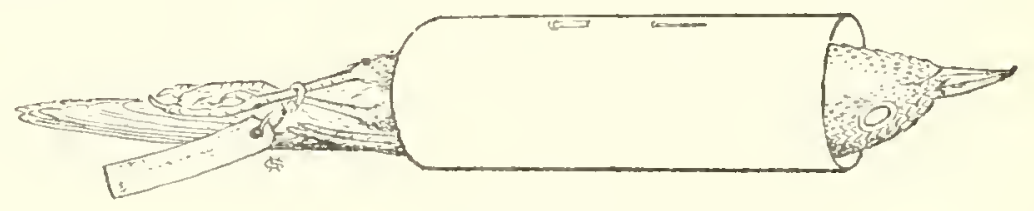

FIG. 24.

Take the forceps, and catching the wing close in against the body, push and lift it up under the scapulars and at the same time place the flight feathers back on the tail and pull over the breast feathers.

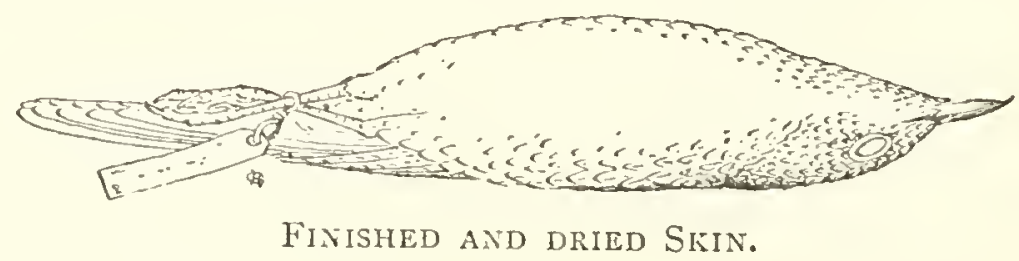

Repeat this on the other side, and the skin is finished.

All that is required now is to tie or pin the mandibles 
of the bill together, if they require it, and place the bird in a long paper cylinder (Fig. 24) for it to dry in good shape, and for travelling.

In the case of some large birds and others such

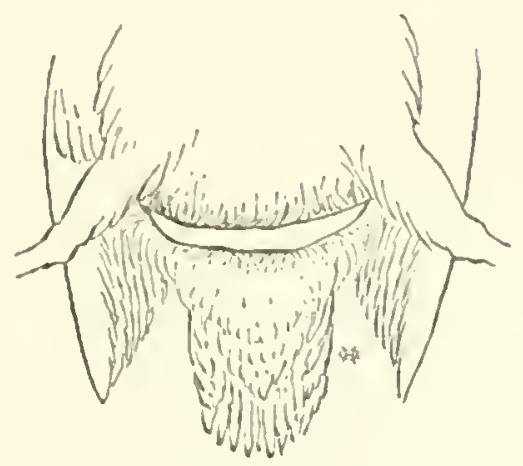

FIG. 25 .

as ducks, grebe, etc., that have short feathers, the first incision should be made between the legss, i.e., from thigh to thigh across the root of the tail (Fig. 25) and not down the belly, then proceed as above. When making up, more stuffing will be required-that is to

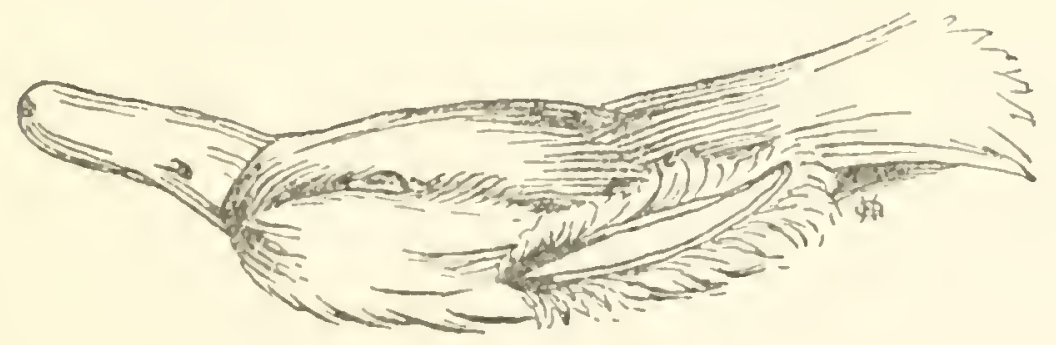

FIG. 26.

say, extra pieces placed over and under the stick as well as on each side. Also, in the case of a few species, such as duck, woodpechers, and parrots, the skin will not pass over the head, so that the neck must be cut 
off close up and the head skinned out later by making an incision down the poll (Fig. 26), and after finishing sewing it up.

SKINNING A MAMMAL.-Skinning a mammal for

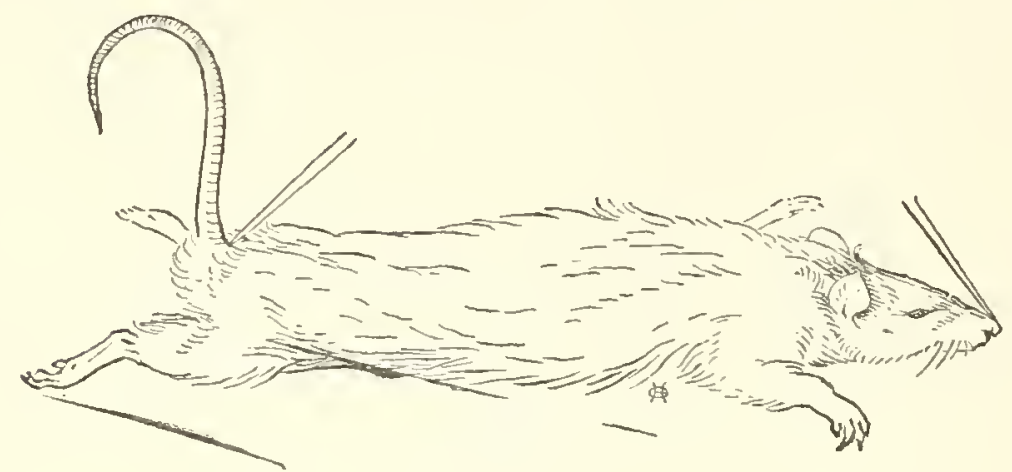

FIG. 27.

scientific use is very much the same process, but there are certain essentials that are different and need explaining.

A mammal, large or small, needs to have four

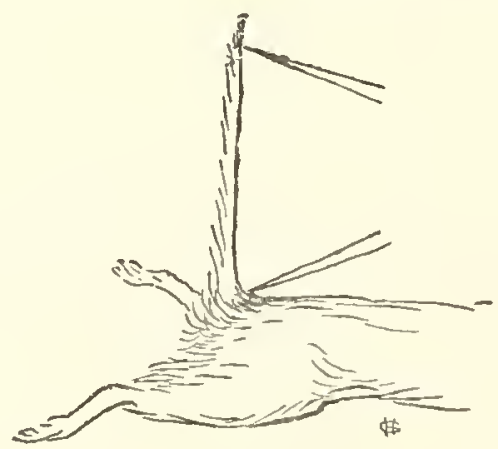

FIG. 28.

measurements taken from it before it is skinned-i.e., the head and body. To do this, lay the beast on its belly and press it down flat, hold the tail up at a right angle, and with the compasses measure between 


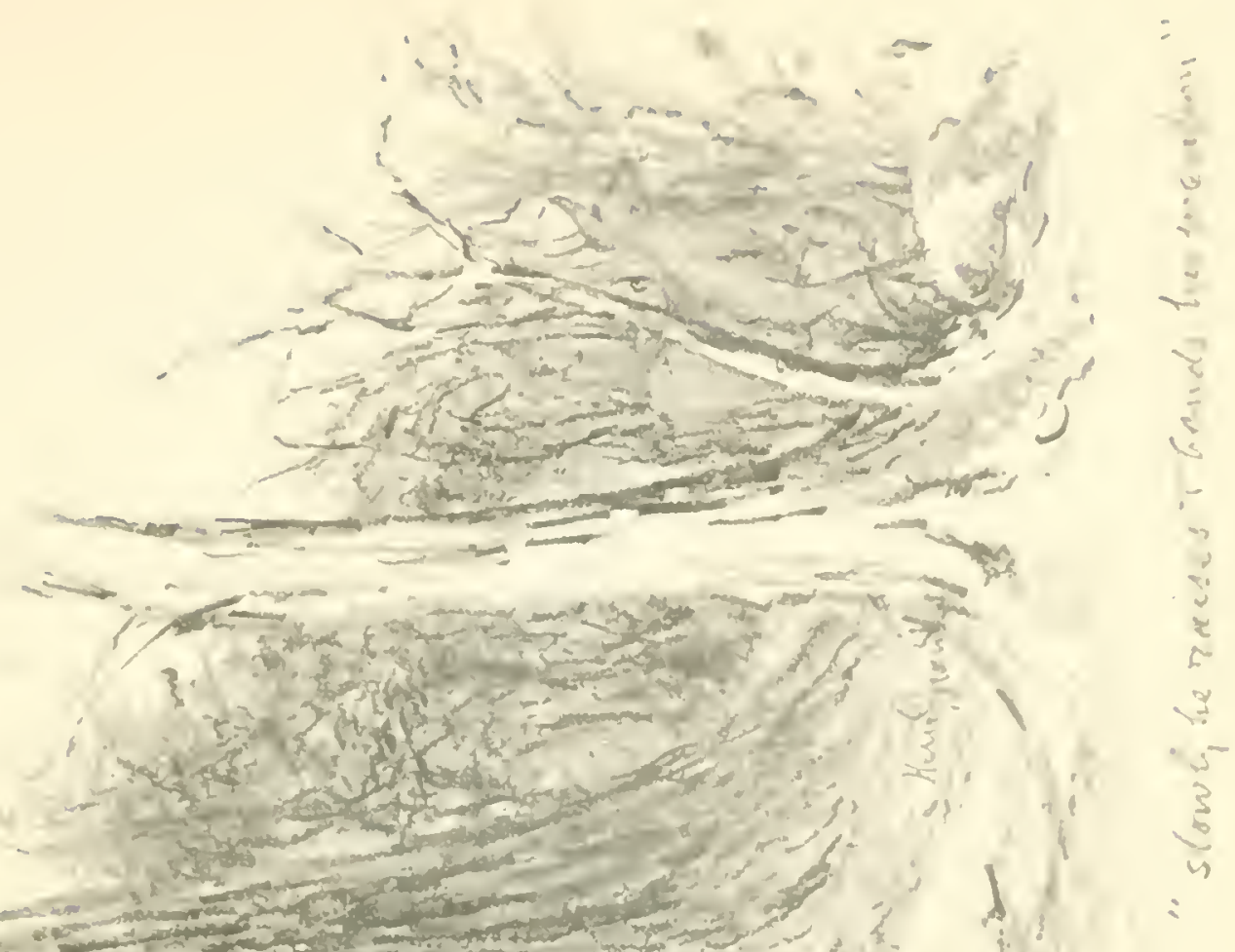

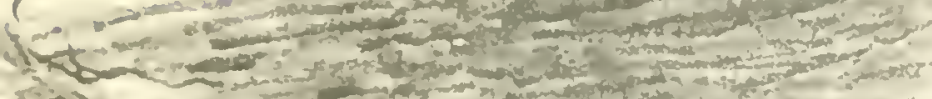

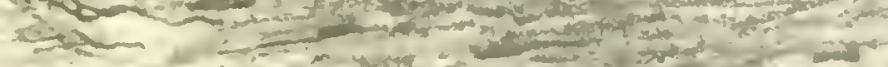

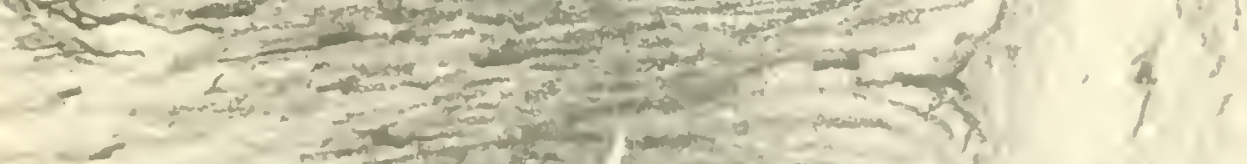

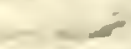

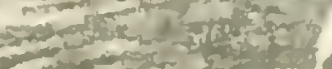

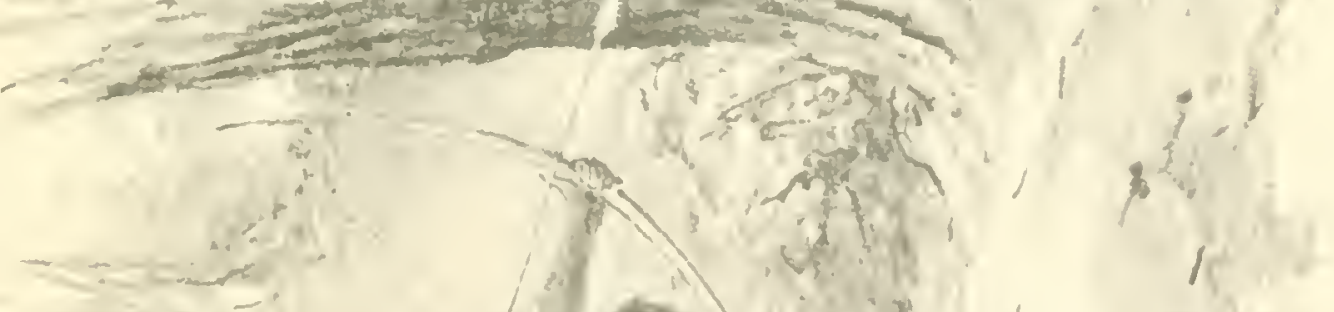

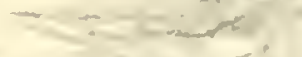

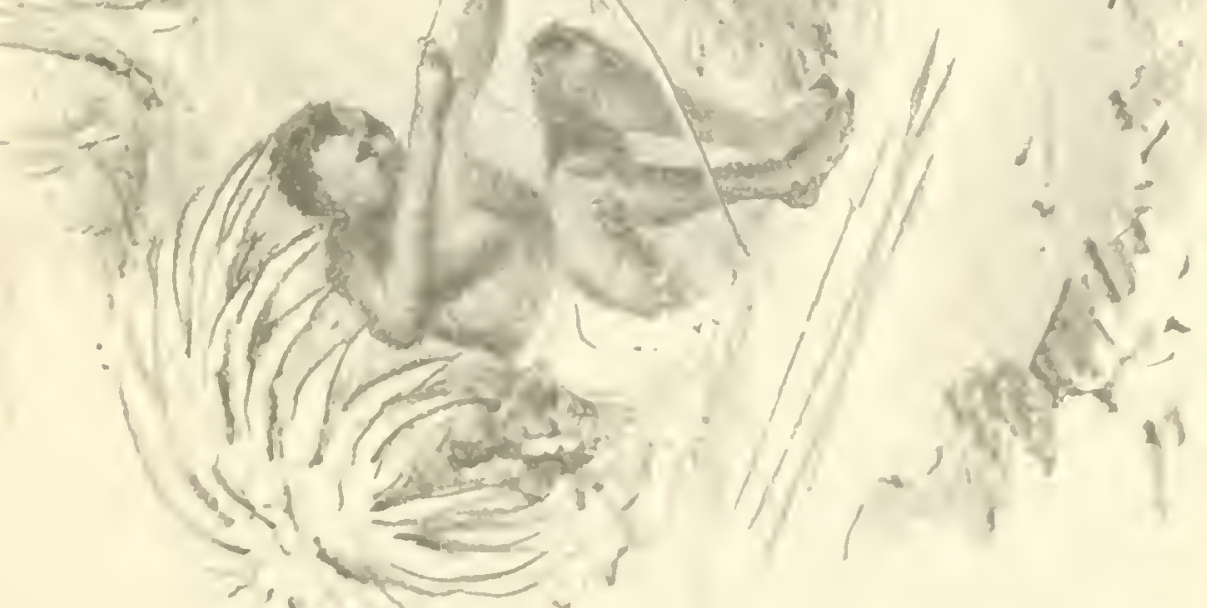


. 
the angle of the tail and body and the tip of the nose (Fig. 27).

The tail is taken from the same angle to the tip

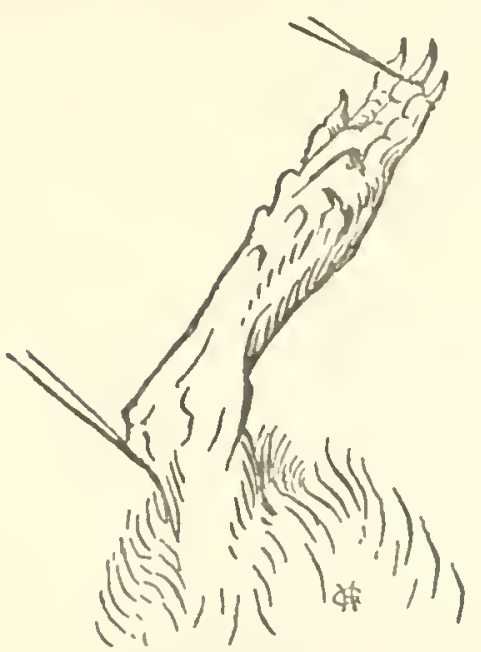

FIG. 29.

of it, but not including the hairs (if any) at the point (Fig. 2S).

The hind-foot is taken from the heel to end of the

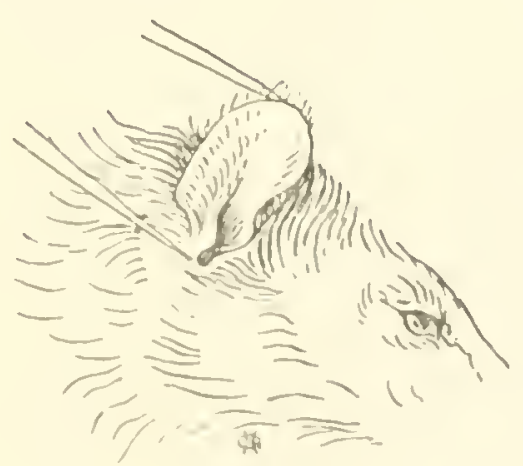

FIG. 30 .

longest toe, but not including the claw (Fig. 29), and the ear from the apex to the tip, also exclusive of the hairs (Fig. 30). 
In the case of game animals the height at the shoulder is of interest, as also is the weight, if it can be obtained. Of course, with large animals all these measurements have to be taken with the tape.

To skin, make an incision, and remove the pelt as in birds, cutting off the legs at the knee and elbowjoints, pulling out the tail, and skinning the head right out.

With small beasts, as mice, rats, etc., a neater way is to cut them between the thighs as mentioned for ducks and grebes. Clean off the leg bones and wrap

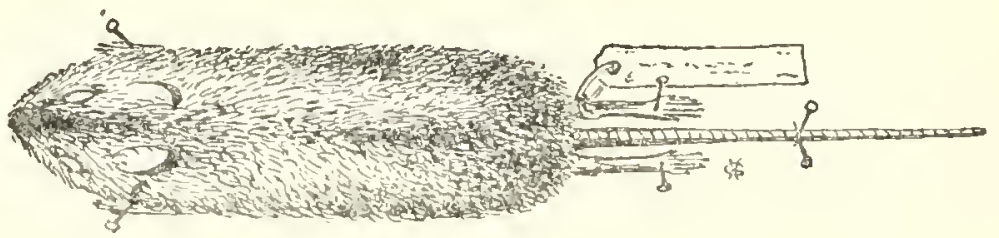

FIG. 3 I.

them round with cotton-wool. Take the forceps (in the case of mice, etc.), and roll round some wadding the same size and length as the extracted body, place the tip to the tip of the nose of the skin as it lies inside out, and reverse the skin over this false body as a glove over the hand.

Cut a piece of straight wire longer than the tail and roll tightly some wadding on it to the size of the tail and push it up to the tip. Insert the exposed end of the wire into the body wool, press the skin into shape, and neatly sew up the opening.

Tie the label on the right hind-leg, place the skin 
on its belly, and pin it down in a box or on a piece of wood to dry, by one pin through the nose, one through each foot (drawing the forefeet forward and the hind feet back, and turning the pads downwards), and two crossways over the tail (Fig. $3 \mathrm{I}$ ).

Vrite out and tie a label on the skull, having carefully removed without breaking from the trunk, and leave it to dry.

In medium and large beasts a certain amount of meat can be roughed off, but do not boil them, and be careful of breaking small bones.

Large beasts should be shinned and dried as if for rugs, but avoid overstretching them.

If time can be found the sportsman should get some lessons from a practical man on all these matters, as seeing birds and animals skinned and made up will convey more rapidly to the beginner the exact idea than hosts of books on the subject. 


\section{CHAPTER VII}

\section{PHOTOGRAPHY}

No more interesting way of recording one's travels, the incident and accident of the trip, and the country passed through, can be found than by photography.

For besides being the most charming of hobbies, it gives far better records than any words can describe of the many episodes, and is often of far more interest to the many friends that have not the good fortune to find time or opportunity for a shooting trip themselves, appealing to them perhaps more than one's trophies, as they are at least of public interest, where often the trophies are wrapped round with a story known only to the shooter and have a romance for him alone.

So every sportsman should endeavour to take with him a camera of some sort, as records obtained by this means of the country, game (dead or alive), of the daily life in camp, natives and their villages, etc., are quite as interesting and will be looked back upon in after-years with as much pride as the trophies themselves. 
And after all one owes it to one's stay-at-home friends to bring them back something that will at the same time interest them and enlarge their knowledge of the world abroad.

In considering this sort of outfit, sizes and weights are of importance, especially for the sportsman who is on a shooting trip of only a few months all told, and is not going in for telescopic photography or cinematography.

In the choice of cameras individual taste and pocket are great factors, but preference should be given to those which are simple and compact in design and easily carried.

Medium Cameras.-If a wide range of subjects is expected to be obtained besides the ordinary snap-shot, such as monuments, native idols, carvings, etc., a camera of, say, a $5 \times 4$ size, that can be adapted both for films and plates, would serve the purpose, a large quantity of films being taken for all ordinary subjects and just a few plates that could be used for special subjects where careful focusing with the ground glass is required.

It is, however, often found that even a camera of a $5 \times 4$ size is too large and bulky, and more often than not is left in the camp, so that very many excellent photos are not taken just where the opportunity occurs.

Another great disadvantage of an ordinary camera is that many studies of natives, etc., are spoilt by 
their observing what the operator is doing and instantly posing in conscious actions and attitudes.

Though there are disadvantages, as pointed out, to the medium-sized cameras, one should certainly be carried, as the size of the finished prints, especially the $5 \times 4$, is extremely useful for all purposes.

SMALl CAMERAS. - The traveller would be well advised to carry also a small "vest-pocket" camera, having a fixed indefinite focus, which he could personally carry in any pocket without in any way inconveniencing himself. With this small camera just as good photos can be taken as with the larger sorts, and the difficulties and inconveniences of carrying are nil, and the weight of the films, etc., is reduced to a minimum.

It need hardly be said that if a certain weight has been fixed for the photographic outfit considerably more films can be carried for the small camera than for the big, in which case very many more photos can be taken, allowing some experimenting with light, artistic effects, etc.

It must not be overlooked that perhaps the most important point in favour of the small camera is that the photographer is able to take numbers of "snaps" of natives, village scenes, etc., unobserved by the subjects, and with a fixed focus there is no worrying about the distance.

Enlargements from Small Negatives.-There are many who dislike the small camera because of 
the small picture that results, and of course there was a lot to be said against this, but now at least one large well-known firm print enlargements by the dozen at quite a nominal charge. In working out the actual cost of production per dozen of these enlargements from a small camera, it was found in one instance at least that it was less than what the dozen could have been produced for from a camera giving a contact print equal in size to the enlargements, and no consideration was given to the difference in the initial cost of the cameras themselves, which is quite an item.

ApPARATUS AND CHEMICALS.-These small cameras are not usually adapted for plates, but for all-round general use they are not easily superseded, and the intending traveller would be well advised to give them his careful consideration. Having obtained the camera, the next matters for consideration are the films and plates, the necessary apparatus and chemicals.

Filus.-Where weights are the most important factors, practically all negatives should be taken in the film form: either pack or roll, according either to the make of camera or the traveller's individual tastes. It will, however, be generally found that the roll form of film is the most useful, as not only is there somewhat less chance of them sticking, but they are more easily developed in the strip, especially where a daylight tank is used. There is also far less chance of the films being spoilt by fingermarks or scratches, due to either inadvertent or careless handling. 
It must, however, be borne in mind that if the sportsman is visiting a country with a very humid climate, or is there during a wet season, films soon go off, and become spotted by damp, lose their sensitiveness, or stick to the paper in which they are rolled. This can be obviated to a very great extent by having each lot packed in tight tins sealed with adhesive tape, and in each of which a piece of chloride of calcium (calcium asbestos) has been placed to absorb any damp.

If films are taken to a damp climate, rolls of not more than six should be carried, as the whole roll can be usually used at one time, and should be immediately developed-if possible, the same day as opened.

However, the sportsman on a shooting trip of a few months seldom has to consider this point, as he usually visits the country during the best season, i.e., the dry season, when films can be carried with safety, though even then it is advisable to have them packed in tins to counteract any damp that may exist, and as the extra cost is very slight the precaution is well worth taking.

PLATES.-Plates, although far less sensitive to damp, are also liable to become affected, and even in the driest of climates it is as well to have the tins in which they are packed sealed by tape.

It is not proposed to discuss the numerous makes of plates or the various types for special purposes, as these are matters which apply strictly to the kind 
of subjects that they are required for, and it is seldom that the sportsman need carry other than ordinary "speedy" or "extra speedy," which will serve nearly all his purposes, though he might carry a few backed plates if he foresees any chance of securing photos of native carvings or drawings.

Developing.-The developing of the negatives is always the most serious point for the sportsmanphotographer, as not only has he seldom or never a dark room at his disposal, but it is a matter that involves time and care, and it also often happens that he cannot obtain water sufficiently cool for the purpose.

If the operator has had sufficient practice to know what the results of the photographs will be like, and they are taken in dry weather and in a dry climate, they can with almost certain safety be repacked in their tins and sealed and not developed till the return to civilization and even to England.

But if he is not practised he will have to do some developing, at least in the beginning, to be sure that he is taking exactly what he wants and that the exposure is correct. For this purpose he cannot do better than invest in a daylight developing machine and follow carefully the directions given with the machine and use the special developers supplied for each make.

For the developing he will require a developer, fixer, and in any warm climate alum for hardening the gelatine on the plates (if these are used). 
All the chemicals should be carried and packed either in glass or tins, never in paper or cardboard, as they are affected by the atmosphere and are liable to deteriorate. Developers can be obtained either in powder or tabloid form, and should always be in glass; fixing salts can be taken in tins, as also can the alum.

WATER.-If, as often happens, the water near which one is camped is too warm, the temperature can generally be brought down either by water-bags or by standing a bucket or two in the shade. It should be drawn from the river or water-hole in the very early morning, when the water is at its coolest, and if not used at once or is not cool enough, can be kept as stated till the evening, when it will often be found to be within the necessary temperature.

If the temperature of the water will not go below $70^{\circ} \mathrm{F}$. it is useless attempting to do any developing, as the films or plates will only peel. They must be held over till cooler water is come to, which can often be found in a more shady river or water-hole or at a rather higher elevation.

It will be found that streams and rivers flowing from wooded hills or mountains are generally cool if the water is taken either in the hill or at the foot; but the same water will be usually found to be quite hot if it has flowed for any distance through the open where the sun has reached it.

The clearest and cleanest water should be used for 
this work; though if, as often happens, this cannot be found, and if, after washing, the films and plates are found to have a deposit of grit or fine sand on them, it is better to first dry them as they are and to have them washed on the return.

DRYING.-It is not advisable to dry either films or plates in the sun-especially plates, as the glass becomes so warm that the whole film will simply slide off it.

WASHING.-Care should be taken that all negatives be most thoroughly washed to remove absolutely all the fixing salts, otherwise it will be found that chemical action has taken place and in many negatives the image totally destroyed.

PRINTING.-It is quite unnecessary to go into the question of printing, as the traveller will hardly have time to do any, and will be only increasing the weight and size of his outfit for no practical purpose. All the printing should be left till the return, when the photographer has time and convenience for making really good results from his negatives.

Other ApParatus.-As well as the camcra, negatives, and developing apparatus, a few other articles should be considered; for instance, a light folding tripod stand for taking time photos in dull weather or for use of plates with the ground glass. Then there are plate-holders, which need not be expensive ones, and the slides should be made of some material other than aluminium, as this metal is very liable 
to corrode, especially with any dampness, and if slides are made with it they will stick so badly that good work is impossible.

Then a small thermometer is very useful for testing the temperature of the water, etc. A lamp also may be taken, as this is useful for putting plates in the holders, even if not required for the other work. These can be obtained in many forms and at variant prices, ranging from a mere red-linen framework to wellmade metal lamps; a medium priced one and not too large will be found to be the most serviceable, and should be so constructed that candles can be used in it.

KeEping Films.-A very essential point that can hardly be sufficiently emphasized is that after the films have been thoroughly dried by being hung up in the strip as developed and have afterwards been cut apart, they should not be packed away without something to keep them from coming in actual contact with each other, as most films are gelatined on both sides and with the least bit of damp will stick together. To prevent this, film albums may be carried, but as these are rather bulky, a slip of clean paper between each and then the whole roll put into an envelope will do all that is required to properly preserve them.

NUMBERING.-If so packed, a pencil number can be inscribed on the edge of each, and on the face of the envelope all the data can be written, somewhat after the following plan:- 
Roll I.

$$
\begin{aligned}
& \text { No. r. Valley of Brahmaputra ... } 24 \text { May, } 1900 \\
& \text { " 2. Group of Natives ... ... } 26 \text { May, } 1900
\end{aligned}
$$

Or instead of specifying each roll and starting again at No. I, the numbers can be carried right through the whole series.

The TAking of Photos.-Finally a word or two may be said about the taking of photos, grouping, position for typical views, etc.; though really little can be written on this subject, as it is all a matter of practice. However, the intending photographer cannot be better advised than to study many of the books on travel and judge for himself what he considers to be good photographs and so follow these for grouping, position, etc. He also can obtain the numerous manuals that are given away with the cameras or can be purchased for a very small sum; which give concise and useful points with regard to light, focusing, etc., for each particular make of camera.

In fact, if he has in his mind's eye many of the pleasing photos that have been so often published, and will take a little trouble in carefully following the directions given with the camera he purchases, and can find a few minutes to be shown how to develop his negatives, which is after all only a simple matter requiring care, he ought to get quite good results even at the outset of his trip. 
Photography, especially field photography, has now been reduced to such a fine point of simplicity that it is not trouble that is involved but carefulness.

Scientific Photography.-This by no means covers all the work of field photography, as nothing has been said about photography for surveys or scientific purposes, as they hardly come within what the shooting man may hope to do with only a limited time at his disposal.

However, if he can see his way to getting any data for scientific purposes and visiting a country from which little has been recorded, he cannot be better advised than to call on the authorities interested in such work and learn from them exactly what they may require.

The man with an inquiring mind will not only have gathered that photography is not so formidable a subject as many amateurs imagine, but that the subjects it can cover are legion, and the pleasure to be extracted from so absorbing an hobby is unlimited, both at the time and in after-years.

There are many who even now find as much excitement in hunting big game with the camera as with the rifle, and though it is too much to expect the sportsman to abandon his gun altogether, many a fine duplicate can be bagged in this way and be hung on the wall as a trophy enclosed in a frame instead of on a shield. 


\section{CHAPTER VIII}

\section{TROPHIES AND COLLECTIONS}

AN expedition over, the strain and excitement passed, the sportsman again in his smokingroom with his memories and his trophies! The years go by, the remembrances of details wane, while the interest of the curios tends to grow. The sportsman, wearied by his day of family or financial cares, looks round at his walls and catches the eye of a buffalo. His tired brain revives. "Ah! ah!" he says; "you old wretch! What a splendid fight we had in IS9-! Heavens, what a day that was, and what a trip! I'll drop a note to $B$. and $C$. and ask them to come round to-night, and we'll yarn till all's blue."

A collection is worth the taking of unlimited trouble; make it accurate and above criticism. Perhaps the length of the horn falls short of record, but never mind-the story of that head is yours, and yours alone. See that it is correctly mounted. When a first head is shot a note should be taken of the colour of the nose and cyes, and when examining game through glasses, in its natural habitat, 
the position in which each species carries the ears should be recorded, as no two species carry the ears in exactly the same way. Study how the ears are carried when the game is either on the alert or at rest. Notes such as these are of great use to the man who mounts the trophies, and the result repays you.

The sportsman is seldom a trained taxidermist, and the setting up and mounting of his trophies should be given to some well-known and competent firm of taxidermists. The prices charged are various. The author personally has always been fortunate in having his trophies mounted by that well-known and practical naturalist, Mr. L. C. Harwood, of 35 St. Peter's Square, Hammersmith, London, W.

Mr. Harwood has been on numerous expeditions to various parts of Africa. The extensive practical knowledge he has gained on these trips reveals itself in the beautifully modelled and mounted specimens that can be seen in his studios.

An especial feature of his work is the lightness of his mounting. In his case no need exists of strong walls to support the head. All that is necessary is the common nail. In addition to the technical training of a lifetime, the field experience is a unique advantage to the taxidermist, and both are apparent in the work executed by Mr. Harwood.

The finishing of trophies for ornamental or decorative purposes must be left to individual taste, but a short list of the uses to which trophies may be put 


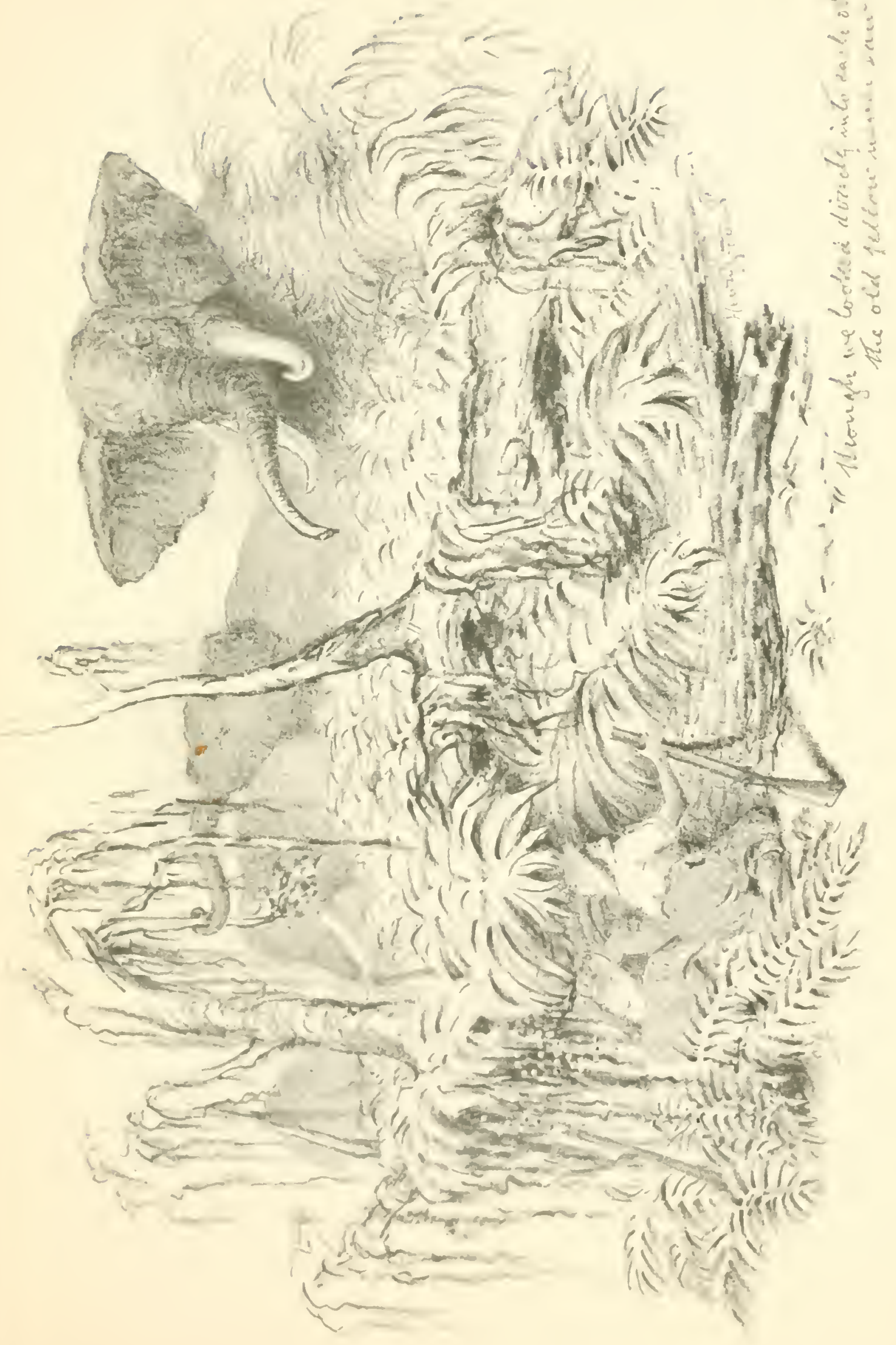




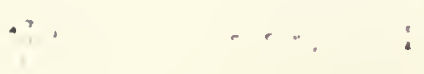

$$
\therefore, \ldots,
$$


may be of interest, as the traveller and sportsman may like to use up everything he brings back.

HEAD AND HORNS, ETC.-First and foremost stand horns and mounted heads; skins for rugs, mats, or walls. Under "skins" may be mentioned those of the hippo and rhino, which, when polished make beautiful table-tops, walking-sticks, etc.

HoOfS AND FEET. - Many of the hoofs of the larger animals and the feet of hippo, rhino, and elephant can be made into such useful and ornamental articles as inkpots, ash and match bowls, tobacco-jars, and many other things that will suggest themselves to the collector.

ORNAMENTAL TABLES.-Odd pairs of horns, such as waterbuck and impala, can be made to form the legs of tables; for instance, the horns of the waterbuck and a polished piece of hippo or rhino hide make a very pretty trophy.

HAT-STANDS AND MiRRORS.-The teeth of hippos, warthog, and other animals can be made to serve the uses of pegs on an ornamental hat-stand, and the tusks of elephants can be so arranged that they enclose a mirror, which makes a very handsome, though heavy, piece of furniture.

Native CuRIOs. - Native curios should be piched up wherever possible at first hand-that is to say, purchased or bartered direct from the natives as the traveller passes through the country, as when obtained in this way each curio has its own particular history 
to the collector, and so will be much more prized than any quantity, even if better specimens, that have been picked up at some store or bazaar in the towns or at the coast.

In collecting these it should be borne in mind for what they will be required. If groups of spears, battleaxes, arrows, or bows are wanted, then those things should be got if possible in pairs, so that a pattern can be made on a wall or arranged around shields or mounted heads.

PACKING.-When procured, these trophies should be tied in bundles and packed in canvas, with some shavings, if necessary, to protect the points from damage, and all that will be required to be done when they are hung is to oil the wood shafts to keep them from cracking and grease the metal blades, etc., so that they will not rust.

In some museums, notably those in Java, the blades of some of the weapons have been painted black, presumably to prevent rust, but this should never be done, as it entirely destroys the beauty of the specimen.

Native basket and bead work are also interesting articles to collect, and if the latter are obtained and have been much worn next the skin and so saturated with perspiration, care must be taken that insects do not get into them and by eating through the threads cause the beads to become loose and so destroy the whole. 
Beadwork and other articles of that nature can alsobe prettily displayed in a group or pattern on the wall or each set encased in flat glazing which can be hung up.

Though heads and horns have to follow the conventional method of mounting, there is no limit to the ways in which other trophies can be displayed, and much individual taste can be exercised in the making up and grouping, hence the foregoing does not by any means exhaust the uses to which a collection can be put for decorative and ornamental purposes, but it is hoped will give some data to go upon.

Scientific Collections.-Collecting for scientific purposes is by no means a difficult matter, requiring only care and above all accuracy; but, in fact, if the sportsman is not prepared to do the thing according to the modern ideas, he had far better not touch it at all.

This modern and accurate method has been fully treated under Chapter VI, and it is also fully explained in the "Hints to Travellers" published by the Royal Geographical Society and in the handbooks published by the British Natural History Museum at South Kensington.

The intending collector would, however, be well advised not to attempt to handle all the subjects discussed in the various works, but to confine himself to one or two only, such as birds, mammals, insects, or reptiles, and so in a sense specialize and be able to bring back a more or less perfect series of one 
thing from any locality, instead of a very incomplete set of everything.

Thus the traveller will see that besides his original object of collecting big and small game trophies he can make his expedition as full and interesting as he cares, and apart from covering his walls with specimens of great and peculiar interest to himself, he can gather trophies and collections of great public utility and interest, and confer lasting benefits and additions to our still very imperfect knowledge of the fauna and flora of the world. 


\section{CHAPTER IX}

\section{GENERAL NOTES}

IN the preceding chapters the big and small game hunter has been discussed, his equipment, the pursuit of his quarry, and the uses to which his trophies and curios can be put for the beautifying and decorating of his home.

But there are still several points that have suggested themselves, or could not well have come within what has already been written, about which it may be both useful and desirable to say something.

GAME LAwS. - There are few countries in the world, where game of any kind is found, that have not now some form of Game Law, more or less rigidly enforced, especially in those territories or States well known to all sportsmen as big-game countries.

Before the advent of these laws, vast territories had been denuded of their game, more especially the larger beasts, as the bison of North America, and the innumerable wildebeest, eland, etc., that once overran the high veldt of South Africa.

Even now the process of destruction and ultimate 13.3 
extinction is more or less rapidly taking place in many countries, notably the republics of South America, where, though in parts Game Laws have been granted, they have never been actively enforced and are pracrically a dead-letter.

In the settled districts this is partly due to the utilitarian principles of the stock-raisers, who have worked out to a fine point the exact carrying power of their "camps," and this has meant the extermination of all grass-eating creatures to give place to a few more head of sheep or cattle.

Where deer, rhea, guanaco, etc., still exist on the older stock farms, it will be found either to be due to a part not being suited to stock-raising and thus left in a wild state, or the owner having a personal desire to see some of the original wild creatures still roaming on his extensive property; but unfortunately these are in the minority.

In this connection it behoves the beginner not to let his name be handed down as one of the men who helped to shoot out the big fauna, either through utter wantonness or a fiendist desire to make a bag bigger than any one else. There is no sport in that; the sport is in picking out the best heads and shooting them alone, and if the whole country swarmed with the same species and the desired number of trophies had been secured they should be passed by-unless meat is required, when further shooting would be fully justified. 
To take toll of the game is legitimate; to wantonly destroy is unsportsmanlike and ungentlemanly, and does not show forethought for those who follow after.

Somewhere a sportsman has been defined as "a man who, having the attribute of sportsmanship fully developed, uses it in a skilful manner, by which he shall obtain for himself and others the greatest possible amount of sport."

Carefully drafted and strictly enforced Game Laws not only bring into the exchequer of each country considerable sums through licences, payments to natives which in part, at least, revert to the Government in taxes, etc., and in many other ways make game a sound asset, but perpetuate for all time a paradise for the big-game hunter, and preserve a fauna which is of interest to the ever increasing body of naturalists. Thus should all Governments try to see their way to prevent the total extermination of the big and small game of the world, both from a sentimental and business point of view.

Perhaps the example is Africa, where the Government has seen the advantage of preserving the wild famna, in consequence of which a goodly number of sportsmen visit that continent to shoot its bier game. East Africa easily holds the palm for attracting the big-game shot, principally because it is quickly and comfortably reached, a good railway takes one within easy striking distance of the game veldt, and the visitor finds the 
well-organized firm of Messrs. Newland, Tarlton \& Co. ready to fit him out with all the necessary transport, native carriers, guides, and native hunters, so that he has all worry and trouble taken off his shoulders.

It is to this firm that much of the glamour East Africa has, as a game country, is due, and they take every care to see that the stranger gets good sport and every comfort in return for his money.

Being Lost.-Being lost has already been mentioned in Chapter I; but as this is one of the worst and most nerve-destroying things that can befall the traveller, a few further remarks will not be out of place.

It is not always realized immediately that one is lost; but when it dawns upon the hunter that he not only does not know exactly where he is, but does not even know the direction in which he ought to turn to regain his whereabouts or his camp, he is liable to lose his head completely, think himself farther afield than he really is, do the most idiotic things, and end by walking or running himself to a standstill and dies from pure exhaustion and madness brought on by unnecessary fright and panic, as has happened to many a good traveller and even experienced hunter. Cases could be cited where deaths have occurred, or the lost and recovered men been unhinged for some days after being brought back.

The first and foremost thing is to keep cool and collected (by no means an easy matter), for therein 
lies the sole salvation, unless by accident or chance a road, trach, or camp is run across.

If the day is young a little time can be spent in endeavouring to think things out, but if the morning's walk won't adjust itself in the brain, the direction can be taken by the sun, remembering where it rose and where it is sinking, and by keeping straight on, some track, road, river, or railway can be cut, which will be recognized, and by keeping to it some known point can be finally reached.

Should the day be far spent and it is felt that no hope of location can be accomplished before darkness sets in, the hunter should set about making a fire, cutting and erecting a small shelter, and endeavour to make himself as comfortable as circumstances will permit, get some sleep, and with the first streaks of dawn set forth again.

At all times keep the ears open for shouts or shots from the possible search party, and above all do not expend all your cartridges in vain attempts at summoning help, but reserve a few for answering shots. When on the move searching for the way back, a shot fired every half-hour or so should be ample for summoning purposes; unless an answering shot is heard, when another will give the searchers your direction. If a shot is not answered it is reasonable to suppose the search party or the camp is not within hearing, and it would be useless to waste another cartridge within a few minutes. 
Only by keeping cool, and the brain clear and sensible, will the hunter bring himself out of really difficult bits of country; though the obvious remedy is not to go out without a native in any bushed or tricky parts of the hunting veldt.

Maps, Diaries, ETC.-Every hunter should take sufficient interest in his trip, however short it may be, or however well known the country or that part of it in which he intends shooting, as to at all times keep a careful diary and make careful notes of all things that strike him-of the natives, the country, and the fauna and flora. Even the most trivial and everyday experiences may be of value later on, and it is just these recurring incidents that are tiıe first to be forgotten.

Only the other day the question arose in the Field as to how the wart-hog carried its tail, a matter that one would have thought was well known, and yet a division of opinion was expressed on the point.

Maps of the districts, if such exist, are always of use and of interest, even if it is only to note where they are wrong.

Grammars and vocabularies of the native dialect and languages should be carried and studied, and if only the residents themselves can be conversed with an added interest and pleasure is given to the trip, and many useful notes can be picked up at first hand.

Surveying.-Surveying and map-making is quite one of the most interesting hobbies that can be taken 
up by the explorer and hunter, but, as with every branch of science nowadays, it requires to be accurate and reliable.

Even when country is rapidly passed through or only a short time spent in it a route survey with a prismatic compass is of value, especially if the locality is not mapped or is imperfectly known-if it is carried out with all due care.

There are many works published on this geographical part of surveying, notably "The Text Book of Topographical and Geographical Surveying," by Major Close, and the "Hints" by the Royal Geographical Society, both of which give the subject in its clearest light. These works, combined with lessons, should soon give the veriest novice some idea of how to carry out a route survey at least.

In almost every country it will be found that several points, such as towns, big rivers, boundaries, etc., have been fixed, and on to one or more of these the hunter's rough map can be adjusted so that the part he has traversed can be located. To the man who may come after, the distance between water, native villages or kraals, the number and size of rivers and lagoons, the swampiness or otherwise of the veldt, and the nature of the country-whether forested, plains, arid or grassy, or mountainous, native tracks and roads-and the extent and range of the game, will be of principal interest and should be first noted.

If the scientific side of the expedition has been 
entered into, that is to say if collections of the fauna, insects, or plants have been made, a map should show every locality and name, whether of a village or hill or other place mentioned by the collector on his labels; so that no difficulty will be experienced in trying to find these places on an existing map, which will most probably not give any of the localities.

On the labels of specimens and on the map importance should be given to the nearest natural feature of the country, such as a river, hill, etc., and not too much emphasis be attached to native villages, which in Africa at least may be constantly shifting.

In this respect it should be a sine quâd non that every collection should have a map sent with it, however rough, and even if it has to be traced off one already existing, with the hunter's own localities jotted in where he knows or thinks they should be. Should the beginner desire to take up geographical surveying seriously, he cannot be better advised than to call on the institutions interested in this branch, chief among which stands the Royal Geographical Society.

Cinching.-The method of girthing or saddling up called "cinching" is pretty well known throughout the world, but except for South America, where it originated, and among the comparative few who use it after their experiences in that part of the globe, the alternative of the cinch as against the strap and buckle is an uncommon practice. There is, however, no surer or safer way of securing a pack or riding 
saddle on an animal; there are no buckles to get rusty and stiff and no short straps to break off across the holes.

Often with the modern system no pressure can be brought to bear on the girth, and frequently, where animals have the habit of swelling themselves out when they feel the girth touch them, the saddle will after a time be found to be quite loose.

The system is a very simple one: just four fair-sized rings, one on each side of the saddle under the flaps, and one on each end of the girth, and two lengths

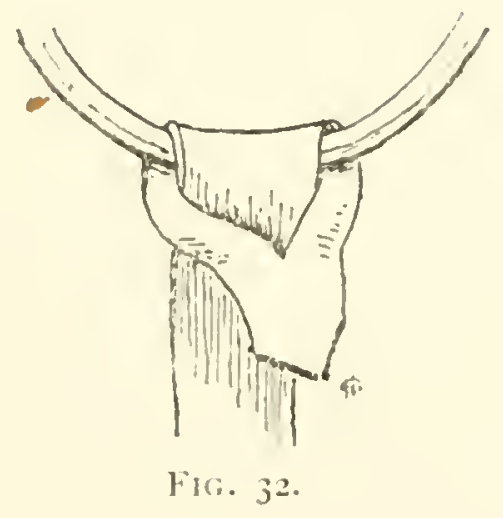

of raw dressed hide. Near one end of each of the two lengths of hide make an incision on the flat. By passing the other end through the ring and then through the incised slit each length can be permanently secured to the saddle-rings (Fig. 32).

On the off side, the rings of the girth and saddle are secured with a medium length of hide, which is never undone except to bring the rings closer together or put them farther apart, according to the size of the beast being saddled. 
On the near side a longer piece of hide is required.

Now place the saddle on the animal, catch hold of the loose end of the girth, pass the end of the hide through the ring from the inside, now through the saddle ring from the outside, once again through girth ring from the inside, over the saddle ring again, tighten

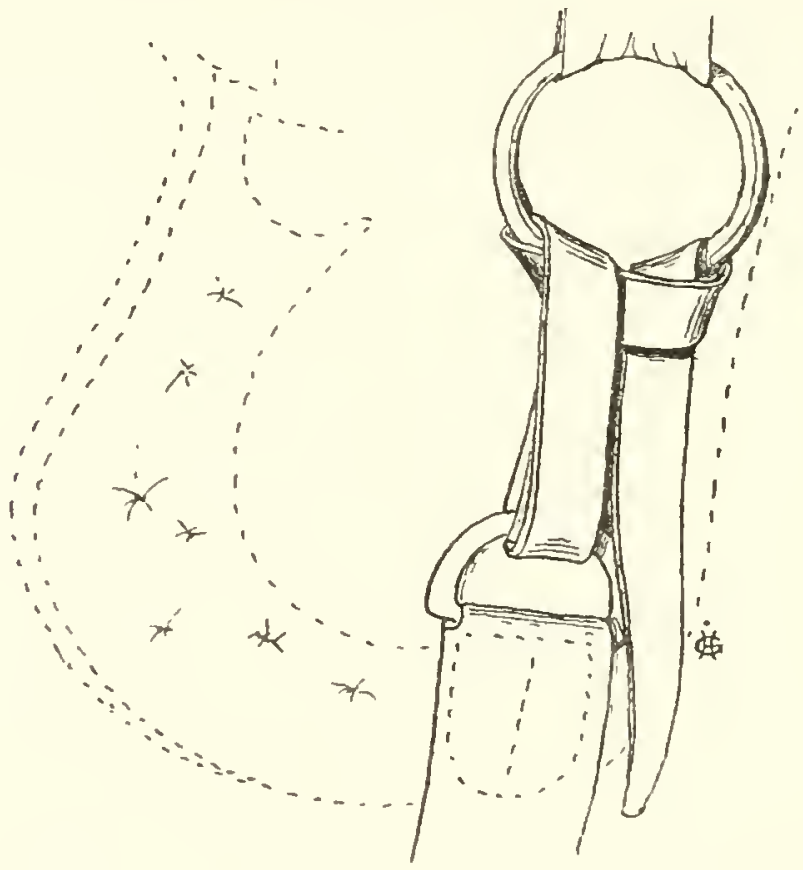

FIG. 33 .

up and finish off with the kind of half hitch as illustrated (Fig. 33).

When the idea is gripped it will be obvious how much better this system is than the other.

The twice over through the rings gives tremendous leverage when tightening up, and there is little or no risk of it ever loosening. In fact, so much pressure can be put on, not by main strength, but by the system 
of levering, that an animal can easily be over-saddled and almost cut in half, so to speak.

CARRIERS AND LOADS.-Little need be added to what has already been written in Chapter II on this matter, but it may be mentioned that where a good headman is used the adjustment and apportioning of the loads should be left to him, and in every way, if the headman is really reliable, quite a lot of the camp work, looking after the men, etc., can be left to him.

The author has found that by giving full responsibility the man feels the importance of his position, and matters often go far more smoothly the less he and his work are interfered with. All orders should also be given through him, except, of course, those to the personal body-servants, such as the tracker, cook-boy, etc.

Another thing is that, given full charge, the boy generally takes good care no other native steals his master's goods, though he himself would probably not be above pilfering from another man's camp.

The point can be again reiterated that the carriers and animals should not be overloaded, especially where good fast trekking is required or the distances between water are great.

TRAPPAG.-The trapping of animals and birds is probably one of the most highly scientific arts, and one of the few that have been brought to the acme of perfection. To the trap we owe the majority of the 
furs, the menagerie specimens, and most of the mammals in our museums.

To the native the trap is part of his life, for it brings him both food and skins, and it is to him we turn to find some of the most cunning contrivances ever invented by the brain of man for encompassing the death or captivity of the wild fauna that roam within his reach.

The life of the trapper is almost as exciting, and oftentimes much harder than that of the big-game hunter. Both the trapping, the stalking, and hunting of game call forth at times the greatest skill and cunning of the hunter, that skill and cunning which combines with it a true knowledge of woodcraft and an exhaustive study of the habits of the beasts and birds, and which enables the hunter to exercise his best mental and bodily qualities in bringing the trophies into his possession.

Apart from securing good skins to be used as furs, rugs, or karosses, trapping is really the only way of obtaining the majority of the mammals in any given district, especially the smaller beasts, such as the mice, rats, opossums, mongoose, etc., many of which are never seen in the daytime, even if diurnal species, and of course very many are strictly nocturnal in habits.

Thus, if a series of the mammals are required for museum or scientific use, trapping must be resorted to, and for this purpose traps can be taken from home 


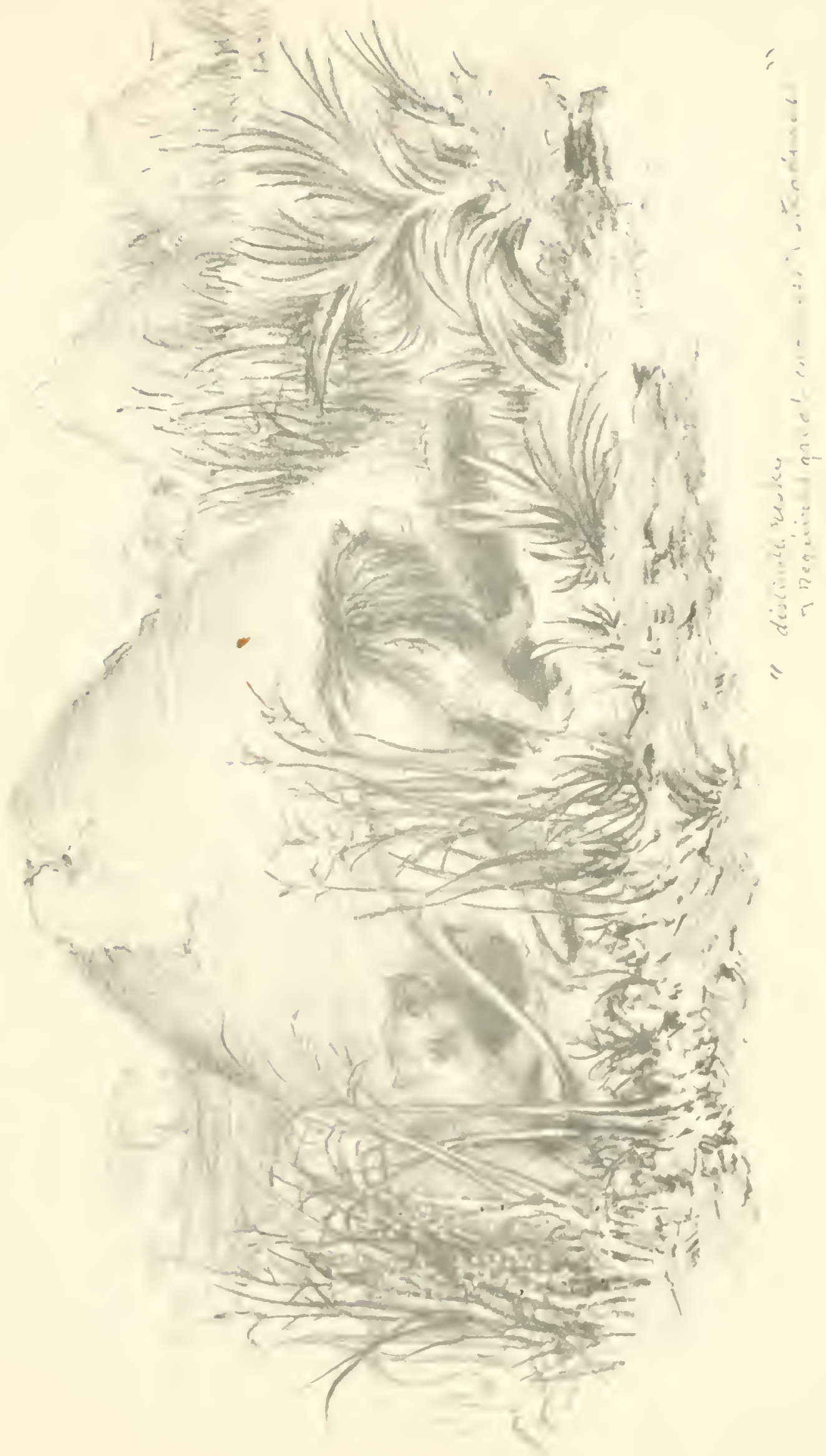




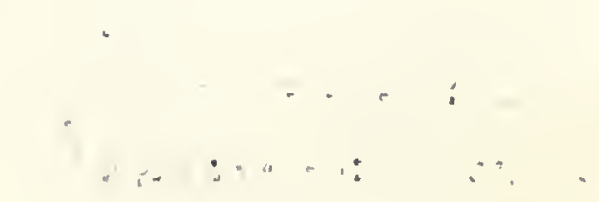


and set around the camp either by oneself or by a local native, who probably knows the whereabouts and habits of many interesting and valuable species.

For the medium and larger beasts small and large gins should be taken, and if carefully set just on a level with the ground, covered over, a zareba of stones or branches so arranged that the animal can only reach the bait by walking across the trap, many a good specimen and fur will result.

If several traps are out and set over a fair area, the morning holds great excitement as to what each or any will contain. In fact, trapping grows on the trapper and in time holds him as does the gun. Very great skill is frequently necessary to so set the trap that the natural timidity and cunning of the beast is overcome.

That trapping is likely to be a cruel practice must be admitted, but if the traps are visited early and often, so that the animals are in them as short a time as possible, and the object is worthy of the practice, as the collecting for science, then there is no more to be said against it than there is against many of the other forms of sport.

That a man interested in one sport often belittles or despises the sport of another is well known, and when in a mountainous district of these islands the other day, a keeper to whom I was talking about game and tourists said, "Funny amusements some people have; there are folk who come up here to climb 
rocks. I can't understand it, can you, sir?" Merely climbing rocks was his idea of the sport of mountaineering.

Measuring Trophies.-One of the most important matters, if not the most important, that the big-game hunter wants to know next to the shooting and preserving of his trophies is how to measure the horns, tusks, teeth, etc., accurately and in the approved way.

This is by no means easy to convey lucidly in a few lines, as big game is variously formed, and two animals almost identical need to be measured differently.

These measurements have been divided into nine groups, with their variations-i.e., eighteen altogether. It has been thought a good plan to place these in a sort of key, so that the beginner or even the experienced hunter can at a glance and with a minimum of trouble see under which measurement his particular trophy has to be classed.

Not every species throughout the world can be mentioned, but under one or other of the headings will be found a family into which any known game animal will naturally fall; so that if the general name of the beast be known, such as reed-buck, gazelle, deer, etc., little or no difficulty should be experienced in deciding under which heading it has to be measured.

The following is the key:- 
Antlers and Horns.

1. Lingth on front curve, circunference, tip to tip.All the hartebeest and allies (except Hunter's), all duikers, dikdiks, oribis, sunis, or Livingstone's antelopes, grysbok, steinbucks and allies, klipbucks, water bucks, kobs, rhebucks, reedbucks, bushbucks, springbuck and all gazelles, tahrs, all ibex, sable, roan, gemsbucks, ory and allies, four-horned antelope, Tibetan antelope, nilgai, chamois, saiga, Beira, goral, serow, takin, Rocky Mountain goat, anoa and all sheep.

(a) Length on front curve, straight, circumference, tip to tip.-Hunter's hartebeest, impala, addax, nyala, situtunga, bongo.

(b) Length on front anve, tip to tip, brardth of palm, widest inside and ontside.-Brindle and white-bearded gnus.

(c) Isngth on front curve, tip to tip, breadth of palm.Black gnu, musk-ox.

(d) Length on front curve, circumference. - Rhinoceros horns (both front and hind).

2. Length on outside curve, circumference, tip to tip, widest inside, spread, points.-All deer (except fallow, elk, and moose).

(a) Length on ontside curec, circumference, tip to tip, widest inside, points, width of palm.-The fallow-deer and allies.

(b) Length on ontside curic, circumfercnce, tip to tip, 
widest inside.-Pronghorn, European and American bison, domesticated cattle.

(c) Length on outside curve, circumference, tip to tip.Yak, domesticated gayal, all the small buffalo (as Ashanti, S. Nigerian, Philippine, Bornean, Lake Chad, etc.).

(d) Lcngth on outside curve, circumference, tip to tip, widest inside and outside.-Indian bison, Indian buffalo, bantin.

3. Round spiral ridge (outside curve).-Mountain nyala, kudus, markhors (except straight-horned).

4. Length in straight line on front of horn, circumference, tip to tip.-Eland, blackbuck, and straighthorned markhors.

5. Greatest width (outside and inside), tip to tip, width of palm.-African (Cape) buffalo.

6. Length to longest tine, circumference, tip to tip, greatest width, breadth of palm, points.-Elk and moose.

\section{Tusks and Teeth.}

7. Length on ontside curve (note if in or out of jaw and whether upper or lower teeth). - Musk-deer, wart-hog, boars and babirusa.

(a) Length on outside curve, circumference.-Hippo, walrus, narwhal and elephant.

Hornless Game.

8. Maximum height and shoulder height.-Giraffe. 
9. Nose to tip of tail, height at shoulder, nose to root of tail, length of tail, girth of body.-Lion, tiger, bears, leopards, pumas, lynxes, foxes, hyxnas, etc.

And now for the way in which these measurements have to be taken : first we have the front curve (I); this is taken on the front of the horn, and it makes no difference whether the curve is back, like the ibex, or forward, like the waterbuck, or forward and then back, like the hartebeest. The tape is placed on the front of the horn and the measurement taken from its base to the tip, just laying and holding the tape down on the surface of the horn and not pressing it into the corrugations. Now take the circumference round the thickest part near the base, and the distance between the tips of the horns.

With sheep the tape is laid on the flat top surface (front curve), and the curve followed right over and round to the tip: it will also be found that the distance between the tips cannot be taken with all the species.

In the case of the Spanish ibex the front curve measurement appears mixed, but the start is made on the front flat face, and this is followed right to the tip; thus the last part of the measurement is on the outside, and in some specimens underneath, at the extreme tip.

With chamois, some measure the spread also, i.e., the distance between two uprights placed against the outside of the horns and parallel to each other. The 
straight measurement ( $\mathrm{I} a$ ) is taken direct from the base to the tip of the horn.

With the gnus ( $\mathrm{I} b$ ) the front curve is really the top curve and carries the tape round on the inside of the back-curved tips; also the widest inside is taken and the widest outside or spread. The breadth of palm is measured over the face of the widest part of the horn at or near the base.

The black gnu and musk-ox (Ic) are measured like ( $\mathrm{I} b$ ) ; that is to say, the tape follows down the front of the horn and up on the inside of the upturned tips.

With ( $I d$ ) the length is of course on the front of the horn and the circumference at the base.

In the author's opinion the takins should also be measured on the palm, though this measurement has not been recorded with this family.

Next we have the outside curve (2), the necessity for which is apparent when a deer head is examined and it is noted that the tines effectually preclude a front curve measurement being taken. This is taken from the base of the burr or coronet up the outside of the main part of the antler, which is called the beam, to the tip, not of the longest tine, but to the tip of the beam. This requires a little judgment as to which of the topmost points represents the beam; this can usually be decided by taking the thickest.

The circumference is taken between the second and third tine (bez and trez), except where the bez-tine is well up the horn (as in the sika and hog-deer), when 


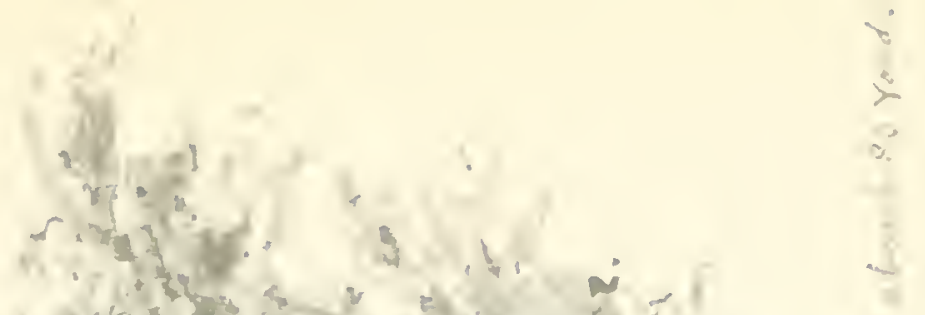

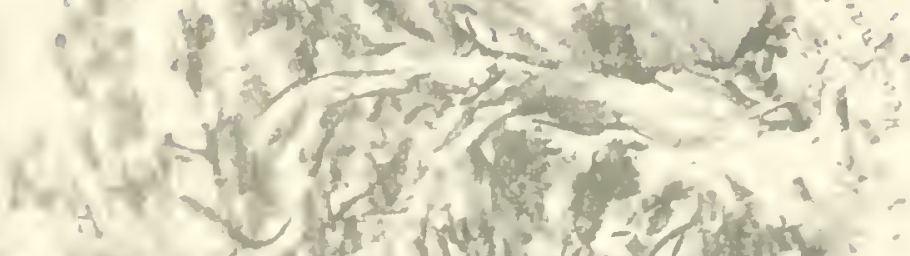

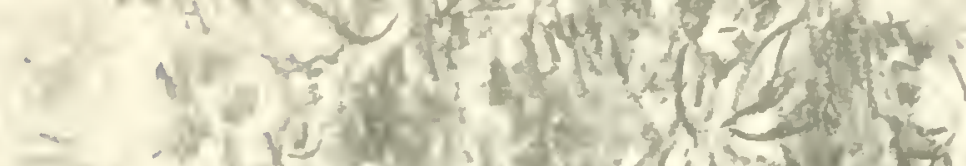
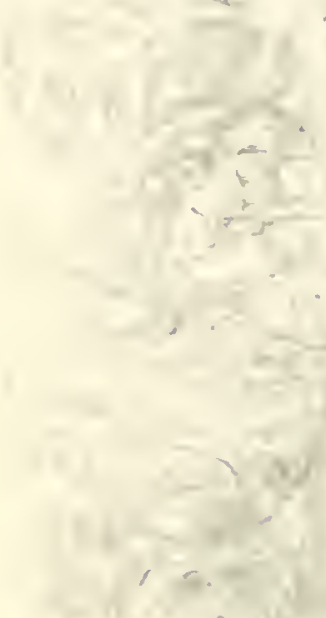

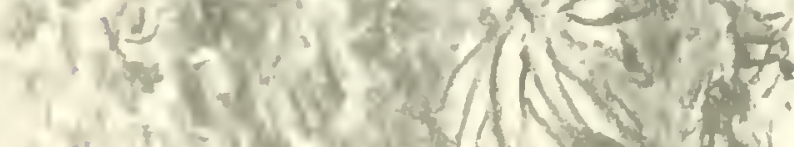

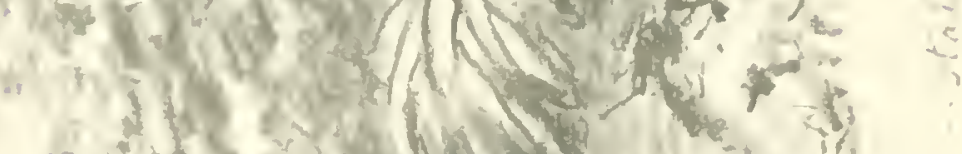

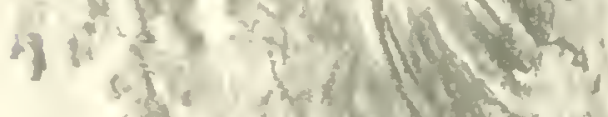
39

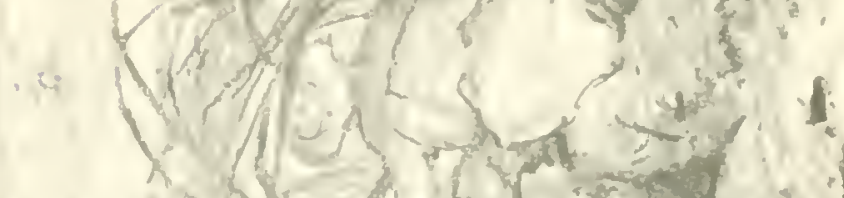

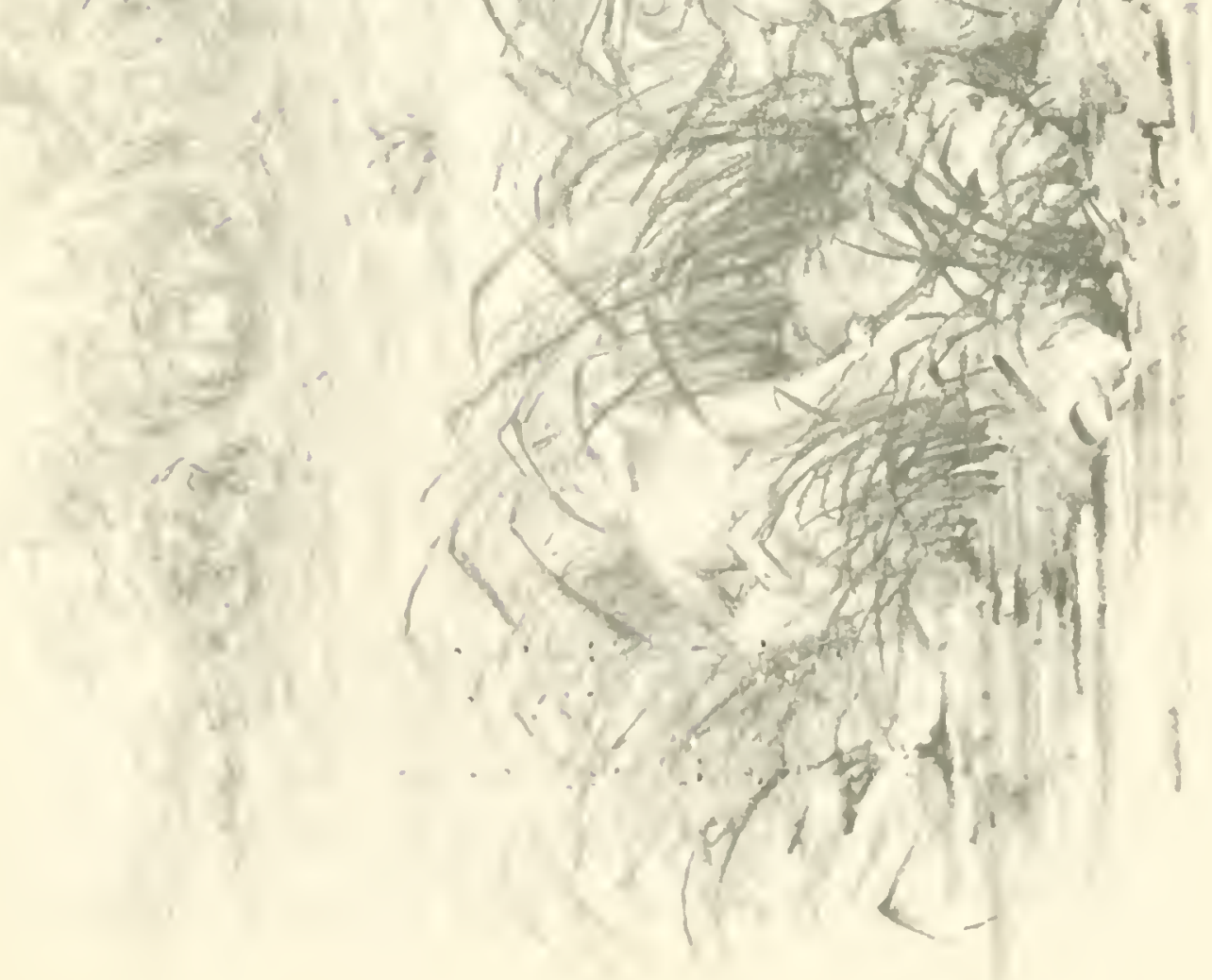




$$
\begin{aligned}
& \therefore \quad+\quad= \\
& \because \quad \therefore \quad \therefore \quad \therefore \quad .
\end{aligned}
$$


the measurement is taken above the brow tine. The tip to tip is of the topmost points; the widest inside is the greatest distance between the beams on their inside.

The spread is the greatest width, either between the outside points, if these are beyond the beam, or between the outside of the widest curve of the beam if the points are within.

The points include the total number on both antlers.

With the fallow-deer $(2 a)$, the palm at the end of the antler is measured across the widest part of it on the face.

With the bison and cattle, etc. (2b), (2c) and (2d), the length is measured on the outside, i.e., underneath, as opposed to the front-curve measurement of gnu; that is to say, the tape is placed on the under side of the horn at its base and the curve followed round to the tip on the outside. The circumference is taken at or near the base. With the pronghorn the length is of course taken as with deer.

With reindeer the breadth of the brow tine should also be measured, as this is often a feature of a good head.

One of the most remarkable heads amongst deer is that of Père David's, in which the beam is comparatively short and the first tine (at the back) remarkably long. Many have made the mistake of running the tape along this instead of up the beam for the 
length, which would at once give a fictitious record. This remarkably long tine should be measured separately, taking it from the beam.

With the kudus, etc. (3), the so-called outside curve measurement for the length is taken right round the spiral; for instance, if a kudu's head is examined a ridge starting on the front of the horn at the base will be seen, and this follows the horn round the spiral and to its tip. This ridge must be followed with the tape and thus the length obtained. The length in the straight should also be taken.

The mountain nyala is sometimes known as the spotted kudu.

Eland, blackbuck, and the straight-horned markhors (4), as the Cabul and Suleman races, are simply measured in a straight line from the base to the tip on the front of the horn; that is, the tape is stretched between the two points and no consideration is given to curves or spirals.

The African buffalo (5) stands alone in only having the greatest outside and inside width taken-that is, the distance straight between two uprights placed against the outside of the horns, and the distance between the deepest part of the inside curve. Some hunters, however, think that the length round the front curve should also be taken, as the width alone makes no allowance for horns that may have a distinct droop and finely inturned tips, many of which are, and look, much finer trophies than straighter 
specimens. The author agrees that a much better idea of a head would be recorded by taking this measurement as well. Other measurements as with (I $b$ ).

Elk and moose (6) are measured up the outside curve to the tip of the longest tine; tip to tip of highest points; greatest width between two uprights on the outside; and the palm at its widest on the front face. The circumference is taken just above the burr or coronet, and some care and judgment is required in counting the points so as not to include mere knobs or excrescences.

(7) and (7a) need few instructions, except that in recording the length care must be taken to note whether they are measured their whole length-i.e., out of the skull, or whether only that part which stands out of the jaw. If the latter, a mark can usually be seen where the tusk or tooth has joined the gums, and the measurement must be taken from this to the tip, though if possible they should be extracted from the jaw and their total length recorded. With those animals having both upper and lower tushes or teeth, both should be measured and recorded separately.

IVe now come to the hornless game, (\$) and (9), which require measurements that must be taken before the animal is skinned and cut up. As the animal lies on its side, pull and stretch it out as straight as possible, and either place pegs to keep it there or get one's natives to hold it. With the 
tape measure from the tip of the nose over the head along the back to the tip of the tail, and the nose to root of tail the same way.

The girth of body is taken just behind the fore legs, and the height at shoulder from the foot of the outstretched foreleg to a stick held against the top of the shoulders? (withers). This latter measurement can be taken both with the foot held straight and with the foot bent as if standing upon the ground.

With giraffes the maximum height is from the end of the hoof to the top of the head, the leg and head being pulled out to the perpendicular as though the animal were standing up.

Skull measurements, as of lion and tiger, etc., need to be taken carefully and with a pair of accurate callipers.

All measurements must be taken with a steel tape, as linen ones are liable to stretch or shrink. Care should be taken to keep the measure oiled, to prevent rusting and obliteration of the divisions.

All horns have a tendency to shrink after death, sometimes over a period of several years, so that a head measured immediately it is shot will seldom record the same after it has become thoroughly hard and dry. Impala heads, for instance, have been known to shrink a quarter of an inch or more, and sheep often shrink quite two inches in their circumference.

The length of time horns take to finally reach their minimum through shrinkage is always governed by 
the hardness or pulpiness of the horn itself. Owing to this taking place, it seems manifestly unfair that measurements taken from the fresh animal should be recorded against those from heads that have been killed some time, and though no standard has hitherto been laid down, it seems the most fair and least disputable that no measurements should be recorded except from heads that have been thoroughly dried. Should a fresh head measurement be recorded, a later measurement from the dried specimen should be recorded by the side of it; hence this last would fairly compete with other heads that either through the want of a tape, not knowing how, or any other cause, were not measured in the field.

Recording both the fresh-killed measurement and the later one would be of interest, and give the sportsman the satisfaction of seeing his greatest measurement recorded.

In certain species females are sometimes shot with horns that normally are not horned, one of the best known of these being the common duiker (C. grimmi). These should always be carefully kept and the sex correctly determined and recorded, as otherwise they may afterwards be thought to be young males, especially where, as with the duikers, the female horns are smooth and imperfectly formed, almost exactly as with the young male.

A beginner shooting in any given district must not be disappointed if his heads of a certain species 
do not come anywhere near the official record, as locality has a great bearing on the length and size of horn, and though a record may have been shot, say, in Central Africa, of a certain antelope, the whole of the species might be shot, say, in South Africa, and not one would come anywhere near the Central African specimens. So that district records should be looked for, and if general records are to be obtained, the hunter must obviously, in most cases, visit that district from which the record has been brought, though of course there is no guarantee that a record may not be shot right away from the locality where the present record has come from.

In the measuring of trophies, especially with deer, some judgment and common sense must be exercised, and the larger the animal the less should the hunter consider $\frac{1}{8}$ or even $\frac{1}{4}$ inches in comparing heads; as if half a dozen men measured a large horn, probably not any two of them would get quite the same result.

Cutting UP GAME, ETC.-Almost at the eleventh hour it has been thought that a few remarks on how to cut up game, and a few hints on camp cooking, might be extremely useful to the would-be hunter.

It will frequently be found that one's hired cookboy is lamentably deficient in practical methods, and if only the white man himself has some knowledge of how to cook things in the way in which he likes them, he can teach the boy, and it is remarkable how 
quick they are in picking up anything they take an interest in.

Little need be said on the preparing of birds for the pot, though one very good way of cooking them is to split them down the back, open them out, and either put them in a frying-pan or, better still, place them direct on the hot embers of the fire.

There is no nicer way of cooking birds than the old time-honoured method of baking them whole in their feathers, by covering them in clay, and having dug a hole in the ground and thoroughly heated it, place the bird in as a loaf of bread in an oven.

Antelopes, etc., need to be carefully jointed, taking off the hind and fore quarters at the joints, cutting off the juicy muscles along the backbone, or, by leaving these on, dividing the back and ribs into neat chops. The neck and other parts, and even the whole animal, can be cut up and stewed, or the meat cut off in suitable pieces and made into curry.

An excellent way of making meat tender and really palatable is to parboil it in the "Kaffir pot," then pour off any remaining water, put in some fat, and bake it until it is crisp.

In the cutting up of larger beasts the meat must, of course, be removed in large pieces, and as the hunter will require only a small quantity of it for his own table, he cannot do better than select the meat that lies along the top of the backbone, which will nearly always be found to be tender. 
The liver, too, makes an excellent dish for breakfast, fried with some of the tinned bacon, though with some animals, as the waterbuck, even this part is tough and almost uneatable.

To make bread (with baking powder); puddings of rice or sago with condensed milk and custard powder; poach, boil and fry eggs, etc.; cook potatoes, make good tea and coffee, and the other simple but necessary culinary matters that make an expedition more pleasant, requires but a little knowledge and practice, and the beginner can pick up a few useful hints from his cook at home before he starts out, and should carry a small and concise cookery-book in his outfit.

Above all insist on the boy keeping the pots and pans and the table requisites clean and bright; though most African camp boys are almost too good at this, and will wear the knives to paper thinness and the pots through the bottom in endeavouring to keep them polished.

There is the old story of the man who had a new boy, and as a start gave him his gun to clean; the boy was away some time, and when he handed the gun to his "boss" it was polished inside and out like a piece of new steel. Lacking minute instructions, he had gone down to the river bank and with sand and water rubbed off all the browning, which he in ignorance thought was dirt.

REVOLVERS.-A revolver or automatic pistol can 
be carried in many parts of the world, though it would probably be made little use of and voted an unnecessary encumbrance.

In countries like South America a revolver or a knife is almost universally carried outside the environs of the large towns and frequently within their precincts; but the stranger need not necessarily follow this custom, as he would or should not have any private quarrel, unless he has been resident long in the country, when, according to circumstances, he may be compelled to arm himself.

Certainly the fact of being armed gives a greater sense of security; and is there any more defenceless creature in the world than an unarmed man?

Should it be desired to carry some such concealed weapon, the IVebley Mark IV of the 3 So bore and the Colt Automatic are about the best two to choose from.

In all sports experience makes for knowledge, and if in any way these personal experiences have helped the Shikari to organize his hunting trip on the right lines, or added to his collection one trophy worth acquiring, the author will feel that the many hardships and troubles of his early days have been passed through to some advantage. 
Tbe Sicsban piess

[NWIN REOTHERS, LIMITED

WOKING AND LONDON 

THIS BOOK IS DUE ON THE LAST DATE STAMPED BELOW

AN INITIAL FINE OF 25 CENTS WILL BE ASSESSED FOR FAILURE TO RETURN THIS BOOK ON THE DATE DUE. THE PENALTY WILL INCREASE TO 50 CENTS ON THE FOURTH DAY AND TO \$1.00 ON THE SEVENTH DAY OVERDUE.

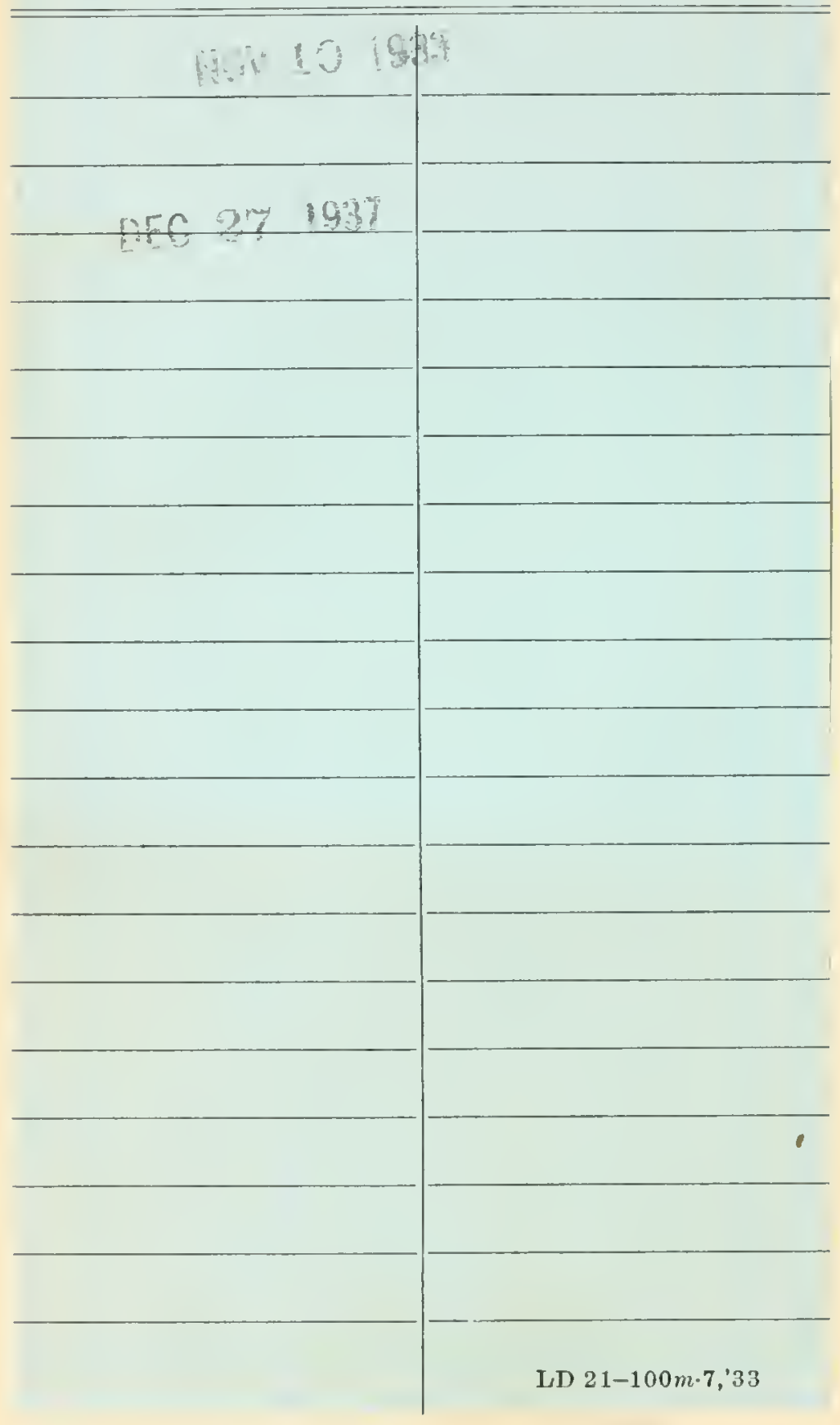


495889

UNIVERSITY OF CALIFORNIA LIBRARY 
